Pontifícia Universidade Catálica $_{\text {Do Rio de Janelro }}$

Rafael Ferreira Godoy

\title{
Remediação de Cromo Hexavalente Utilizando \\ Polissulfeto de Cálcio - Estudo de Caso: Rio de Janeiro
}

Dissertação de Mestrado

Dissertação apresentada ao Programa de PósGraduação em Engenharia Urbana e Ambiental como requisito parcial para obtenção do título de Mestre em Engenharia Urbana e Ambiental

Orientador: Prof. Eurípedes Vargas 


\section{Pontifícia Universidade C atólica $_{\text {nate }}$

Rafael Ferreira Godoy

\section{Remediação de Cromo Hexavalente Utilizando \\ Polissulfeto de Cálcio - Estudo de Caso: Rio de Janeiro}

Dissertação apresentada como requisito parcial para obtenção do grau de Mestre pelo Programa de PósGraduação em Engenharia Urbana e Ambiental da PUCRio. Aprovada pela Comissão Examinadora abaixo assinada.

Prof. Eurípedes Vargas

Orientador

Departamento de Engenharia Civil - PUC-Rio

Prof. Antonio Roberto Martins Barboza de Oliveira Departamento de Engenharia Civil - PUC-Rio

Prof. Raquel Quadros Velloso Departamento de Engenharia Civil - PUC-Rio

Prof. José Eugenio Leal Coordenador Setorial de Pós-Graduação do Centro Cientifico - PUC-Rio 
Todos os direitos reservados. É proibida a reprodução total ou parcial do trabalho sem autorização da universidade, da autora e do orientador.

\section{Rafael Ferreira Godoy}

Graduou-se em Engenharia Ambiental pelas Faculdades Oswaldo Cruz (São Paulo/SP) em 2008. Trabalha com projetos de investigação ambiental e remediação.

Ficha Catalográfica

Godoy, Rafael Ferreira

Remediação de Cromo Hexavalente Utilizando Polissulfeto de Cálcio - Estudo de Caso: Rio de Janeiro / Rafael Ferreira Godoy; orientador: Eurípedes Vargas. 2014.

105f.: il.(color); $30 \mathrm{~cm}$

Dissertação (mestrado) - Pontifícia Universidade Católica do Rio de Janeiro, Departamento de Engenharia Civil, Programa de Pós-Graduação em Engenharia Urbana e Ambiental, 2014..

Inclui bibliografia.

1. Engenharia civil - Teses. 2. Cromo hexavalente. 3. Polissulfeto de cálcio. 4. Remediação. 5. Rio de Janeiro. 6. Redução química in situ. 7. Injeção. I. Vargas, Euripedes. II. Pontifícia Universidade Católica do Rio de Janeiro. Departamento de Engenharia Civil. III. Título. 


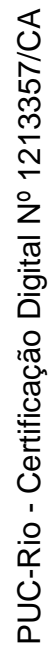

A

Minha Esposa

Meu Filho

Meus Pais

Meu Irmão

Meus Mestres 


\section{Agradecimentos}

A AECOM que me incentivou para cursar o Mestrado Profissional em Engenharia Urbana e Ambiental da PUC-Rio.

Ao meu orientador Eurípedes Vargas pelo estímulo e parceria para elaboração deste trabalho.

A minha esposa e filho, por todo o apoio, paciência e compreensão ao longo do estudos e elaboração da dissertação.

Aos meus pais e sogros que de uma forma ou de outra me estimularam e incentivaram ao longo das aulas e na conclusão da dissertação.

Aos professores do curso por todo o conhecimento técnico transmitido nas aulas. 


\section{Resumo}

Godoy, Rafael Ferreira; Vargas, Eurípedes (Orientador). Remediação de Cromo Hexavalente Utilizando Polissulfeto de Cálcio - Estudo de Caso: Rio de Janeiro. Rio de Janeiro, 2014. 86 p. Dissertação de Mestrado - Departamento de Engenharia Civil, Pontifícia Universidade Católica do Rio de Janeiro.

Esta dissertação apresenta os resultados obtidos no processo de remediação de uma área contaminada por cromo hexavalente por meio da técnica de remediação química in situ (ISCR). A área de estudo localiza-se na cidade do Rio de Janeiro e foi ocupada por uma fábrica de vidros por cerca de 40 anos e comprada para construção de condomínios residenciais. A área de estudo passou um processo de gerenciamento ambiental que contemplou diversos estudos ambientais para aquisição de dados e delimitar a contaminação, horizontal e verticalmente. $\mathrm{O}$ teste de bancada realizado com o reagente químico polissulfeto de cálcio demonstrou ser eficiente para reduzir as concentrações de cromo hexavalente em solo e água subterrânea. Com base nos dados adquiridos neste teste foi possível calcular a dose de injeção do polissulfeto de cálcio. Foram realizados 72 pontos de sondagem, pela técnica direct push, para injetar 252.030 litros de solução de polissulfeto de cálcio e água, sendo aproximadamente 3.500 litros por ponto de injeção. Os resultados após a injeção demonstraram que o polissulfeto de cálcio conseguiu remover o cromo hexavalente que estava adsorvido ao solo e reduziu a concentração de cromo hexavalente na água subterrânea entre 46,67 e 99,95\%, após 19 meses da injeção. Dessa forma, comprovou a eficiência deste reagente químico para remediação de áreas contaminadas por cromo hexavalente, assim como foi observado nos artigos técnicos de estudos de casos nos Estados Unidos e Europa.

\section{Palavras-chave}

Cromo hexavalente; polissulfeto de cálcio; remediação; Rio de Janeiro; redução química in situ; injeção. 


\section{Extended Abstract}

Godoy, Rafael Ferreira; Vargas, Eurípedes (Advisor). Hexavalent Chromium Remediation Using Calcium Polysulfide - Study Case: Rio de Janeiro. Rio de Janeiro, 2014. 86 p. MSc. Dissertation Departamento de Engenharia Civil, Pontifícia Universidade Católica do Rio de Janeiro.

This dissertation presents the results obtained in the remediation process remediation of a contaminated area by hexavalent chromium applying the technology in situ chemical remediation (ISCR). The study area is located in the Rio de Janeiro city and was occupied by a glass factory for 40 years and purchased for construction of residential condominiums.

This dissertation presents the results obtained in the remediation process remediation of a contaminated area by hexavalent chromium applying the technology in situ chemical remediation (ISCR). The study area is located in the Rio de Janeiro city and was occupied by a glass factory for 40 years and purchased for construction of residential condominiums.

Chromium is an important metal for the industry and is used in various products and processes, such as electroplating, leather treatment, pulp, wood preservation, and refractory manufacturing. The trivalent chromium is essential from a nutritional point of view, non-toxic and poorly absorbed in the body, acting in the maintenance of some functions. $\mathrm{Cr}$ (III) is the most common being found and occurs naturally, since the element $\mathrm{Cr}(\mathrm{VI})$ can occur naturally, but in low concentrations, if the groundwater has geochemical conditions the $\mathrm{Cr}$ (III) can be oxidize to $\mathrm{Cr}$ (VI). The hexavalent chromium is the most dangerous valence state and, according to ATSDR (2012), have greater mobility in the groundwater, being carcinogenic by inhalation of high doses of soluble chromate salts. The mobility of hexavalent chromium is high in soil and groundwater because it is not adsorbed by the soil in that valence state, on the other hand when it is in trivalent form is strongly adsorbed by the soil, forming insoluble precipitates, having low mobility in soil and groundwater.

The hexavalent chromium remediation by in situ chemical reduction using calcium polysulfide has been the subject of several field studies documented in the literature, both for soil and groundwater from the Chromite 
Ore Processing Residue (COPR) (Storch, et al., 2002; Graham, et al., 2006; Charboneau, et al., 2006; Wazne, et al., 2007a; Wazne, et al., 2007b; Chrysochoou, et al., 2010; Chrysochoou \& Ting, 2011; Pakzadeh \& Batista, 2011; Chrysochoou, et al., 2012).

Calcium polysulfide is a fertilizer to soil and commercially available and has been used in some remediation studies cases for reducing hexavalent chromium in soil and groundwater. Being commercially available and used as fertilizer, it is a relatively cheap chemical reagent in comparison with other chemical compounds exclusively developed for this purpose.

The stoichiometric demand and the chemical kinetics of the reduction of $\mathrm{Cr}$ (VI) by the calcium polysulfide in aqueous solution was studied by Graham et al. (2006) from the chromite ore processing residue (COPR). With this study it was reported that a molar ratio of 1.66 is required (close to the theoretical value of 1.5) and a first-order kinetics with an initial concentration of 26.8 $\mathrm{mg} / \mathrm{L}$ and $\mathrm{pH}$ of the CPS solution around 11.5, with the presence of oxygen. Thus, the hexavalent chromium is reduced to chromium hydroxide, slightly water soluble compound which is precipitated to the soil. The trivalent chromium has low solubility, toxicity, mobility, reactivity and is considered stable.

There are various application techniques of chemical reagents in the underground environment, and choosing the most appropriate method for each area depends on the type of contaminant, geological environment, groundwater and surface interference, depth, thickness and size of the contaminated area. As described by Suthersan (1996), the injection of chemical reagents has to achieve two objectives: (1) creating and maintaining an ideal redox environment and other parameters such as $\mathrm{pH}$, presence or absence of dissolved oxygen, etc.; and (2) the delivery and distribution of the necessary reagents for a homogeneous way throughout the injection area, both horizontally and vertically. Thus, it is essential that the conceptual model of the study area is very detailed, so there is no doubt in the choice of chemical reagent application methodology.

Although there are numerous laboratory studies on hexavalent chromium remediation using calcium polysulfide, there are few reports in the literature on the field application, especially case studies in Brazil, therefore, this case study 
becomes a demonstration applying calcium polysulfide as a remediation technique for hexavalent chrome, with geochemical data, which are important for monitoring chemical reduction. This case study shows the effectiveness, dosage and concentration of the study area, and may apply to other hexavalent chromium remediation projects.

\section{Materials and Methods}

A former glass factory (the "Site") operated in the North Zone of Rio de Janeiro / RJ, Brazil from the mid-1950s to 2005. A portion of the facility was used to store raw material to produce glass, including arsenic oxide, and another portion of the Site was used to conduct industrial plating using hexavalent chromium $(\mathrm{Cr}(\mathrm{VI}))$ in the glass molds. In 2009, the Site was purchased for mixed use redevelopment, demanding an environmental assessment and subsequent remediation.

Between 2009 and 2012 several phases of site investigation was conducted. The results of the investigation indicated that $\mathrm{Cr}(\mathrm{VI})$ was present in soil at concentrations up to approximately $21,000 \mathrm{mg} / \mathrm{kg}$ and in groundwater at concentrations up to approximately $30 \mathrm{mg} / \mathrm{L}$. These concentrations exceeded regulatory criteria of $300 \mathrm{mg} / \mathrm{Kg}$ for soil and $0.05 \mathrm{mg} / \mathrm{L}$ for groundwater. A phased remedial approach was developed consisting of the following: (a) excavation and off-site disposal of 2,400 ton of $\mathrm{Cr}$ (VI) impacted soil from the source area, performed in the unsaturated and saturated zone soils in the $\mathrm{Cr}(\mathrm{VI})$ source area; (b) post-excavation monitoring of the groundwater conditions; and (c) groundwater treatment following the excavation program. Hexavalent chromium concentrations in groundwater decreased significantly following the excavation, however, additional reduction of concentrations of $\mathrm{Cr}(\mathrm{VI})$ contaminant in groundwater was required.

Then was designed and implemented a set of bench-scale treatability tests in order to evaluate groundwater remediation alternatives. Several proprietary and non-proprietary reductants for co-treatment of $\mathrm{Cr}(\mathrm{VI})$ were evaluated. Calcium polysulfide were selected to treat $\mathrm{Cr}(\mathrm{VI})$.

To reduce residual $\mathrm{Cr}(\mathrm{VI})$ concentrations in the groundwater plume located downgradient of the former excavated source area, 2,700 cubic meters were targeted for active treatment. The groundwater remediation approach consisted of the injection of 30,000 liters of CPS (29\%) diluted in 220,000 
liters of water, yielding a total of 250,000 liters of solution injected using direct push technology into 72 locations.

\section{Groundwater Monitoring}

As part of chemical reagent injection stage was performed the baseline monitoring with collection of soil and groundwater samples. The soil sampling was performed by direct push technique using PVC liner with two inches in diameter, to analyze the total and hexavalent chromium concentrations.

Six months after the injection were installed 16 monitoring wells, eight shallow wells ( 5 meters) and eight deep wells (9 meters) spread upstream, side, middle and downstream of the injection area.

Groundwater geochemical parameters (i.e., temperature, total solids dissolved, specific conductance, $\mathrm{pH}$, oxidation-reduction potential, and temperature) were measured at the time groundwater samples were collected. Groundwater samples were collected and analyzed for total and dissolved chromium, hexavalent chromium, iron, arsenic, manganese, calcium, sulfate, and sulfide. Samples were field-filtered with disposable $0.45 \mu \mathrm{m}$ polyethylene filter capsules prior to collecting samples for dissolved metals.

\section{Results and Discussion}

Dose calculations for the reduction of hexavalent chromium have been performed with the data obtained in the bench-scale treatability test and resulted in a stoichiometric demand of $4 \mathrm{mlCPS} / \mathrm{kg}$ soil to the treatment of the study area. Therefore 30,000 liters of solution was used containing $29 \%$ calcium polysulfide and approximately 222,000 liters to perform their mixture, totaling 252,030 liters of solution.

For solution injection were performed 72 soil borings with 8.5 meters deep, and the product was injected range between 2.5 and 8.5 meters. The depth of injection was from $2.5 \mathrm{mbgl}$ covered any change in water level due to seasonal variation.

In each soil boring was injected chemical reagent solution comprised 417 liters of calcium polysulfide diluted in 3,083 liters of water for a total volume of 3,500 liters of solution injected per point.

The comparative analysis results of the third monitoring campaign (18 months post-injection) with the baseline campaign (september/2012) indicated reduction of hexavalent chromium concentrations between 46.67 and 99.95\%. 
Regarding the second monitoring campaign (12 months post-injection), the hexavalent chromium concentrations reduced between 23.98 and $99.79 \%$ in five of the 15 monitoring wells that were sampled. In three of the 15 monitoring wells the hexavalent chromium concentrations remained below the quantitation limit used by the analytical laboratory method. There was no increase in hexavalent chromium concentration, compared the results of the third and second monitoring campaign.

The evaluation of the $\mathrm{Eh}$ and $\mathrm{pH}$ values measured in the monitoring campaigns showed that the $\mathrm{pH}$ value was in the acidic range (about 4) and after removal of contaminated soil with hexavalent chromium $\mathrm{pH}$ raised to between 5 and 6 , after the chemical reagent injection $\mathrm{pH}$ increased to the basic range (above 7.5). In the second and third campaign the $\mathrm{pH}$ reduced to acid range (below 6.5), which can be regarded as the $\mathrm{pH}$ value of the area background. The Eh has inversely proportional behavior, increasing between the first and third campaign, and in the third campaign the measured values are in the ranges considered as moderately reducing (100 to $400 \mathrm{mV})$ and oxidizer ( $>400$ $\mathrm{mV})$.

The $\mathrm{pH}$ variation also showed a relationship between increased concentrations of calcium, iron, manganese and sulfate (in some monitoring wells). There were also reductions in hexavalent chromium concentrations in monitoring wells.

\section{Conclusion}

This case study indicates that the use of different remediation techniques when applied together (excavation and chemical reduction), reducing the time required for remediation of a contaminated site without impacting the final cost of remediation. The chemical reduction of hexavalent chromium using calcium polysulfide was effective to reduce the concentration to less than the quantification limit of the analytical method used.

Therefore, as presented it is necessary to carry out several studies to detail the hexavalent chromium concentration in the site, as well as understand the geochemistry of groundwater and performing bench-scale tests to evaluate the effectiveness of the chemical reagent in the site study hydrogeological environment and calculate the required dose. 
The treatability test with calcium polysulfide demonstrated the feasibility of using this chemical reagent by In Situ Chemical Reduction (ISCR) to reduce the hexavalent chrome concentration in soil and groundwater. The test resulted in a stoichiometric demand of $4 \mathrm{mlCPS} / \mathrm{kg}$ soil to the treatment of the study area.

Soil samples collected six months after injection showed that the calcium polysulfide could desorb hexavalent chromium from the soil, since, contaminant concentrations were not detected in the samples.

19 months after the injection of the chemical reagent the groundwater concentrations of hexavalent chromium reduced from 46.67 to $99.95 \%$ in relation to baseline campaign. And, of the 15 monitoring wells in just three wells hexavalent chromium concentrations were detected.

This demonstrates the effectiveness of using calcium polysulfide to remediate hexavalent chromium in soil and groundwater, confirming the studies by Storch et al. (2002), Graham et al (2006), Charboneau et al. ( 2006), Wazne et al. (2007a), Wazne et al. (2007b), Chrysochoou et al. (2010), Chrysochoou \& Ting (2011), Pakzadeh \& Batista (2011), Chrysochoou et al (2012) in several areas in United States and Europe.

\section{Keywords}

Hexavalent chromium; calcium polysulfide; remediation; Rio de Janeiro; in situ chemical reduction; injection. 


\section{Sumário}

1 Introdução 19

2 Revisão Bibliográfica 22

2.1 Processo de Gerenciamento de Áreas Contaminadas 22

2.1.1 Termos 22

2.1.2 Etapas de Gerenciamento 23

2.2 Revitalização de Áreas Industriais 24

2.3 Valores Orientadores 28

2.4 Comportamento de Metais em Subsuperfície 29

2.5 Cromo 34

2.5.1 Principais Ocorrências do Cromo 36

2.5.1.1 Natural $\quad 36$

2.5.1.2 Antropogênica 37

2.5.2 Uso 37

2.5.3 Toxicologia 38

2.5.4 Exposição 38

2.5.5 Caracterização em Solo e Água Subterrânea 39

2.5.6 Métodos Analíticos para Determinação das Concentrações em Solo e Água Subterrânea 39

2.5.7 Coeficiente de Adsorção $(\boldsymbol{K} \boldsymbol{d})$

2.6 Propriedades Químicas do Polissulfeto de Cálcio 42

3 Caracterização da Área de Estudo 44

3.1 Fechamento da Unidade Industrial 44

3.2 Estudos Ambientais 45

3.2.1 Avaliação Ambiental Preliminar 46

3.2.2 Investigação Ambiental Confirmatória e Detalhada 47

3.2.2.1 Sondagens $\quad 48$

3.2.2.1.1 Análises Laboratoriais $\quad 48$

3.2.2.1.2 Análise com Fluorescência de Raios-X $\quad 49$

3.2.2.1.3 Análise Geotécnica 50

3.2.2.2 Poços de Monitoramento 50

3.2.2.2.1 Análise Laboratorial 51

3.2.2.3 Determinação da Condutividade Hidráulica 52

3.2.2.3.1 Metodologia 53

3.2.2.3.2 Processamento dos Dados 55 
3.2.2.4 Fluxo da Água Subterrânea 58

3.2.3 Plano de Intervenção da Área de Estudo 64

3.2.3.1 Medidas de Controle Institucional 64

3.2.3.2 Medidas de Engenharia 64

4 Remediação da Área de Estudo 65

4.1 Escavação do Solo Contaminado 65

4.2 Redução Química In Situ 65

4.2.1 Teste de Bancada 66

4.2.2 Injeção de Reagente Químico 68

4.2.2.1 Monitoramento de Linha de Base 68

4.2.2.2 Método de Injeção 68

4.2.2.3 Monitoramento Analítico Pós-Injeção 69

5 Resultados Obtidos $\quad 71$

5.1 Modelo Conceitual da Área de Estudo $\quad 71$

5.2 Cálculo da Dose do Reagente 78

5.3 Injeção do Reagente Químico 80

5.1 Monitoramento de Linha de Base 82

5.1.1 Solo 82

5.1.2 Água Subterrânea 82

5.2 Monitoramento Pós-Injeção 83

5.2.1 $1^{\text {a }}$ Campanha 83

5.2.1.1 Solo 83

5.2.1.2 Água Subterrânea 84

5.2.2 2 $2^{\mathrm{a}}$ Campanha $\quad 85$

5.2.2 3 $3^{\mathrm{a}}$ Campanha $\quad 86$

6 Discussão dos Resultados 90

7 Conclusões e Recomendações 99

8 Referências Bibliográficas 102 


\section{Lista de Figuras}

Figura 1. Principais controles para concentrações de metais no solo (em: Mclean \& Bledsoe, 1992)

Figura 2. Processo de partição do contaminante $X$ entre as fases móvel e imóvel (modificado de Hering \& Harmon, 2004).

Figura 3. Fluxo da água subterrânea no meio geológico anisotrópico (modificado de Bear, 1972).

Figura 4 - Diagrama de distribuição das espécies de cromo (adaptado: (Hering \& Harmon, 2004)

Figura 5 - Terreno da antiga fábrica de vidros e destaque da área contaminada por cromo hexavalente

Figura 6 - Desenho Esquemático dos parâmetros medidos durante a realização do slug test.

Figura 7 - Variações dos Valores de Condutividade Hidráulica e Permeabilidade (Freeze \& Cherry, 1979).

Figura 8 - Mapa Potenciométrico dos Poços de Monitoramento Rasos e Profundos- Agosto/13

Figura 9 - Mapa Potenciométrico dos Poços de Monitoramento Rasos e Profundos - Fevereiro/14

Figura 10 - Fluxograma do Teste de Bancada 66

Figura 11 - Seção Hidrogeológica A-A'

Figura 12 - Seção Hidrogeológica B-B' 75

Figura 13 - Concentrações de cromo hexavalente, velocidade da água subterrânea e linhas potenciométricas nos poços de monitoramento rasos e profundos - 2013

Figura 14- Concentrações de cromo hexavalente, velocidade da água subterrânea e linhas potenciométricas nos poços de monitoramento rasos e profundos - Fevereiro/2014

Figura 15 - Pluma de concentrações de cromo hexavalente no monitoramento de linha de base e pontos de injeção de reagente químico

Figura 16 - Dados da pluviometria e nível d'água da área de estudo.

Figura 17 - Evolução das concentrações de $\mathrm{Cr}(\mathrm{VI})$ na área de estudo

Figura 18 - Tendência dos dados físico-químicos e geoquímica 95 Figura 19 - Tendência das concentrações do cromo (total e hexavalente), ferro e arsênio

Figura 20 - Variação do $\mathrm{pH}$ ao longo das campanhas de monitoramento

Figura 21 - Variação do Eh ao longo das campanhas de monitoramento

Figura 22 - Diagrama de Eh-pH para cromo (Palmer and Wittbrodt, 1991) 


\section{Lista de Tabelas}

Tabela 1 - Valores orientadores para cromo

Tabela 2 - Propriedades físico-químicas do elemento cromo e seus compostos

Tabela 3 - Métodos analíticos para determinação de cromo em solo e água subterrânea

Tabela 4 - Propriedades físicas do solo

Tabela 5 - Condutividade Hidráulica - Slug Test

56

Tabela 6 - Condutividade Hidráulica - Robbins, Aragon-Jose \& Romero (2009) e Negrão (2012) 56

Tabela 7 - Monitoramento dos Poços 58

Tabela 8 - Condutividade Hidráulica, Velocidade da Água

Subterrânea e Velocidade da Pluma de Contaminação 61

Tabela 9 - Concentrações dos compostos químicos de interesse no solo da área de estudo (mg/kg) 73

Tabela 10 - Concentrações dos compostos químicos de interesse na água subterrânea da área de estudo (mg/L) 73

Tabela 11 - Dados da área de injeção e cálculo da dose $\quad 79$

Tabela 12 - Concentrações de cromo nas amostras de solo (mg/kg) 82

Tabela 13 - Concentrações de cromo nas amostras de água subterrânea (mg/L) 83

Tabela 14 - Concentrações de cromo nas amostras de solo $(\mathrm{mg} / \mathrm{kg})$

Tabela 15 - Concentrações dos compostos químicos de interesse e parâmetros físico-químicos nas amostras de água subterrânea (Agosto/13)

Tabela 16 - Concentrações dos compostos químicos de interesse e parâmetros físico-químicos nas amostras de água subterrânea (Fevereiro/14) 88

Tabela 17 - Concentrações dos compostos químicos de interesse e parâmetros físico-químicos nas amostras de água subterrânea (Outubro/14)

Tabela 18 - Cronologia da Variação da Carga Hidráulica nos Poços de Monitoramento 


\section{Lista de Siglas}

CE - Condutividade elétrica

Cetesb - Companhia Ambiental do Estado de São Paulo

CONAMA - Conselho Nacional de Meio Ambiente

CPS - Polissulfeto de cálcio

Cr(III) - Cromo trivalente

Cr(VI) - Cromo hexavalente

DNPM - Departamento Nacional de Produção Mineral

DOC - Carbono orgânico dissolvido

EPA - Environmental Protection Agency

IARC - International Agency for Research on Cancer

ICP-ES - Inductively Coupled Plasma - Emission Spectroscopy

OD - Oxigênio dissolvido

ORP - Potencial de oxi-redução

$\mathrm{pH}$ - Potencial hidrogeniônico

PCB - Bifenilas policloradas

PVC - Cloreto de polivinila

SVOC - Compostos orgânicos semi-voláteis

TDS - Sólidos totais dissolvidos

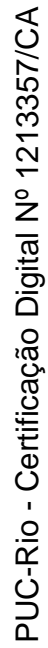

TPH - Hidrocarbonetos totais de petróleo

VI - Valor de Intervenção

VM - Valor Máximo

VMP - Valor Máximo Permitido

VOC - Compostos orgânicos voláteis

VP - Valor de Prevenção

XRF - Fluorescência de Raio-X 


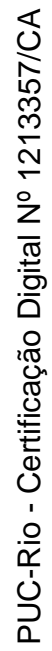

"Não é a força, mas a perseverança que realiza grandes coisas."

Samuel Johnson 


\section{1 Introdução}

A instalação de refinarias de petróleo, gás mineral e algumas indústrias se deram no Brasil no início do século XIX, principalmente em São Paulo e Rio de Janeiro, por homens visionários e idealistas. Contudo, a industrialização tem uma dinâmica própria, que requer investimentos contínuos em pesquisa e desenvolvimento de processos de produção cada vez mais eficientes e produtivos.

A escalada da urbanização e sua expansão teve seu ritmo ditado pela instalação das indústrias, onde seu entorno foi ocupado pelos trabalhadores, o que acabou tornando-se áreas urbanas sem planejamento. O poder público demorou a montar o contexto legal sobre o uso e ocupação do solo e das normas ambientais para regular as atividades industriais.

O primeiro processo de desindustrialização no Brasil ocorreu no final do século XX, com o início da concorrência internacional e declínio de alguns setores industriais acarretou no fechamento e abandono de várias áreas industriais nos grandes centros urbanos. E, em conjunto, vieram os protestos da população do entorno e de regulamentos cada vez mais exigentes quanto à emissão de poluentes, logo as indústrias que não faliram, acabaram por transferir suas unidades para áreas industriais onde às autoridades eram mais complacentes com a degradação ambiental.

Devido a falta de fiscalização dos processos produtivos e da destinação dos resíduos gerados nas indústrias, o poder público não atuou na desativação dos empreendimentos industriais abandonados e, dessa forma, permaneceram por vários anos poluindo o solo e água subterrânea.

$\mathrm{Na}$ cidade do Rio de Janeiro diversas áreas industriais foram abandonadas na região central e na zona norte, próxima as vias que ligavam a São Paulo e ao porto da cidade, e ficaram esquecidas por cerca de 20 anos pela baixa demanda de terrenos. Em meados de 2008, houve o aumento da especulação imobiliária induzida pelo prefeito para a construção de 
condomínios para a população de baixa renda. Algumas áreas industriais contaminadas foram ocupadas por condomínios residenciais sem a avaliação de passivo ambiental e a avaliação de risco à saúde humana. Devido a pressão da população e Ministério Público, o órgão ambiental estadual iniciou a enrijecer o processo de reabilitação de antigas áreas industriais.

Dessa forma, cresceram as oportunidades para as empresas de consultoria ambiental para realizarem as etapas de avaliação ambiental preliminar e investigação ambiental. Contudo, a falta de profissionais adequados para atuar nos projetos de remediação fez com que alguns projetos fossem mal dimensionados e executados e, em alguns casos, projetos de remediação de sucesso nos Estados Unidos foram replicados em áreas no Brasil, culminando na má eficiência da técnica aplicada porque não foram adaptados as condições locais.

Dessa maneira, os órgãos ambientais começarem a se especializar nas técnicas de remediação para que soubessem avaliar os planos de intervenção que as consultorias estavam executando nos terrenos em processo de alteração de uso industrial para residencial, chegando em alguns casos, em paralisar todo o processo de gerenciamento ambiental para reavaliar o caso e, por vezes, solicitar que o mesmo fosse reiniciado, pois não haviam garantias de que a técnica de remediação que estava sendo aplicada seria eficiente ou mesmo o modelo conceitual da área estava adequado.

No Brasil não há publicações sobre o uso de polissulfeto de cálcio no tratamento de áreas contaminadas por cromo hexavalente, sendo que, este reagente químico é amplamente utilizado nos Estados Unidos e Europa e diversos artigos técnicos foram publicados relatando os estudos de caso e a eficiência dos projetos de remediação por meio da Redução Química In Situ (In Situ Chemical Reduction - ISCR).

Neste contexto, esta dissertação de mestrado tem como objetivo abordar as características químicas e comportamento do cromo hexavalente no solo e água subterrânea e seu processo de remediação por meio da redução química in situ (ISCR) com o reagente químico polissulfeto de cálcio na área de estudo localizada na cidade do Rio de Janeiro.

Para cumprir com os objetivos aqui tratados, esta dissertação está dividida da seguinte maneira: 
No capítulo dois é apresentada a revisão bibliográfica sobre: o processo de gerenciamento de áreas contaminadas; revitalização de áreas industriais; valores orientadores; comportamento de metais em subsuperfície; características do elemento cromo; e propriedades químicas do polissulfeto de cálcio. A abordagem destes assuntos é importante para compreender o estudo de caso aqui apresentado.

No capítulo três será apresentado a caracterização da área de estudo com base no histórico da área e os estudos ambientais realizados para caracterizar o passivo ambiental.

No capítulo quatro serão apresentados as etapas da remediação aplicadas na área de estudo.

Os resultados obtidos durante os monitoramentos realizados antes e após a injeção do reagente químico na área de estudo serão apresentados no capítulo cinco.

Por fim, no capítulo seis, será realizada a discussão de todo o trabalho realizado na área de estudo, assim como, a avaliação da eficiência das técnicas de remediação aplicada. 


\section{2 \\ Revisão Bibliográfica}

Com o objetivo de introduzir o tema de gerenciamento de áreas contaminadas anteriormente a abordagem ao cromo hexavalente e a remediação da área de estudo, é necessário entender as etapas do gerenciamento de áreas contaminadas e os valores orientadores, para solo e água subterrânea, estabelecidos pela Resolução CONAMA 420, assim como, o processo de revitalização de áreas contaminadas. Dessa forma, a revisão bibliográfica foi divida em: a) resolução CONAMA 420; b) revitalização de áreas industriais; c) cromo hexavalente; d) técnicas de remediação para cromo hexavalente.

\section{1 \\ Processo de Gerenciamento de Áreas Contaminadas}

A Resolução CONAMA 420, publicada em 28 de Dezembro de 2009, estabeleceu diretrizes para o gerenciamento ambiental de áreas contaminadas, assim como, os valores orientadores para solo e água subterrânea. A remediação do solo e água subterrânea é a penúltima atividade do processo de gerenciamento e, para tanto, são necessários alguns estudos ambientais para detalhamento dos contaminantes. Abaixo seguem algumas definições dos termos referentes ao estudo e um breve relato sobre as etapas do gerenciamento de áreas contaminadas.

\subsection{1}

\section{Termos}

- Bens a proteger: a saúde e o bem-estar da população; a fauna e a flora; a qualidade do solo, das águas e do ar; os interesses de proteção à natureza/paisagem; a infraestrutura da ordenação territorial e planejamento regional e urbano; a segurança e ordem pública; 
-Valores orientadores: são concentrações de substâncias químicas que fornecem orientação sobre a qualidade e as alterações do solo e da água subterrânea;

- Valor de Referência de Qualidade (VRQ): é a concentração de determinada substância que define a qualidade natural do solo, sendo determinado com base em interpretação estatística de análises físico-químicas de amostras de diversos tipos de solos;

- Valor de Prevenção (VP): é a concentração de valor limite de determinada substância no solo, tal que ele seja capaz de sustentar as suas funções principais de acordo com o Art. 3 do capítulo da CONAMA 420; e

-Valor de Investigação (VI): é a concentração de determinada substância no solo ou na água subterrânea acima da qual existem riscos potenciais, diretos ou indiretos, à saúde humana, considerando um cenário de exposição padronizado.

\subsection{2 \\ Etapas de Gerenciamento}

- Avaliação preliminar: avaliação inicial, realizada com base nas informações históricas disponíveis e inspeção do local, com o objetivo principal de encontrar evidências, indícios ou fatos que permitam suspeitar da existência de contaminação na área;

- Investigação confirmatória: etapa do processo de identificação de áreas contaminadas que tem como objetivo principal confirmar ou não a existência de substâncias de origem antrópica nas áreas suspeitas, no solo ou nas águas subterrâneas, em concentrações acima dos valores de investigação;

- Investigação detalhada: etapa do processo de gerenciamento de áreas contaminadas, que consiste na aquisição e interpretação de dados em área contaminada sob investigação, a fim de entender a dinâmica da contaminação nos meios físicos afetados e a identificação dos cenários específicos de uso e ocupação do solo, dos receptores de risco existentes, dos caminhos de exposição e das vias de ingresso; 
- Avaliação de risco: processo pelo qual são identificados, avaliados e quantificados os riscos à saúde humana ou ao bem de relevante interesse ambiental a ser protegido;

- Remediação: uma das ações de intervenção para reabilitação de área contaminada, que consiste em aplicação de técnicas, visando a remoção, contenção ou redução das concentrações de contaminantes;

- Monitoramento: medição ou verificação, que pode ser contínua ou periódica, para acompanhamento da condição de qualidade de um meio ou das suas características.

\section{2 \\ Revitalização de Áreas Industriais}

No século XIX a construção de grandes empreendimentos industriais sempre foi visto como um marco revolucionário ou mesmo uma engenhosidade da mente humana capitaneada por grandes visionários e idealistas que traziam o desenvolvimento e o progresso nas cidades onde eram instaladas as indústrias. Contudo, os grandes visionários nunca pensaram na vida útil das indústrias ou que haveria a mudança de geração de renda nos países desenvolvidos, onde a produção industrial seria trocada como fonte de renda pela produção de informação, conhecimento ou tecnologia.

Os primeiros a sofrerem com a migração das industriais para outros países, devido a mudança da economia, foram os Estados Unidos da América (EUA) e alguns países da Europa no século XIX, no período pós-industrial, onde as industriais migraram para países onde a mão de obra e matéria-prima eram mais baratas e abandonaram as antigas áreas industriais sem um planejamento para sua reutilização, ou mesmo diante da necessidade de investir na modernização industrial, adotando tecnologias mais limpas, as empresas acabaram por transferir as unidades industriais para locais onde não há fiscalização ou as autoridades eram mais complacentes com a degradação ambiental.

Sánchez (2001) cita dois mecanismos relacionados ao processo de desindustrialização: transferência e mortalidade. A transferência está relacionada ao fato da indústria não possuir mais área física para expandir, como por exemplo, quando a cidade cresce ao redor da indústria e acaba 
estrangulando a área de expansão e a mesma tem que construir um novo complexo industrial em outro local, por muitas vezes em outra cidade. A mortalidade está relacionada ao dinamismo industrial, onde algumas vezes o setor industrial entra em decadência e não há outros setores para ocupar seu espaço.

O abandono das áreas industriais dentro do espaço urbano é complicado pelos seguintes fatores:

- Contribui para desvalorizar o entorno;

- Pode ser objeto da ocupação clandestina, desvalorizando ainda mais o entorno;

- Deteriora a imagem de uma cidade perante a opinião pública e os investidores;

- Provocam cortes no tecido urbano;

- Representa risco ao meio ambiente devido a possível contaminação do solo e água subterrânea causada pela antiga indústria;

- Risco à segurança e saúde pública por ser uma área sem controle de acesso e acaba tornando-se uma área de lazer clandestina a população vizinha.

O planejamento para recuperar uma área industrial teve início com as mineradoras onde sabe-se que a capacidade de exploração de um mineral é finita.

A problemática da desativação e revitalização de áreas industriais ganhou notoriedade pública a cerca de 40 anos nos Estados Unidos e Europa com casos críticos de indústrias que desativaram seu processo industrial e venderam os terrenos para outras entidades, e que, por consequência a área contaminada provocou problemas à saúde humana das comunidades que ocuparam o local.

A partir de então o processo de gerenciamento de antigas áreas industrias chamou atenção da sociedade civil que pressionou os órgãos públicos para fiscalizar as atividades industrias no tocante ao seu gerenciamento ambiental. Dessa forma, nos EUA foi criada a EPA (Environmental Protection Agency), que se tornou o órgão ambiental de referencia mundial. Dessa forma, os instrumentos e políticas públicas relacionadas a desativação de áreas industriais ficou relacionado aos procedimentos e políticas para o gerenciamento de 
passivo ambiental, mas sem muito foco para parte técnica de como realizar a desativação e descomissionamento de uma área industrial.

No Brasil a primeira política de meio ambiente foi a Política Nacional de Meio Ambiente - Lei 6.938, sancionada em 31 de agosto de 1981, a qual não tinha regulamentação, procedimentos e normas técnicas específicas para gerenciamento de áreas contaminadas e tão pouco sobre o gerenciamento dos resíduos sólidos. Essa lei continha as diretrizes para o licenciamento apenas para instalação de indústrias no território nacional.

Atualmente a revitalização de áreas industriais é regulamentada com base nas leis, normas e procedimentos técnicos para gerenciamento de passivos ambientais, onde os técnicos dos órgãos ambientais possuem mais conhecimento técnico e podem controlar o processo de reurbanização dessas áreas. $\mathrm{O}$ processo sofreu grandes alterações porque antigamente não havia interesse da sociedade em reutilizar essas áreas devido a grande oferta de terrenos nos grandes centros urbanos.

Contudo nos últimos anos os grandes terrenos vazios próximos aos centros urbanos ficaram escassos e o mercado imobiliário começou a enxergar as antigas áreas industriais como terrenos com ótima localização, devido a proximidade a transportes e acessos, e principalmente pelo baixo valor imobiliário. Por outro lado, as construtoras e incorporadoras não tinham conhecimento sobre áreas contaminadas ou como realizar o levantamento de passivo ambiental e que ocasionou grandes transtornos a sociedade civil pois foram construídos condomínios residenciais em áreas contaminadas e que traziam riscos à saúde dos moradores.

Dessa forma, os órgãos ambientais perceberam que precisavam agir de forma efetiva para que as construtoras/incorporadoras não cometessem os mesmos erros e começaram a ser mais rígidos no processo de licenciamento ambiental dos empreendimentos residenciais.

Devido ao incentivo dos governantes públicos para que as áreas industriais abandonadas fossem ocupadas, o processo de licenciamento ambiental foi alterado. Antigamente todo o processo dos estudos ambientais e etapas de remediação deveriam ser realizados para então qualquer tipo de obra fosse iniciado e, atualmente, os dois processos andam em paralelo para que as 
áreas não fiquem por muitos anos sem ocupação, causando o desinteresse pela sua ocupação.

Os processos e procedimentos para revitalização de antigas áreas industriais já são de conhecimento de quase todas as construtoras/ incorporadoras, as quais por muitas vezes calculam/estimam o valor que será necessário para realizar todo o processo de gerenciamento de uma área contaminada para avaliar a viabilidade econômica do seu projeto.

Porém, ainda não há procedimentos ou normas que estabeleçam as etapas de um programa de fechamento de uma unidade industrial, ou processo chamado de desativação, descontaminação e descomissionamento. Esse processo combina a avaliação de alto nível dos ativos para a estratégia de desinvestimento da propriedade e entrega do programa de descomissionamento, descontaminação e demolição, visando auxiliar o proprietário a avaliar os materiais que possuem valor de mercado como sucata, separando os materiais ou entulho que possam estar contaminados, evitar a demolição descontrolada e que causa a contaminação da área, e agregar valor final ao terreno.

Esse processo tem como principal benefício evitar que haja a contaminação do terreno durante o processo de desativação e demolição da unidade industrial, devido a falta de planejamento. O processo mais comum é o proprietário vender o terreno ao incorporador e deixar por conta dele a demolição e limpeza da área, o que geralmente provoca a contaminação do terreno pela falta de planejamento de todo o processo de descomissionamento, descontaminação e demolição, trazendo sérios danos a reutilização da área.

O estudo de caso abordado nesta dissertação é um dos casos clássicos de falta de planejamento durante o processo de fechamento e desativação de uma unidade industrial, que acarretou na contaminação do solo e da água subterrânea.

O processo de fechamento e desativação é composto das seguintes etapas:

- Avaliação das estruturas das unidades industriais;

- Remoção e destinação final adequada de fluídos e resíduos perigosos;

- Cálculo da quantidade de material que pode ser reciclado e gerar renda no processo; 
- Triagem do material contaminado para destinação final adequada; e

- Restauração do terreno para reutilização.

\section{3}

\section{Valores Orientadores}

Com base nas legislações ambientais vigentes no Brasil, abaixo é apresentado uma tabela que apresenta a compilação dos valores orientadores para o elemento cromo.

Tabela 1 - Valores orientadores para cromo

\begin{tabular}{|c|c|c|c|}
\hline Matriz & $\begin{array}{c}\text { Valor } \\
\text { Orientador }\end{array}$ & Descrição & Referência \\
\hline Solo-Cromo total & $\begin{array}{c}75 \mathrm{mg} / \mathrm{kg} \\
150 \mathrm{mg} / \mathrm{kg} \\
300 \mathrm{mg} / \mathrm{kg} \\
400 \mathrm{mg} / \mathrm{kg} \\
\end{array}$ & $\begin{array}{c}\text { VP } \\
\text { VI - agrícola } \\
\text { VI - residencial } \\
\text { VI - industrial } \\
\end{array}$ & $\begin{array}{l}\text { CONAMA } \\
420 / 2009\end{array}$ \\
\hline $\begin{array}{l}\text { Água subterrânea - } \\
\text { Cromo total }\end{array}$ & $\begin{array}{c}0,05 \mathrm{mg} / \mathrm{L} \\
1 \mathrm{mg} / \mathrm{L} \\
0,1 \mathrm{mg} / \mathrm{L} \\
0,05 \mathrm{mg} / \mathrm{L} \\
\end{array}$ & $\begin{array}{c}\text { VI } \\
\text { VMP - dessedentação } \\
\text { VMP - irrigação } \\
\text { VMP - recreação }\end{array}$ & $\begin{array}{l}\text { CONAMA } \\
\text { 420/2009 } \\
\text { CONAMA } \\
\text { 396/2008 }\end{array}$ \\
\hline Água Potável & $0,05 \mathrm{mg} / \mathrm{L}$ & Padrão de potabilidade & Portaria 2.914/2011 \\
\hline Águas Doces & $0,05 \mathrm{mg} / \mathrm{L}$ & $\mathrm{VM}-$ classes 1,2 e 3 & $\begin{array}{c}\text { CONAMA } \\
357 / 2005\end{array}$ \\
\hline Águas Salinas e Salobras & $\begin{array}{c}0,05 \mathrm{mg} / \mathrm{L} \\
1,1 \mathrm{mg} / \mathrm{L}\end{array}$ & $\begin{array}{l}\mathrm{VM}-\text { classe } 1 \\
\mathrm{VM}-\text { classe } 2 \\
\end{array}$ & $\begin{array}{l}\text { CONAMA } \\
357 / 2005 \\
\end{array}$ \\
\hline $\begin{array}{c}\text { Efluente } \\
\text { Cromo trivalente }\left(\mathrm{Cr}^{3+}\right) \\
\text { Cromo hexavalente } \\
\left(\mathrm{Cr}^{6+}\right) \\
\end{array}$ & $\begin{array}{l}1,0 \mathrm{mg} / \mathrm{L} \\
0,1 \mathrm{mg} / \mathrm{L}\end{array}$ & $\begin{array}{l}\text { VM - padrão de } \\
\text { lançamento }\end{array}$ & $\begin{array}{c}\text { CONAMA } \\
430 / 2011\end{array}$ \\
\hline
\end{tabular}

No Brasil ainda não foram estabelecidos o valor de investigação ou máximo permitido para cromo hexavalente e, consequentemente, os resultados analíticos são comparados com o valor orientador do cromo total. Em relação aos EUA, a EPA estabeleceu para cromo hexavalente em água subterrânea o valor de $0,035 \mathrm{mg} / \mathrm{L}$ (EPA, 2014), porém atualmente está realizando um estudo para reduzir esse valor com base em novos estudos relacionados ao riscos toxicológicos, como por exemplo a ingestão de água contaminada por cromo hexavalente. 
Cabe ressaltar que no dia 21 de Fevereiro de 2014 foi publicada pela Cetesb, órgão ambiental do Estado de São Paulo e referência no Brasil, a atualização dos valores orientadores para solo e água subterrânea. Nesta atualização foram adicionados os valores de intervenção para cromo hexavalente em solo (agrícola, residencial e industrial), entretanto não foi publicado valor orientador para água subterrânea.

\section{4}

\section{Comportamento de Metais em Subsuperfície}

Metais são definidos como elementos que possuem boa condutividade elétrica e calor, e geralmente tem cor prateada ou amarelada. Existem vários termos para classificar os metais, tais como: metaloides, metais de transição, micronutrientes, metais tóxicos e metais pesados, contudo, esses termos são usados arbitrariamente na literatura (McLean \& Bledsoe, 1992).

Todo solo possui naturalmente concentrações de metais, devido a sua geologia de formação e aos processos erosivos que a rocha mãe é submetida ao longo dos anos. Dessa forma, as concentrações dos metais no solo variam de acordo com a região e os processos erosivos por quais as rochas foram alteradas, consequentemente, as concentrações naturais de metais no solo devem ser estabelecidas localmente com a análise de amostras de solo coletada onde o solo não sofreu nenhuma ação antrópica.

Os metais não podem ser degradados, como os compostos orgânicos. Alguns metais como o cromo $(\mathrm{Cr})$, arsênio (As), selênio (Se) e mercúrio (Hg), podem ser transformados em outros estados de oxidação no solo, reduzindo a sua mobilidade e toxicidade (McLean \& Bledsoe, 1992).

O comportamento dos metais no solo está relacionado ao mecanismo de adsorção e precipitação, que podem alterar a mobilidade do metal do solo para a água subterrânea. Quando o metal é introduzido na superfície do solo, o elemento só impactará uma grande extensão vertical se a capacidade de retenção do meio for saturada ou se a interação do metal com o meio subterrâneo aumentar a sua mobilidade.

Para avaliar o comportamento do metal no solo deve-se levar em consideração seu equilíbrio multifásico, como pode ser observado nas Figuras 1 e 2 . 

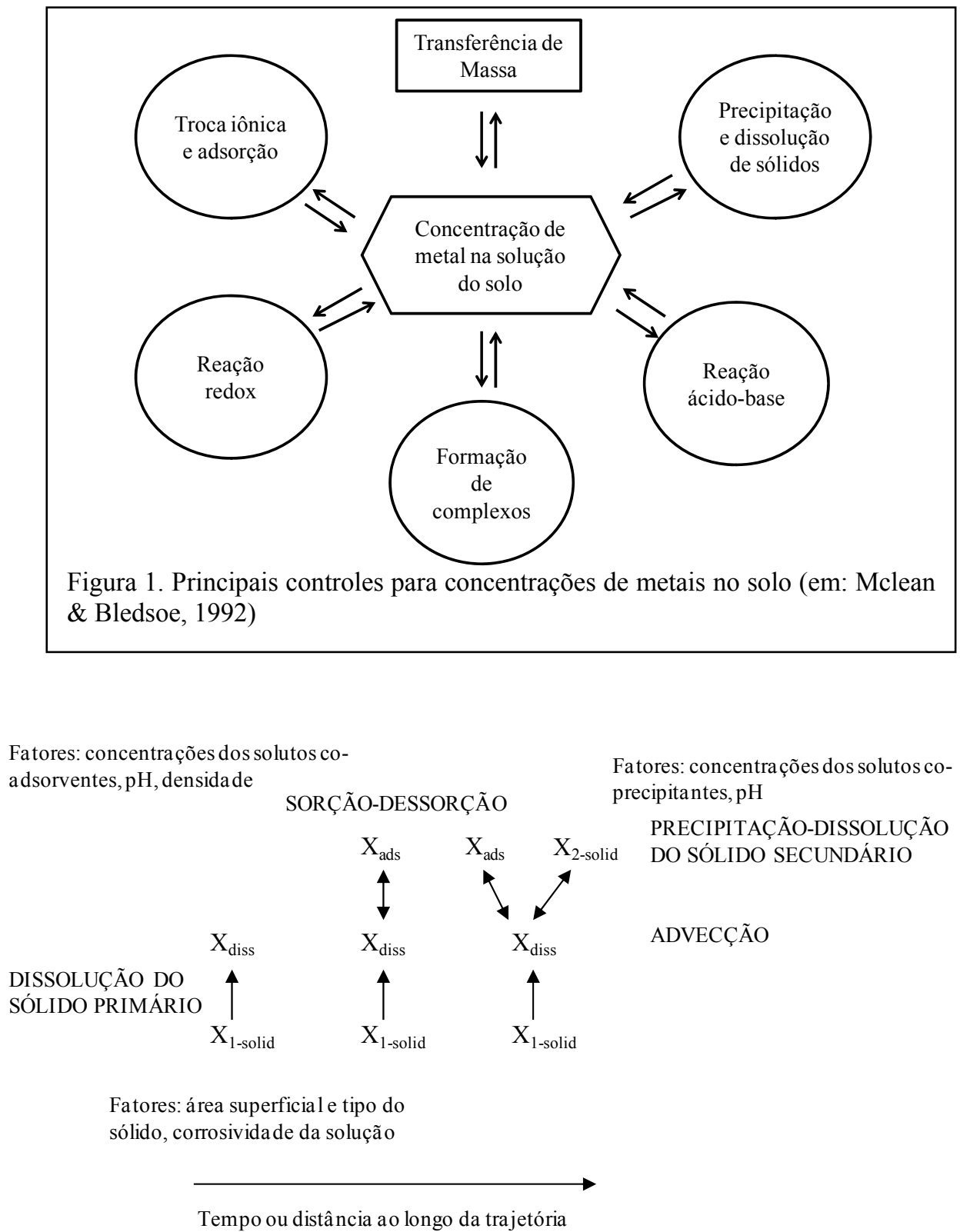

Figura 2. Processo de partição do contaminante $\mathrm{X}$ entre as fases móvel e imóvel (modificado de Hering \& Harmon, 2004).

Os metais podem formar complexos com ligas orgânicas e inorgânicas, sendo que, as ligas inorgânicas são: $\mathrm{SO}_{4}^{2-}, \mathrm{Cl}^{-}, \mathrm{OH}^{-}, \mathrm{PO}_{4}^{3-}, \mathrm{NO}^{3-}$ e $\mathrm{CO}_{4}^{2-}$. A presença de espécies complexas no solo pode afetar o transporte de metais através do solo em relação ao íon do metal livre. Isso afeta tanto a mobilidade do metal no meio quanto a biodisponibilidade e a toxicidade do metal, as quais são maiores no íon do metal livre.

A capacidade de adsorção de metais pelo solo está relacionada principalmente com as suas propriedades, tais como: $\mathrm{pH}$, potencial de oxi- 
redução, conteúdo de argila e matéria orgânica, óxidos de ferro e manganês e conteúdo de carbonato de cálcio.

Quando um contaminante atinge o solo e/ou a água subterrânea ocorre uma alteração geoquímica das condições naturais do meio e, de acordo com o princípio de Le Châtelier, se for imposta uma alteração das concentrações em um sistema em equilíbrio, a composição do sistema se deslocará no sentido de contrariar, ou balancear, a alteração que foi sujeita. Ou seja, a geoquímica do meio tentará reduzir os efeitos do distúrbio causado pelo contaminante.

As interações entre os meios água/solo/gás distribuem os contaminantes entre essas fases (processos geoquímicos) impactando a mobilidade dos contaminantes e criando vias de exposição (Deutsch, 1997). As fases sólidas e dissolvidas dos contaminantes podem ser ingeridas pelos receptores ou absorvidos pela pele por meio do contato dérmico e a fase gasosa pode ser inalada ou também absorvida pela pele. Em relação à fase gasosa apenas o elemento metálico mercúrio $(\mathrm{Hg})$ pode volatilizar e causar riscos à saúde humana através da inalação de seus vapores.

As concentrações das fases móveis serão limitadas pela solubilidade do mineral e gás, caso o metal seja volátil, e por processos de adsorção/dessorção no solo do aquífero.

Dessa forma, o contaminante que foi introduzido no meio deslocará outros metais que estão adsorvidos nos minerais, de acordo com a afinidade de adsorção de cada metal, assim o resultado será a redução da concentração do contaminante e, consequentemente, o aumento da concentração de outros metais no meio.

Esse desequilíbrio causado também pode alterar a mobilidade do contaminante, uma vez que, as reações geoquímicas tendem a diminuir a concentração do metal em qualquer fase que o contaminante seja adicionado ao meio, como por exemplo, se água subterrânea passar por um local onde o solo está limpo, a concentração do contaminante na água subterrânea reduzirá e a concentração no solo aumentará, essa relação também é inversamente proporcional, devido a resposta de adsorção e dessorção do contaminante.

Os compostos dissolvidos (solutos) são transportados por meio do movimento da água subterrânea, denominado processo de advecção. Contudo, a migração do contaminante tem relação com a partição de sua concentração e 
a superfície sólida do aquífero. Essa relação é o coeficiente de distribuição $\left(\mathrm{K}_{\mathrm{d}}\right)$, que é representado pela proporção da concentração do contaminante adsorvido pela superfície de fase sólida $\left(C_{s}, \mathrm{mg} / \mathrm{kg}\right)$ e da concentração dissolvida $\left(\mathrm{C}_{\mathrm{aq}}, \mathrm{mg} / \mathrm{L}\right)$ do contaminante (Deutsch, 1997). Ou seja, o contaminante se deslocará numa velocidade inferior a da água subterrânea.

A velocidade real de um fluído em um meio poroso pode ser calculada conforme a seguinte equação.

$$
v_{x}=\frac{k}{N_{e}} \frac{\Delta h}{\Delta x}
$$

Sendo:

$v_{x}=$ velocidade real da água subterrânea $(\mathrm{cm} / \mathrm{s})$

$\mathrm{k}=$ condutividade hidráulica $(\mathrm{cm} / \mathrm{s})$

$N_{e}=$ porosidade efetiva $(\%)$;

$\Delta \mathrm{h}=$ perda de carga hidráulica $(\mathrm{m})$ na direção x; e

$\Delta \mathrm{x}=$ distância $(\mathrm{m})$ entre os poços de monitoramento.

Devido a anisotropia do meio geológico a velocidade real calculada pela Equação 1 representa a velocidade média da água subterrânea, uma vez que, uma parcela da água subterrânea se deslocará mais rápido do que outra, conforme é demonstrado na Figura 3, devido tanto ao nível microscópico (poros e grãos) quanto macroscópico (camadas litológicas), que resulta na dispersão longitudinal e vertical do contaminante (Cleary, 1989). 


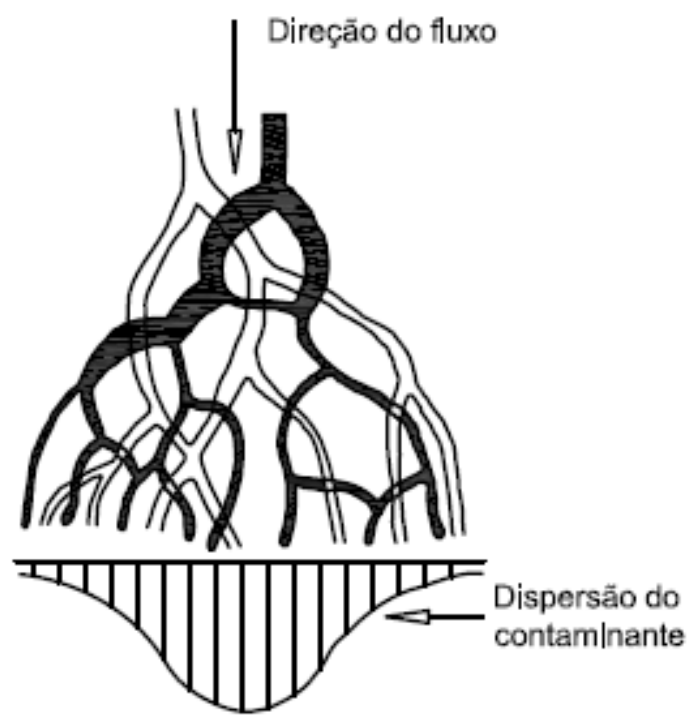

Figura 3. Fluxo da água subterrânea no meio geológico anisotrópico (modificado de Bear, 1972).

Se o soluto é reativo, o mesmo deverá se movimentar a uma velocidade menor do que a água subterrânea devido ao fenômeno de adsorção. O grau de retardação de velocidade de uma pluma de contaminação ao atravessar o solo pode ser calculado conforme a equação a seguir.

$v_{c x}=\frac{v_{x}}{\left[1+(\rho / N) \cdot\left(K_{d}\right)\right]}$

Sendo:

$v_{c x}=$ velocidade média da pluma do soluto (m/dia);

$v_{x}=$ velocidade real da água subterrânea ( $\mathrm{m} /$ dia);

$K_{d}=$ coeficiente de adsorção $(\mathrm{L} / \mathrm{kg})$;

$\rho=$ densidade do solo $\left(\mathrm{kg} / \mathrm{m}^{3}\right)$; e

$\mathrm{N}=$ porosidade do solo $(\%)$.

Para alguns solutos aniônicos, como por exemplo o cloreto $\left(\mathrm{Cl}^{-}\right)$o coeficiente de adsorção adotado é 1 porque o solo não retém a sua migração, ou seja, tais solutos migram na mesma velocidade de fluxo da água subterrânea e não sofrem retardação pelo meio geológico. 
Em relação ao cromo, alguns estudos foram realizados por Rai et al. (1988 e 1989) e Zachara et al. (1989) para avaliar a adsorção do cromo hexavalente no solo, no qual foram utilizados diversos tipos de solo para ponderar quais os parâmetros que mais influenciariam no coeficiente de adsorção deste contaminante. Com base nos dados adquiridos nos estudos foi possível concluir que:

- A adsorção de cromato $\left(\mathrm{CrO}_{4}^{2-}\right)$ no solo aumenta com a redução do pH;

- Solo que contém altas concentrações de óxidos de alumínio e ferro apresentam grande adsorção de $\mathrm{Cr}(\mathrm{VI})$;

- As ligações do cromato foram reduzidas pela presença de sulfato $\left(\mathrm{SO}_{4}^{2-}\right)$ dissolvido e carbono inorgânico, que competem pelo locais de adsorção.

Dessa forma em ambientes que possuem baixas concentrações de óxidos de alumínio e ferro não conseguem retardar a migração do cromo hexavalente.

\section{5 \\ Cromo}

Esse elemento químico foi descoberto e isolado em 1797 por Louis Nicholas Vauquelin ao analisar o metal chumbo vermelho da Sibéria (crocoita - $\mathrm{PbCrO}_{4}$ ). $\mathrm{O}$ cromo foi obtido por meio da redução do trióxido de cromo $\left(\mathrm{Cr}_{2} \mathrm{O}_{3}\right)$ com carvão (Sueker, 2006; IETEG, 2005).

O cromo é um importante metal para a indústria e é utilizado em diversos produtos e processos, tais como: galvanização, tratamento de couro, produção de celulose, preservação de madeira e produção de refratários. O elemento cromo é classificado como um metal de transição (grupo 6 da tabela periódica) e tem como características dureza e cor cinza metálico. O cromo trivalente é essencial do ponto de vista nutricional, não tóxico e pobremente absorvido no organismo, atuando na manutenção do metabolismo da glicose, lipídeos e proteínas, e a deficiência deste elemento acarreta prejuízo na ação da insulina.

O elemento cromo está inserido no grupo de metais que possui estados de oxidação entre -2 e +6 (ATSDR, 2012; Sueker, 2006; Bartlett, 1991; Rai, et al., 1989; Silva \& Pedrozo, 2001). Os estados mais estáveis do cromo são: cromo metálico $\left(\mathrm{Cr}^{0}\right)$, cromo trivalente $\left(\mathrm{Cr}(\mathrm{III})\right.$ ou $\left.\mathrm{Cr}^{3+}\right)$ e cromo hexavalente 
( $\mathrm{Cr}(\mathrm{VI})$ ou $\left.\mathrm{Cr}^{6+}\right)$. O $\mathrm{Cr}(\mathrm{III})$ é o mais comum de ser encontrado e ocorre de forma natural. $\mathrm{O}$ elemento $\mathrm{Cr}(\mathrm{VI})$ pode ocorrer de forma natural, mas em baixas concentrações, se o meio possuir condições geoquímicas de oxidar o $\mathrm{Cr}(\mathrm{III})$ para $\mathrm{Cr}(\mathrm{VI})$

As principais propriedades físico-químicas do elemento cromo e seus compostos são apresentados na tabela abaixo.

Tabela 2 - Propriedades físico-químicas do elemento cromo e seus compostos

\begin{tabular}{|c|c|c|c|c|}
\hline $\begin{array}{c}\text { Propriedades } \\
\text { Fórmula } \\
\text { molecular }\end{array}$ & $\begin{array}{c}\text { Cromo } \\
\text { metálico }\end{array}$ & Ácido crômico & $\begin{array}{c}\text { Cromato de } \\
\text { sódio }\end{array}$ & $\begin{array}{c}\text { Óxido de cromo } \\
\text { (III) }\end{array}$ \\
\hline CAS & $7440-47-3$ & $1333-82-0$ & $7775-11-3$ & $\mathrm{Cr}_{2} \mathrm{O}_{3}$ \\
\hline Massa molecular & 51,996 & 100 & 161,97 & $1308-38-9$ \\
\hline $\begin{array}{c}\text { Fator de } \\
\text { conversão }\end{array}$ & Não aplicável & $\begin{array}{c}1 \mathrm{ppm}= \\
4,08 \mathrm{mg} / \mathrm{m}^{3}\end{array}$ & Nenhum dado & $\begin{array}{c}\mathrm{NarO}_{2} \mathrm{CrO}_{4} \\
6,20 \mathrm{mg} / \mathrm{m}^{3}\end{array}$ \\
\hline $\begin{array}{c}\text { Ponto de fusão } \\
\left({ }^{\circ} \mathrm{C}\right)\end{array}$ & 1.900 & 197 & Não avaliado & 2.435 \\
\hline $\begin{array}{c}\text { Ponto de } \\
\text { ebulição }\left({ }^{\circ} \mathrm{C}\right)\end{array}$ & 2.672 & 250 & 792 & 3.000 \\
\hline $\begin{array}{c}\text { Densidade } \\
\text { relativa }\left(20^{\circ} \mathrm{C}\right)\end{array}$ & 7,2 & 2,7 & Não avaliada & $5,22\left(25^{\circ} \mathrm{C}\right)$ \\
\hline $\begin{array}{c}\text { Solubilidade em } \\
\text { água }\end{array}$ & Insolúvel & $\begin{array}{c}63 \mathrm{~g} / 100 \mathrm{ml} \\
\text { aturcialmente } \\
\text { solúvel }\end{array}$ & Insolúvel \\
\hline $\begin{array}{c}\text { Solubilidade em } \\
\text { outros líquidos }\end{array}$ & ácido nítrico & $\begin{array}{c}\text { etílico, ácidos } \\
\text { sulfúrico e } \\
\text { nítrico }\end{array}$ & $\begin{array}{c}\text { Parcialmente } \\
\text { solúvel em } \\
\text { metanol }\end{array}$ & $\begin{array}{c}\text { Ácidos e bases } \\
\text { concentradas }\end{array}$ \\
\hline
\end{tabular}

Bartlett (1991) afirmou que o ciclo do cromo no solo é maravilhoso porque a oxidação e redução podem acontecer ao mesmo tempo, fator importante para os princípios de aplicação das tecnologias de remediação in situ para redução das concentrações de cromo hexavalente.

O cromo hexavalente é o estado de valência mais perigoso e, segundo a ATSDR (2012), tem maior mobilidade na água subterrânea e é classificado como Classe A sendo carcinogênico por meio da inalação de altas doses de sais de cromato pouco solúveis. A mobilidade do cromo hexavalente é alta no solo e na água subterrânea porque não é adsorvido pelo solo nesse estado de valência, por outro lado quando está na forma trivalente é altamente adsorvido pelo solo, formando precipitados insolúveis, tendo baixa mobilidade no solo e água subterrânea.

Formas do $\mathrm{Cr}(\mathrm{VI})$ em solo são: íon cromato $\left(\mathrm{HCrO}_{4}^{-}\right)$predominante com $\mathrm{pH}$ maior que 6,5 ou como $\mathrm{CrO}_{4}^{2-}$ predominante com $\mathrm{pH}$ 6,5, e como 
dicromato $\left(\mathrm{CrO}_{7}^{2-}\right)$ predominante em altas concentrações $(>10 \mathrm{mM})$ em $\mathrm{pH}$ entre 2 e 6.

Quando há contaminação da água subterrânea por cromo hexavalente em concentração superior a $1 \mathrm{mg} / \mathrm{L}$ a coloração da mesma fica amarela, ou quando há altas concentrações de $\mathrm{Cr}_{2} \mathrm{O}_{7}^{2-}$ a coloração água fica laranja (Palmer \& Puls, 1994).

A especiação do cromo é afetada pela concentração, pressão, temperatura e a presença ou ausência de outros íons na água subterrânea. Alguns estudos em laboratório foram realizados para avaliar os estados de oxidação e os elementos que podiam reagir e transformar o cromo trivalente e cromo hexavalente na água (Sueker, 2006). Alguns dos reagentes são: ferro $\left(\mathrm{Fe}^{2+}\right)$, sulfito $\left(\mathrm{S}^{4+}\right)$, manganês $\left(\mathrm{Mn}^{3+}\right.$ e $\left.\mathrm{Mn}^{4+}\right)$, radical hidroxila $(\cdot \mathrm{OH})$, vanádio $\left(\mathrm{V}^{2+}, \mathrm{V}^{3+} \mathrm{e} \mathrm{V}^{4+}\right)$ e arsênio $\left(\mathrm{As}^{3+}\right)$.

O pressuposto da redução de cromo hexavalente para cromo trivalente imobilizará o cromo, as vezes é irreal porque em águas com altas concentrações de carbono orgânico dissolvido ou manganês, o cromo trivalente reduzido pode formar complexos com o carbono orgânico resultando num aumento do elemento que pode ser lixiviado e ter sua mobilidade elevada. Dessa forma, o cromo trivalente pode se deslocar para áreas onde há condições para oxida-lo, novamente, para cromo hexavalente.

\subsection{1 \\ Principais Ocorrências do Cromo}

\subsubsection{1}

Natural

Os compostos de cromo são encontrados de forma natural em rochas, solos, poeiras, névoas vulcânicas, água, plantas e animais. $\mathrm{O}$ cromo é encontrado em dois minerais: cromita $\left(\mathrm{FeCr}_{2} \mathrm{O}_{4}\right)$ e crocoita $\left(\mathrm{PbCrO}_{4}\right)$. O composto cromita é o mais abundante na natureza, contendo cerca de 40 a 50\% do metal (DNPM, 2013).

Em ambientes que não sofreram atividades antropogênicas as concentrações de cromo no solo, água subterrânea e ar são de aproximadamente 2 a $60 \mathrm{mg} / \mathrm{kg}, 0,001 \mathrm{mg} / \mathrm{L}$ e $0,0001 \mathrm{mg} / \mathrm{m}^{3}$, respectivamente (Cetesb, 2012). Em regiões onde há ocorrência natural de rochas com cromo é 
natural que haja concentrações deste composto acima dos valores orientadores nacionais e internacionais, como por exemplo, na cidade de Urânia/SP, onde foram realizados diversos estudos (Bertolo et al., (2011).

\subsubsection{2}

\section{Antropogênica}

Segundo dados da IETEG (2005), Cetesb (2012) e ATSDR (2012) as maiores fontes para ocorrência do cromo para o ambiente estão relacionadas com as emissões atmosféricas, contaminação do solo e água subterrânea por meio das seguintes atividades industriais:

- Produção de ligas de cromo;

- Refino de minério e seu tratamento químico;

- Queima de combustíveis fósseis, madeira e papel;

- Produção de cimento;

- Soldagem de ligas metálicas;

- Fundições;

- Indústria de galvanoplastia;

- Lixo urbano e industrial;

- Cinzas de carvão;

- Curtumes;

- Preservantes de madeira; e

- Fertilizantes.

\section{5 .2}

Uso

Segundo DNPM (2011), a indústria metalúrgica consome $85 \%$ da produção mundial de cromita, sendo que o cromo é utilizado principalmente para a produção de ligas de ferro-cromo, uma fonte essencial para a produção de aço inoxidável e ligas especiais onde a propriedade fundamental é a de propiciar maior resistência a oxidação, calor, abrasão, corrosão e fadiga.

A indústria química consume cerca de $8 \%$ da produção mundial de cromita, os produtos derivados de cromo a partir do bicromato de sódio $\left(\mathrm{Na}_{2} \mathrm{Cr}_{2} \mathrm{O}_{7}\right)$, têm a sua principal aplicação na manufatura de pigmentos, 
curtimento de couros e peles, indústria de tecidos, artes gráficas, produção de fungicidas (como catalisadores e oxidantes), produtos farmacêuticos e galvanoplastia.

$\mathrm{Na}$ indústria de refratários, responsável por 7\% do consumo mundial de cromita, o cromo participa como um componente fundamental na fabricação de tijolos refratários para revestimento de fornos metalúrgicos, no refinamento das ligas dos metais não-ferrosas, na fabricação de vidros, no processamento do cimento, etc.

O Brasil possui apenas $0,1 \%$ da reserva mundial de cromo, sendo que Cazaquistão e África do Sul possuem 45,1 e 43,0\%, respectivamente (DNPM, 2013). A reserva brasileira de minério de cromo é de cerca de 564 milhões de toneladas, sendo que a capacidade nominal de produção de óxido de cromo é na ordem de 767 mil toneladas/ano, distribuídas geograficamente entre os estados da Bahia (69\%) e Amapá (31\%).

\subsection{3 \\ Toxicologia}

O cromo metálico e os compostos de cromo trivalente são classificados pela Agência Internacional de Pesquisa em Câncer (IARC) no Grupo 3: não classificável quanto a carcinogenicidade. Essa categoria comumente é usada para agentes para os quais a evidência de câncer é inadequada no ser humano e inadequada ou limitada em animais de experimentação. Os compostos de cromo hexavalente são classificados pela mesma agência como cancerígenos para o ser humano.

\subsection{4}

\section{Exposição}

As vias de exposição, para ambientes não industriais, mais comuns com o elemento cromo são: (a) alimentação; e (b) contato com produtos fabricado com o cromo. Contudo, cabe ressaltar que o risco da exposição ao cromo varia de acordo com seu estado de oxidação. O limite máximo diário para ingestão de alimentos que contenham cromo em sua composição varia entre 0,05 e 0,20 $\mathrm{mg} /$ dia, sendo que, esse limite varia de acordo com o país e legislação local (Cetesb, 2012). 
Para ambientes industriais a principal via de exposição ocorre pela inalação de partículas e/ou poeiras contaminadas por cromo, sendo que em industriais podem ocorrer à contaminação por cromo trivalente e/ou cromo hexavalente.

A exposição ao cromo pode causar de maneira geral dermatites, feridas crônicas na pele e vias respiratórias e a falência renal aguda.

\subsection{5}

\section{Caracterização em Solo e Água Subterrânea}

É recomendado que a caracterização do cromo seja focada em: (1) identificar as espécies sólidas e solúveis capazes de reduzir o $\mathrm{Cr}(\mathrm{VI})$; (2) quantificar a capacidade de redução de $\mathrm{Cr}(\mathrm{VI})$; (3) determinar a quantidade de Cr(VI) que pode ser liberado ao longo do tempo; (4) avaliar possíveis mudanças na geoquímica da água subterrânea que pode influenciar na mobilidade da ligação com solo e sedimento com o $\mathrm{Cr}(\mathrm{VI})$; (5) avaliar o comportamento de longo prazo dos redutores devidos as possíveis alterações químicas da água subterrânea; e (6) avaliar o potencial de re-oxidação do Cr(III).

A identificação da forma móvel do cromo no aquífero é relativamente importante para o desenvolvimento do modelo conceitual dos processos que controlam a imobilização desse contaminante. O cromo pode ter alta mobilidade na forma dissolvida ou associada com partícula de matéria orgânica coloidal.

\subsection{6}

Métodos Analíticos para Determinação das Concentrações em Solo e Água Subterrânea

Existem diversos métodos analíticos para determinação das concentrações de cromo em solo e água subterrânea. Em comparação com os EUA, a agência ambiental americana (EPA) solicita para alguns projetos a determinação do cromo por meio de métodos específicos e, com isso, os laboratórios americanos possuem quase todos os métodos disponíveis implantados para atender a demanda dos seus clientes e exigências do órgão 
ambiental. No Brasil, como não há nenhuma legislação específica ou orientação dos órgãos ambientais, os laboratórios apenas implantam alguns métodos analíticos devido aos custos atribuídos as suas certificações.

Dessa forma, em alguns casos os limites de detecção e quantificação são muito altos e limitam a avaliação das concentrações de cromo hexavalente no solo e água subterrânea. Dependendo do método analítico, o limite de quantificação é igual ou pouco inferior ao valor orientador o que trazer problemas na interpretação dos resultados analíticos devido ao erro do método analítico.

Para a caracterização das concentrações de cromo nos estudos ambientais, geralmente são realizadas as análises de cromo total e cromo hexavalente e a concentração de cromo trivalente é obtida subtraindo a concentração do cromo hexavalente do cromo total. A Figura 4 apresenta o diagrama com a distribuição das espécies de cromo.

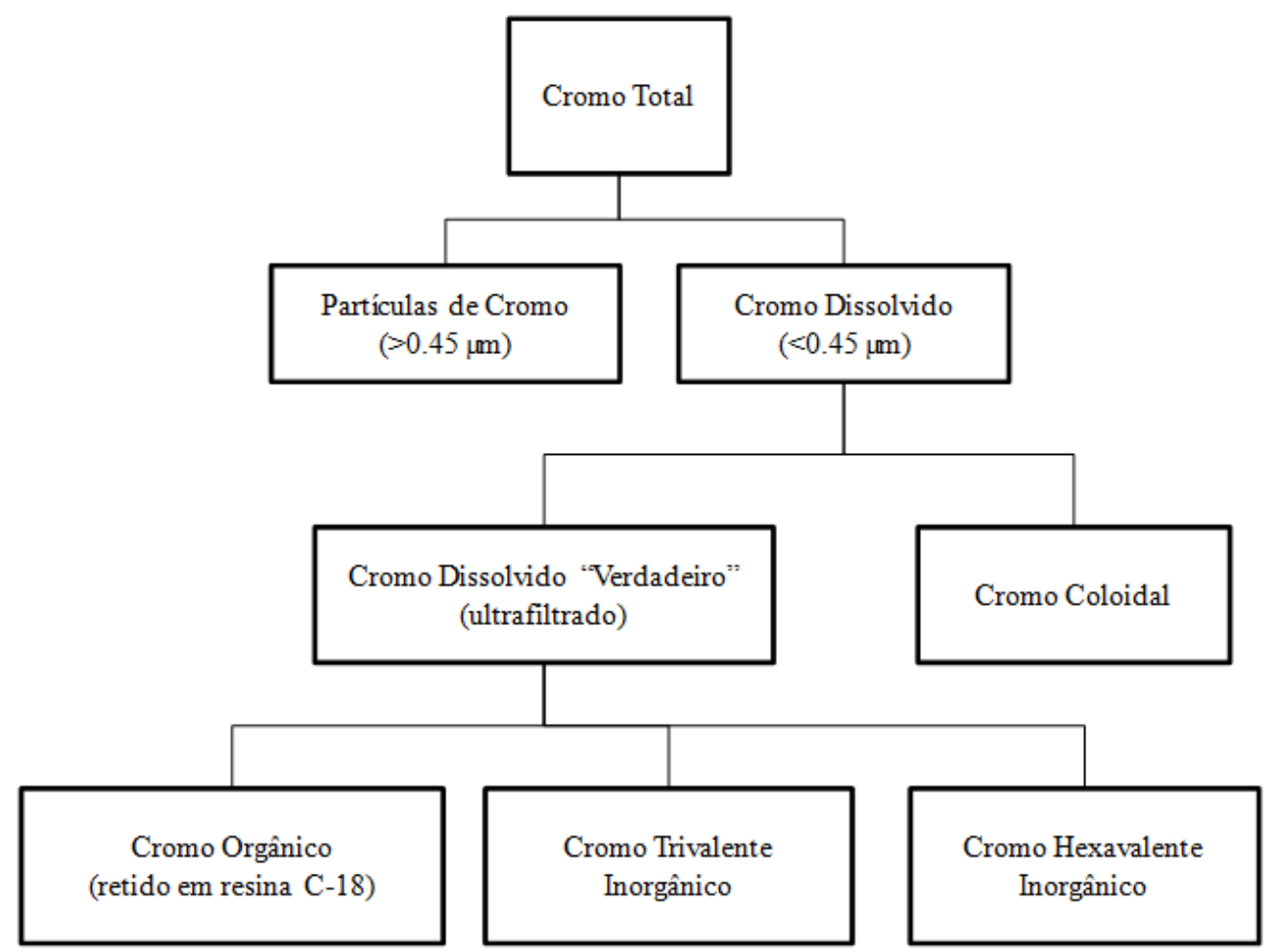

Figura 4 - Diagrama de distribuição das espécies de cromo (adaptado: (Hering \& Harmon, 2004)

A determinação da concentração de cromo hexavalente é crítica devido à validade da amostra após a sua coleta e a acidificação da amostra não é realizada porque o ácido pode reduzir as concentrações de cromo hexavalente 
para cromo total. Dessa forma, a análise de cromo hexavalente tem que ser realizada em até 24 horas após sua coleta, o que torna alguns projetos onerosos por causa de sua logística em locais remotos. Para contornar esse problema, é possível preservar a amostra para análise de cromo hexavalente com hidróxido de amônia $\left(\mathrm{NH}_{4} \mathrm{OH}\right)$ que eleva o $\mathrm{pH}$ da solução e prolonga a validade da amostra para 28 dias, conforme estabelecido pela "Standard Methods for the Examination of Water and Wastewater, 22nd Edition, method $3500-4 b$. Treatment of sample”. Cabe ressaltar que esse método não é muito utilizado e as interferências nas concentrações de cromo hexavalente são desconhecidas devido a mudança do $\mathrm{pH}$ da amostra de água subterrânea causa pelo hidróxido de amônia.

A Tabela 3 apresenta os métodos analíticos utilizados pelos laboratórios brasileiros para determinação de cromo em amostras de solo e água subterrânea.

Tabela 3 - Métodos analíticos para determinação de cromo em solo e água subterrânea

\begin{tabular}{|c|c|c|c|c|c|}
\hline Matriz & $\begin{array}{l}\text { Estado de } \\
\text { Valência }\end{array}$ & $\begin{array}{c}\text { Método de } \\
\text { Preparo }\end{array}$ & Método Analítico & $\begin{array}{c}\text { Limite de } \\
\text { Quantificação }\end{array}$ & $\begin{array}{c}\text { Referência / } \\
\text { Método }\end{array}$ \\
\hline \multirow[t]{2}{*}{ Solo } & $\mathrm{Cr}(\mathrm{VI})$ & $\begin{array}{c}\text { Digestão } \\
\text { prévia à } \\
\text { leitura }\end{array}$ & Espectrofotometria & $2,0 \mathrm{mg} / \mathrm{kg}^{*}$ & $\begin{array}{c}\text { USEPA } \\
\text { 7196A / SM } \\
3500\end{array}$ \\
\hline & Cr Total & $\begin{array}{l}\text { USEPA } \\
\text { 3050B }\end{array}$ & ICP - ES & $0,50 \mathrm{mg} / \mathrm{kg}^{*}$ & $\begin{array}{l}\text { USEPA } \\
6010 \mathrm{C}-\end{array}$ \\
\hline \multirow{2}{*}{$\begin{array}{c}\text { Água } \\
\text { Subterrânea } \\
\text { / Superficial }\end{array}$} & $\mathrm{Cr}(\mathrm{VI})$ & $\begin{array}{c}\text { Leitura } \\
\text { direta }\end{array}$ & Espectrofotometria & $0,01 \mathrm{mg} / \mathrm{L}$ & $\begin{array}{c}\text { USEPA } \\
\text { 7196A SM } \\
3500\end{array}$ \\
\hline & Cr Total & $\begin{array}{l}\text { USEPA } \\
3005 A\end{array}$ & ICP-ES & $0,01 \mathrm{mg} / \mathrm{L}$ & $\begin{array}{l}\text { USEPA } \\
6010 \mathrm{C}\end{array}$ \\
\hline
\end{tabular}

\subsection{7}

\section{Coeficiente de Adsorção $\left(K_{d}\right)$}

Para o composto cromo hexavalente não há um valor teórico para o coeficiente de adsorção como há para compostos voláteis orgânicos. O cenário ideal seria realizar um estudo para determinar o coeficiente de adsorção com solo e água subterrânea da área de interesse.

Contudo, para a área de estudo foi adotado um valor de coeficiente de adsorção com base nos valores identificados nos estudos realizados por Rai et al. (1988; 1989) e Zachara et al. (1989). Na área de estudo foi identificado, ao 
longo dos estudos ambientais, valores de $\mathrm{pH}$ que variavam entre 4,38 e 6,26, dessa forma, foram utilizados os valores de $\mathrm{K}_{\mathrm{d}}$ destas faixas de $\mathrm{pH}$ para se calcular o valor médio do coeficiente de adsorção do cromo hexavalente a ser utilizado no cálculo da velocidade de deslocamento da pluma de contaminação. O valor médio do coeficiente de adsorção é de $3,51 \mathrm{ml} / \mathrm{g}$.

\section{6}

\section{Propriedades Químicas do Polissulfeto de Cálcio}

O polissulfeto de cálcio tem sido estudado e se mostrado um redutor promissor para redução de cromo hexavalente para cromo trivalente, com diversos estudos de campo documentados na literatura, tanto para solo, água subterrânea e Resíduos do Processamento de Minério de Cromita (COPR) (Storch, et al., 2002; Graham, et al., 2006; Charboneau, et al., 2006; Wazne, et al., 2007a; Wazne, et al., 2007b; Chrysochoou, et al., 2010; Chrysochoou \& Ting, 2011; Pakzadeh \& Batista, 2011; Chrysochoou, et al., 2012) (Storch, et al., 2002; Graham, et al., 2006; Charboneau, et al., 2006; Wazne, et al., 2007a; Wazne, et al., 2007b; Chrysochoou, et al., 2010; Chrysochoou \& Ting, 2011; Pakzadeh \& Batista, 2011; Chrysochoou, et al., 2012).

O polissulfeto de cálcio é um fertilizante para solo e comercialmente disponível e tem sido utilizado em alguns estudos de caso de remediação para redução de cromo hexavalente no solo e na água subterrânea. Por ser comercialmente disponível e ser utilizado como fertilizante, é um reagente químico relativamente barato em comparação com outros compostos químicos exclusivamente desenvolvidos para tal finalidade.

Conforme descrito por Chrysochoou \& Ting (2011), os polissulfetos são voláteis e instáveis em solução aquosa. A maioria dos polissulfetos de cadeia longa são estáveis em $\mathrm{pH}$ elevado $(\mathrm{pH}>9)$ e quebram-se em cadeias de comprimento mais curto a medida que o $\mathrm{pH}$ diminui abaixo dos respectivos valores de pKa (Equações. 3 - 6).

$$
\begin{aligned}
& \mathrm{HS}^{-}+\mathrm{S}^{0} \rightarrow \mathrm{S}_{2}^{2-}+\mathrm{H}^{+} \mathrm{pKa}=12,16 \\
& \mathrm{HS}^{-}+2 \mathrm{~S}^{0} \rightarrow \mathrm{S}_{3}^{2-}+\mathrm{H}^{+} \mathrm{pKa}=10,85 \\
& \mathrm{HS}^{-}+3 \mathrm{~S}^{0} \rightarrow \mathrm{S}_{4}^{2-}+\mathrm{H}^{+} \mathrm{pKa}=\mathbf{9 , 8 6} \\
& \mathrm{HS}^{-}+4 \mathrm{~S}^{0} \rightarrow \mathrm{S}_{5}^{2-}+\mathrm{H}^{+} \mathrm{pKa}=\mathbf{9 , 1 8}
\end{aligned}
$$


Além disso, polissulfetos são conhecidos por gerar sulfetos e compreendem apenas aproximadamente $10 \%$ do enxofre (S) total a $\mathrm{pH} 12$ $\left( \pm 6 \% \mathrm{~S}_{5}^{2-}, 4 \% \mathrm{~S}_{6}^{2-}\right.$ e $<1 \%$ de outras espécies) e esta porcentagem diminui para menos de $1 \%$ com $\mathrm{pH} \leq 7$. Com $\mathrm{pH}<8$ as espécies $\mathrm{HS}^{-}$e $\mathrm{H}_{2} \mathrm{~S}$ são dominantes (Chrysochoou \& Ting, 2011). O composto tiossulfato $\left(\mathrm{S}_{2} \mathrm{O}_{3}^{2-}\right)$ também é produto da oxidação tanto do sulfeto como polissulfeto (Eq. 7), sendo que a formação do tiossulfato é depedente do $\mathrm{pH}$ e oxigênio em solução. $\mathrm{O}$ tiossulfato também pode atuar como redutor do cromo hexavalente.

$S_{x}^{2-}+3 / 2 O_{2} \rightarrow S_{2} O_{3}^{2-}+(x-2) S^{0}$ 


\section{3 Caracterização da Área de Estudo}

Devido a confidencialidade dos dados e do cliente, nesta dissertação a localização da área de estudo será descrita de forma genérica e as datas dos estudos ambientais não serão disponibilizadas, porque a área ainda encontra-se em processo de recuperação ambiental.

O presente estudo de caso se trata de uma antiga fábrica de vidros na região metropolitana do Rio de Janeiro. A área em questão foi utilizada como fábrica de vidros por aproximadamente 60 anos e teve sua atividade encerrada devido ao processo industrial estar obsoleto e outras plantas industriais mais modernas estarem instaladas em outras cidades com melhores incentivos fiscais.

A área transformou-se em uma cicatriz no tecido urbano local, sem função social e colocando em risco os moradores da vizinhança. Cabe ressaltar que o terreno era utilizado como área de lazer clandestina por alguns moradores da região, o que aumentou o risco de contaminação do meio ambiente e das pessoas que invadiam o local.

\section{1}

\section{Fechamento da Unidade Industrial}

A empresa não planejou a desativação da unidade fabril e apenas encerrou as atividades e deixou o terreno aguardando algum comprador interessado. Após quatro anos da unidade desativada o terreno foi comprado para ser transformado em uma área residencial e suprir a demanda por novas moradias na região, a qual estava em forte ascensão e pressão imobiliária.

Como não havia procedimento para desativação de empreendimentos industriais ou protocolos a serem seguidos, a antiga proprietária apenas realizou as três etapas do gerenciamento de passivo ambiental, que são: 1) investigação ambiental confirmatória; 2) avaliação de risco à saúde humana, sendo esses dois primeiros para calcular o passivo ambiental do terreno; e 3) 
bombeamento da água subterrânea contaminada por cromo, uma medida de remediação da área.

Contudo, conforme estabelecido na CONAMA 420/2009 é necessário realizar a avaliação ambiental preliminar, na qual consiste no levantamento do uso e ocupação da área de interesse e na classificação das áreas com potencial e suspeitas de contaminação, com base nas atividades que eram desenvolvidas no local, para elaborar o modelo conceitual preliminar da área e as investigações subsequentes para detalhamento das concentrações dos compostos químicos de interesse, para então, realizar a avaliação de risco à saúde humana e estabelecer o plano de intervenção da área. Dessa forma, o órgão ambiental interrompeu e reiniciou todo processo de licenciamento ambiental.

Outro fator que contribuiu para que houvesse maior impacto no terreno foi a negligência durante o processo de descomissionamento dos equipamentos industriais e a disposição dos resíduos que ali estavam armazenados, após o encerramento das atividades. Segundo Sánchez (2001) a existência de passivo ambiental em áreas industriais podem ser geradas a partir do descomissionamento inadequado da unidade fabril, pois a área não deve ser demolida e sim desmontada e os resíduos serem destinados adequadamente de acordo com suas características.

Possivelmente a contaminação identificada no terreno foi proveniente dos 60 anos de operação da fábrica de vidros. Porém não é possível descartar que a demolição não planejada possa ter contribuído com a contaminação ali identificada.

\section{2}

\section{Estudos Ambientais}

Conforme citado anteriormente, o órgão ambiental responsável pelo licenciamento ambiental da área de estudo reiniciou todo o processo devido a inconsistência dos estudos ambientais e, principalmente, da etapa de remediação que estava sendo executada na área de estudo. Dessa forma, abaixo serão descritas todas as etapas realizadas na área de estudo para aquisição de dados e elaboração do modelo conceitual que nortearam as atividades de 
remediação. Na Figura 5 é apresentado o terreno da antiga fábrica de vidros e a localização da área contaminada por cromo hexavalente.

\subsection{1}

\section{Avaliação Ambiental Preliminar}

A avaliação ambiental preliminar realizada foi baseada nos padrões estabelecidos na Norma Brasileira Regulamentadora ABNT NBR 15515-1 Passivo Ambiental em Solo e Água Subterrânea - Parte 1: Avaliação Preliminar; Resolução CONAMA 420/2009; e de acordo com as práticas usuais associadas com a ASTM E1527-05. Foi possível identificar que para fabricação de vidro eram utilizadas os seguintes produtos químicos: óxido de arsênio, óxido de silício, carbonato de cálcio e sódio, alumina calcinada e hidratada, nitrato de sódio, sulfato de sódio, óxido de cobalto, selênio e sulfato de bário, assim como, cromo hexavalente que era utilizado para preparação das fôrmas de vidro. Também foram identificados o armazenamento de óleo diesel para abastecimento das máquinas e óleo BPF para queima nas caldeiras.

$\mathrm{Na}$ área da antiga fábrica de vidros foi possível classificar seis áreas como contaminadas (estudos ambientais realizados), três áreas com potencial de contaminação e nove áreas com suspeita de contaminação. Como o objetivo desta dissertação é de abordar a área contaminada por cromo hexavalente, nos próximos itens serão mencionados apenas as atividades realizadas nesta área que será chamada genericamente como: área de estudo. 


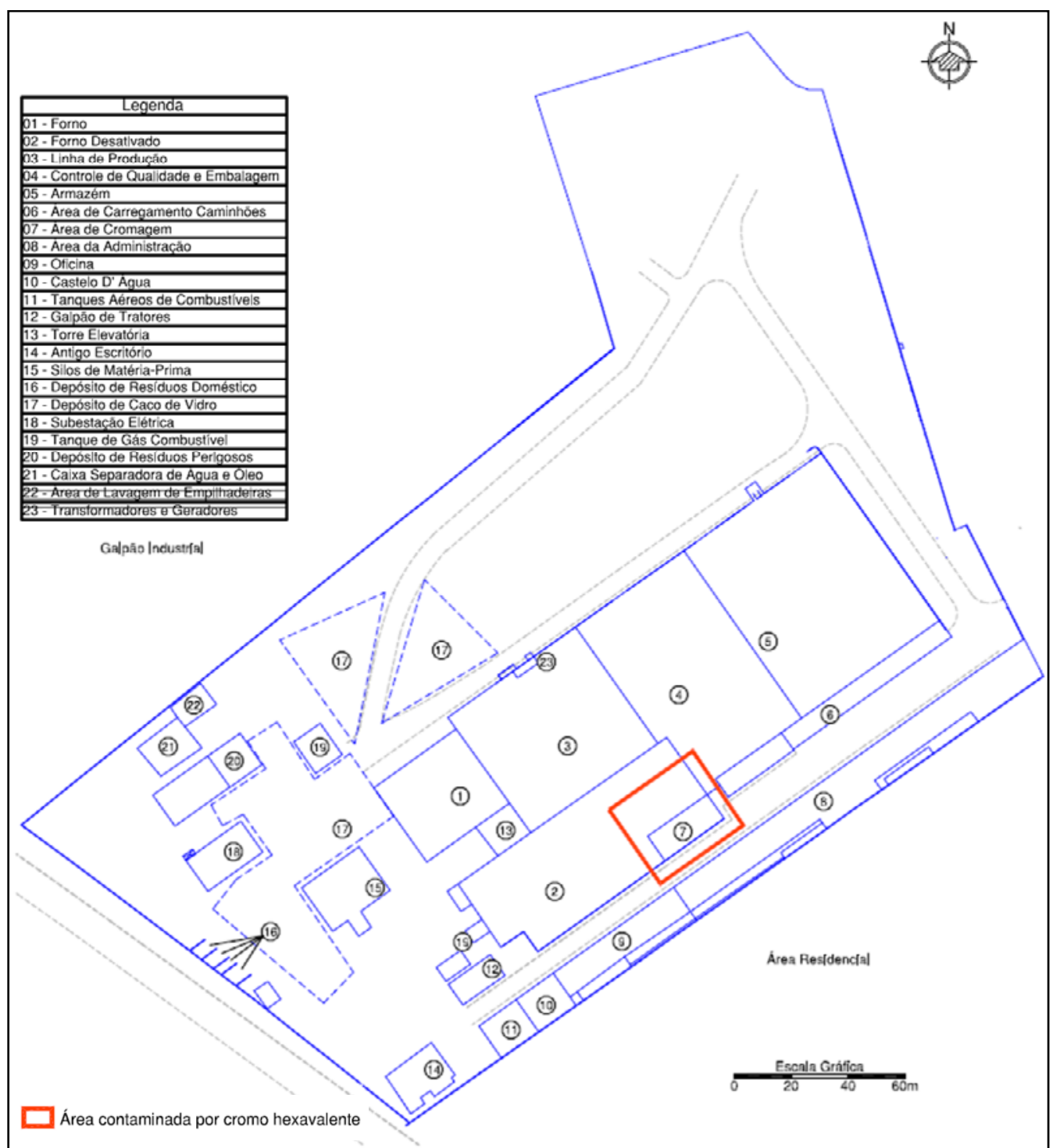

Figura 5 - Terreno da antiga fábrica de vidros e destaque da área contaminada por cromo hexavalente

\section{2 .2}

\section{Investigação Ambiental Confirmatória e Detalhada}

Com base nos dados adquiridos na avaliação ambiental preliminar e nas investigações ambientais realizadas anteriormente na área de estudo, foi necessário realizar um novo estudo ambiental, que consistiu na caracterização geológica por meio de sondagens de reconhecimento com coleta de amostras de solo, instalação de poços de monitoramento para coleta de amostras de água subterrânea e avaliação da hidrogeologia local e análise laboratorial das amostras de solo e água subterrânea. 


\subsubsection{1}

\section{Sondagens}

Nas investigações ambientais realizadas na área de estudo foram realizadas 15 sondagens de reconhecimento do solo, que tiveram como objetivo a coleta de amostras de solo para avaliar a dispersão das concentrações dos compostos químicos de interesse. As sondagens foram realizadas conforme ABNT NBR 15.492:2007 - Sondagem de Reconhecimento para Fins de Qualidade Ambiental - Procedimento.

As sondagens até 5 metros de profundidade, foram realizadas com trado manual com diâmetro de quatro polegadas e as sondagens mais profundas (até dez metros de profundidade) foram realizadas com trado mecanizado Hollow Stem Auger de seis polegadas. Nas sondagens realizadas com trado manual foi realizada a descrição do solo e medições de compostos orgânicos voláteis (VOC) a cada 0,5 metro e nas sondagens realizadas com trado mecanizado foi utilizado liner para coleta contínua de solo para descrição das camadas de solo.

O solo proveniente das sondagens foram examinados para registrar as suas características litológicas, organolépticas (cor, textura e odor) e a presença de contaminantes.

\subsubsection{1 \\ Análises Laboratoriais}

A partir das sondagens realizadas na área de estudo, foram coletadas amostras de solo com o intuito de avaliar sua qualidade ambiental. Na primeira etapa de investigação foram coletadas duas amostras de solo em cada sondagem, sendo uma amostra superficial para análise de metais e outra amostra próxima a franja capilar para análise de VOC, SVOC, TPH e PCB, totalizando oito amostras de solo.

$\mathrm{Na}$ segunda investigação realizada foram coletadas 4 amostras de solo, que foram enviadas ao laboratório analítico para análise dos metais prioritários da CONAMA 402/2009, uma vez que na primeira investigação não foram detectadas concentrações dos compostos VOC, SVOC, TPH e PCB. 


\subsubsection{2}

\section{Análise com Fluorescência de Raios-X}

Fluorescência de Raios-X (XRF) é a propriedade de um material emitir raio- $\mathrm{X}$, com uma energia característica, ao ser irradiado por raios- $\mathrm{X}$ de uma fonte de radioisótopos.

XRF é uma metodologia para avaliação qualitativa das concentrações de metais no solo e tem que ser utilizada em conjunto com análise quantitativa para validar as leituras realizadas (EPA, 2007), em uma porcentagem das amostras coletadas. XRF é normalmente utilizado para dois propósitos principais: a) podem ser utilizados para avaliar rapidamente as condições da área de estudo; e b) pode ser utilizado para analisar grande quantidade de amostras de solo e minimizar o número de amostras que serão enviadas para laboratório para fornecer dados quantitativos das concentrações de metais no solo.

Com base na metodologia do uso do XRF, poder desenvolvido um esquema analítico para confirmar as concentrações dos compostos químicos de interesse o que minimiza o número de amostras que devem ser submetidas a análises químicas laboratoriais, ainda fornece dados a nível definitivo, com um alto grau de confiança, para os tomadores de decisão.

No total foram realizadas nove sondagens até nível d'água (em torno de 1,5 metros), que variou em diversas sondagens, para coleta de amostras de solo para medição de metais por meio da tecnologia XRF. Foram realizadas 52 leituras com XRF e apenas uma amostra foi enviada ao laboratório para análise quantitativa.

Nos pontos com indício de contaminação, o equipamento XRF mediu concentrações entre 184 e $17.309 \mathrm{mg} / \mathrm{kg}$ de cromo, comprovando o impacto na área por cromo hexavalente, uma vez que, no solo sem indício de contaminação não foram detectadas concentrações de cromo.

Nas amostras de 0,5 e 1,5 m coletadas na sondagem próxima ao centro da pluma de contaminação e enviadas para análise em laboratório foram detectadas concentrações de 34,7 e $57,8 \mathrm{mg} / \mathrm{kg}$, respectivamente. Essas concentrações não foram identificadas pelo equipamento de XRF devido ao erro de leitura do equipamento ser alto, com valor mínimo e máximo de 52 e $438 \mathrm{mg} / \mathrm{kg}$, respectivamente. 
3.2.2.1.3

\section{Análise Geotécnica}

As propriedades físicas do solo da área de estudo foram obtidas através da análise geotécnica de uma amostra de solo coletada, em consonância com a Norma ABNT NBR 9813:1987: Solo - Determinação da massa específica aparente in situ com emprego de cilindro de cravação. Os resultados das análises são apresentadas na Tabela 4.

Tabela 4 - Propriedades físicas do solo

\begin{tabular}{|c|c|c|}
\hline \multicolumn{2}{|c|}{ Parâmetros } & Valores \\
\hline \multicolumn{2}{|c|}{ Profundidade da amostra (m) } & 1,5 \\
\hline \multicolumn{2}{|c|}{ Umidade $(\%)$} & 16,3 \\
\hline \multicolumn{2}{|c|}{ Porosidade Total (\%) } & 34 \\
\hline \multicolumn{2}{|c|}{ Porosidade Efetiva (\%) } & 6 \\
\hline \multicolumn{2}{|c|}{ Densidade Aparente $\left(\mathrm{g} / \mathrm{cm}^{3}\right)$} & 1,16 \\
\hline \multicolumn{2}{|c|}{ Matéria Orgânica (\%) } & 3,77 \\
\hline \multirow{5}{*}{ 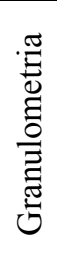 } & Argila (g/kg) & 143 \\
\hline & Silte $(\mathrm{g} / \mathrm{kg})$ & 375 \\
\hline & Areia Total $(\mathrm{g} / \mathrm{kg})$ & 482 \\
\hline & Areia Grossa (g/kg) & 240 \\
\hline & Areia Fina (g/kg) & 242 \\
\hline \multicolumn{2}{|c|}{ Classificação do solo } & Areia siltosa pouco argilosa \\
\hline
\end{tabular}

\subsubsection{2}

\section{Poços de Monitoramento}

Após a conclusão das sondagens foram instalados os poços de monitoramento rasos e profundos, conforme ABNT NBR 15.495-1: Poços de monitoramento de águas subterrâneas em aquíferos granulados. Nas sondagens foram colocados tubos geomecânicos de PVC de duas polegadas de diâmetro e o espaço anelar da seção filtrante foi preenchido com areia granulada selecionada até profundidade de meio metro acima do topo da seção filtrante. Acima disso, o espaço anelar foi preenchido com uma mistura de calda bentonítica e cimento, para evitar qualquer migração de contaminação superficial para a seção filtrante do poço de monitoramento. As diferenças do poço de monitoramento raso e profundo são:

a) comprimento da seção filtrante: raso instalado com três metros de seção filtrante e poço profundo com um metro de seção filtrante;

b) profundidade de instalação: raso entre quatro e cinco metros de profundidade e profundo com dez metros de profundidade; 
c) objetivo: o poço de monitoramento raso tem o objetivo de monitorar o aquífero subterrâneo raso (aquífero livre), e o poço profundo tem como objetivo monitorar o aquífero profundo (confinado) e avaliar a migração vertical da contaminação.

Os poços profundos tiveram suas seções filtrantes instaladas acima da camada impenetrável ao trado mecanizado utilizado, para avaliar a migração vertical da contaminação identificada em estudos anteriores realizados.

Após a instalação, os poços foram desenvolvidos manualmente, com auxílio de bailer descartável de forma a promover a limpeza do mesmo e reestabelecer as condições de fluxo locais, evitando assim o colapsamento da seção filtrante e do selo sanitário.

No total foram instalados onze poços de monitoramento sendo: seis poços de monitoramento rasos e cinco poços de monitoramento profundos. Totalizando 18 poços de monitoramento para monitoramento da área.

Posteriormente ao seu desenvolvimento e a estabilização das condições locais, foi realizado o levantamento topográfico e o monitoramento do nível d'água de cada poço de monitoramento para calcular a carga hidráulica e avaliar a direção do fluxo d'água subterrânea dos aquíferos raso e profundo, assim como, avaliar o fluxo vertical da água subterrânea.

\subsubsection{1}

\section{Análise Laboratorial}

A coleta das amostras foi realizada nos poços de monitoramento instalados ao longo da área de estudo pelo método de baixa vazão, seguindo a norma ABNT NBR 15.847 - Amostragem de Água Subterrânea em Poços de Monitoramento - Métodos de Purga, procedimento Low flow (Minimal Drawdown) Groundwater Sampling Procedures (EPA, 1996) e no guia D677102: Standard Practice for Low-Flow Purging and Sampling for Wells and Devices Used for Groundwater Investigation (ASTM, 2002).

A coleta em baixa vazão pode ser realizada com uma bomba peristáltica ou bomba bexiga acoplados a uma célula de fluxo com leitor de multiparâmetros. A escolha da bomba a ser utilizada é realizada de acordo com o contaminante identificado como prioritário na área de estudo. A vazão da 
bomba é regulada para que o fluxo da mesma seja igual a recarga do aquífero e, dessa forma, a coleta é realizada da água subterrânea proveniente da formação e que não sofreu alterações de suas condições físico-químicas devido a interação da interface água-ar. A água contida na seção filtrante do poço de monitoramento, apesar de estar em movimento, ela não é representativa da formação (ABNT, 2010), e por isso ela não é coletada.

Durante a amostragem de baixa vazão foram monitorados os seguintes dados físico-químicos: $\mathrm{pH}$, ORP, condutividade elétrica, temperatura, OD e TDS, visando a estabilização desses parâmetros para subsidiar a coleta de uma amostra representativa do meio amostrado.

$\mathrm{Na}$ primeira etapa de investigação ambiental foram coletadas oito amostras de água subterrânea que foram enviadas ao laboratório analítico para análise dos parâmetros VOC, SVOC, TPH, Metais prioritários, PCB e cromo hexavalente.

Na segunda etapa foram coletadas 18 amostras de água subterrânea dos poços de monitoramento instalados na área de estudo para análise dos metais prioritários dissolvidos, incluindo o cromo hexavalente, e uma amostra foi coletada para avaliação geoquímica, onde foram considerados os seguintes parâmetros: DOC, alcalinidade, ânions (fosfato, nitrato e sulfato), metano, cátions ( $\mathrm{K}, \mathrm{Ca}, \mathrm{Na}, \mathrm{Mg})$, ferro e manganês (total e dissolvido).

\subsubsection{3 \\ Determinação da Condutividade Hidráulica}

$\mathrm{Na}$ área de estudo foram calculadas as condutividades hidráulicas de alguns poços de monitoramento com o objetivo de calcular a velocidade do fluxo da água subterrânea. Para tanto, foram utilizados a metodologia de Slug Test (Freeze \& Cherry, 1979) e baixa vazão (Robbins, et al., 2009).

Os dois tipos de teste é de rápida realização, baixo custo e com a principal vantagem, em relação ao testes de bombeamento, de não gerar resíduo líquido (água contaminada). 


\subsubsection{1}

\section{Metodologia}

\section{a) Slug Test}

Para determinar condutividade hidráulica $(\mathrm{K})$ da área de estudo, foi realizado o ensaio de permeabilidade do tipo Slug Test. Este teste é um dos métodos utilizados para a avaliação da condutividade hidráulica de um aquífero. O teste consiste no estudo da capacidade de recarga do aquífero do tipo carga variável (Freeze \& Cherry, 1979) através do monitoramento em intervalos pré-determinados utilizando-se medidor Interface com precisão de leitura de $0,5 \mathrm{~mm}$.

O teste, desenvolvido por Hvorslev (1951) e descrito em Oliveira (1992), baseia-se no tempo de recuperação do nível d'água de um determinado poço, após uma variação instantânea induzida. O procedimento de campo consiste na imersão de um corpo rígido (slug) no interior do poço, que provoca um aumento súbito em sua carga hidráulica. Os valores de nível d’água, medidos em espaços regulares de tempo são anotados e plotados posteriormente em gráfico.

Os valores obtidos, devidamente plotados no gráfico, resultam em uma curva de rebaixamento ( $\mathrm{h}$ - ho) em relação ao tempo $(\mathrm{t})$, de onde são extraídos os parâmetros que, juntamente com as características geométricas do poço, fornecem o valor de condutividade hidráulica $(\mathrm{K})$.

O método utilizado para interpretação os dados obtidos no teste considera a equação de Hvorslev (equação 8):

$\boldsymbol{k}=\frac{r^{2} \ln \left(L_{e} / R\right)}{2 L_{e} T_{0}}$

Onde:

$\mathrm{k}$ - condutividade hidráulica

$\mathrm{r}$ - raio do revestimento

$\mathrm{R}$ - raio do poço

$L_{e}$ - comprimento do filtro

$T_{0}$ - tempo que leva para o nível d'água cair 37 \% da variação inicial 
A Figura 6 ilustra os parâmetros geométricos necessários para o cálculo da condutividade hidráulica utilizando o método de Hvorslev (1951).

De maneira geral, as condutividades hidráulicas obtidas nos poços de monitoramento apresentam valores que podem ir de centímetros a milímetros por segundo, indicando a presença de solos com características específicas (Fetter, 1994).

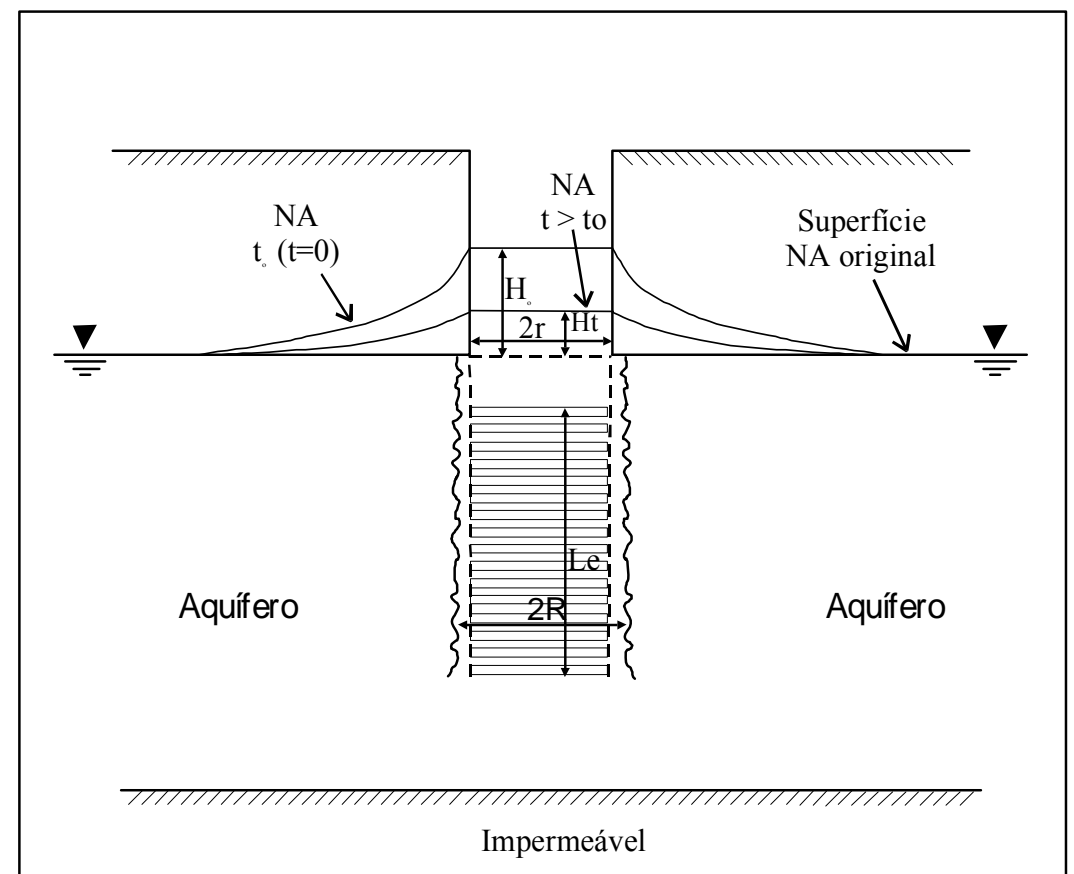

Figura 6 - Desenho Esquemático dos parâmetros medidos durante a realização do slug test.

\section{b) Determinação com Dados da Amostragem de Baixa Vazão}

Com a publicação de Puls \& Barcelona (1996) sobre os procedimentos para amostragem de água subterrânea com baixa vazão e a adoção deste procedimento por várias agências ambientais americanas, Robbins, AragonJose \& Romero (2009) avaliou se os dados da amostragem em baixa vazão poderiam também ser utilizados para calcular a condutividade hidráulica do aquífero, uma vez que, a metodologia de amostragem em baixa vazão preconiza que a coleta da água subterrânea seja realizada após a estabilização do fluxo contínuo da água subterrânea, assim como, os parâmetros físicoquímicos.

Dessa forma, Robbins, Aragon-Jose \& Romero (2009) utilizou dados de amostragem de doze poços de monitoramento disponibilizados por empresas de consultoria para realizar a comparação entre os valores de permeabilidade 
encontrados pela metodologia do slug test e com dados de baixa vazão. Para a determinação da condutividade hidráulica com dados da amostragem de baixa vazão, foram avaliadas três fórmulas: meia elipsoide de Dachler (1936); elipsoide (Hvorslev, 1951); e fluxo radial (Muskat, 1937). Estas fórmulas são utilizadas de acordo com as características do aquífero e do tipo de poço de monitoramento utilizado.

Robbins, Aragon-Jose \& Romero (2009) comparou estatisticamente os ensaios de permeabilidade realizados com slug test e com os dados da amostragem de baixa vazão. Os resultados demonstraram que a determinação da condutividade hidráulica com dados da amostragem de baixa vazão são aceitáveis e podem indicar, ao longo das campanhas de monitoramento, as mudanças na condutividade hidráulica ocasionadas pelas mudanças de recarga do aquífero e/ou mudanças da permeabilidade causadas pelas atividades de remediação.

\subsubsection{2 \\ Processamento dos Dados}

O processamento dos dados dos Slug Tests foi realizado com o software AquiferTest Pro, version 4.2.0.2. A interpretação dos dados seguiu o método de Hvorslev (1951), admitindo-se ainda o meio poroso como homogêneo e contínuo, e o fluxo das águas subterrâneas como laminar.

Os dados da amostragem de baixa vazão foi realizado por meio da tabela em Excel criada por Negrão (2012), com base na fórmula de Hvorslev (1951).

$\mathrm{Na}$ investigação ambiental detalhada realizada, foram executados seis ensaios de permeabilidade em pares de poços de monitoramento multiníveis para a determinação da condutividade hidráulica do terreno. Na ocasião não foram realizados testes nos poços de monitoramento na área do estudo de caso por questões de saúde e segurança ocupacional dos técnicos de campo. $\mathrm{Na}$ Tabela 5 são apresentados os valores de condutividade hidráulica calculadas por meio do Slug Test. Na Tabela 6 são apresentadas as condutividades hidráulicas calculadas por meio do método sugerido por Robbins, Aragon-Jose \& Romero (2009) e com a tabela criada por Negrão (2012). 
Tabela 5 - Condutividade Hidráulica - Slug Test

\begin{tabular}{|c|c|c|}
$\begin{array}{c}\text { Poço de } \\
\text { Monitoramento }\end{array}$ & $\begin{array}{c}\text { Condutividade } \\
\text { Hidráulica }(\mathrm{cm} / \mathrm{s})\end{array}$ & Litologia \\
\hline PMN-16A & $1,33 \mathrm{E}-03$ & Areia siltosa \\
\hline PMN-16B & $8,83 \mathrm{E}-04$ & Areia pouco siltosa a argilosa \\
\hline PMN-25A & $1,29 \mathrm{E}-04$ & Argila arenosa a pouco arenosa \\
\hline PMN-25B & $3,81 \mathrm{E}-04$ & Alteração de rocha \\
\hline PMN-26A & $1,64 \mathrm{E}-04$ & Areia pouco argilosa a argilosa \\
\hline PMN-26B & $3,23 \mathrm{E}-05$ & Alteração de rocha \\
\hline
\end{tabular}

Tabela 6 - Condutividade Hidráulica - Robbins, Aragon-Jose \& Romero (2009) e Negrão (2012)

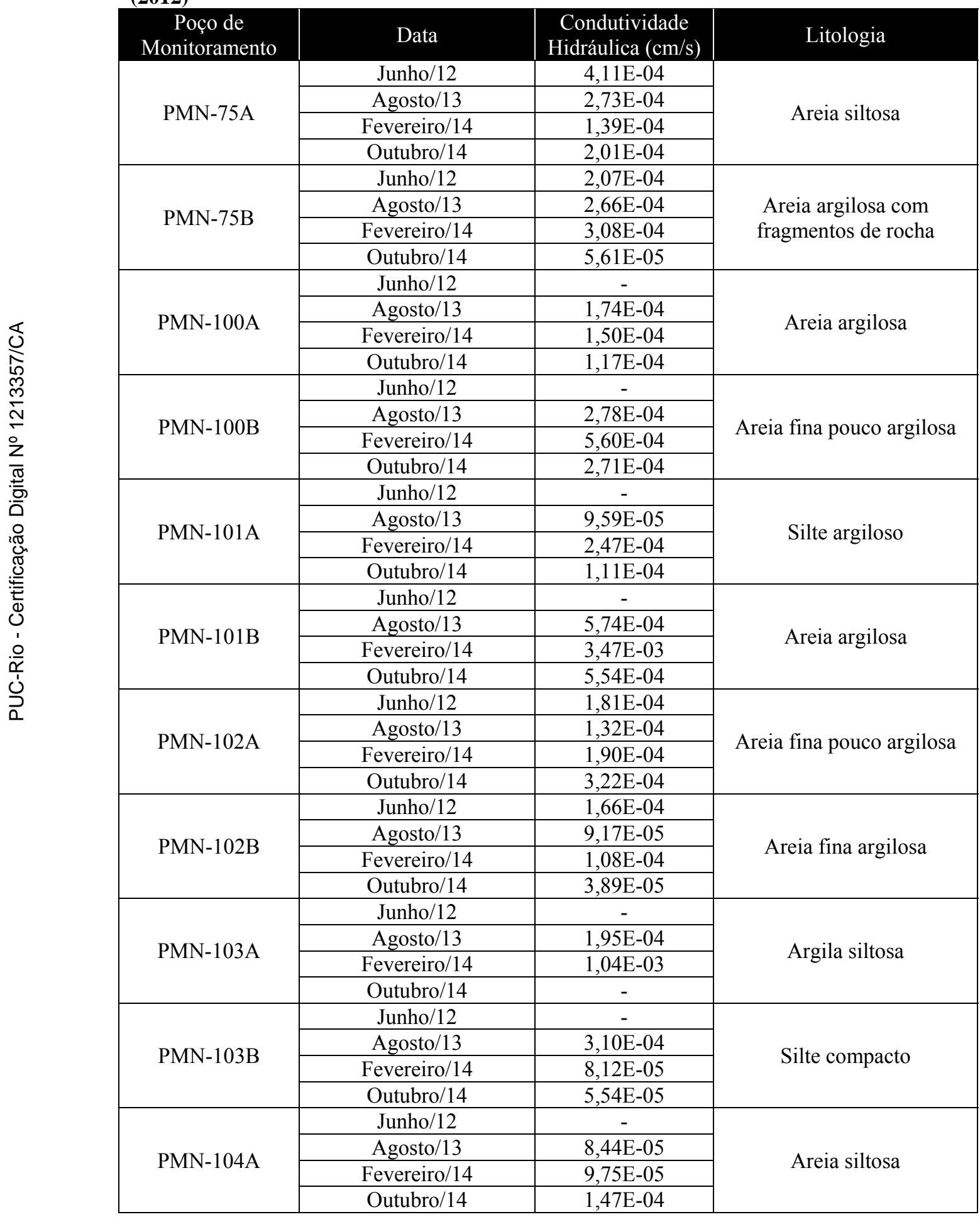


Tabela 6 - Condutividade Hidráulica - Robbins, Aragon-Jose \& Romero (2009) e Negrão (2012)

\begin{tabular}{|c|c|c|c|}
\hline $\begin{array}{c}\text { Poço de } \\
\text { Monitoramento }\end{array}$ & Data & $\begin{array}{l}\text { Condutividade } \\
\text { Hidráulica }(\mathrm{cm} / \mathrm{s})\end{array}$ & Litologia \\
\hline \multirow{4}{*}{ PMN-104B } & Junho/12 & - & \multirow{4}{*}{ Areia siltosa } \\
\hline & Agosto/13 & $8,35 \mathrm{E}-05$ & \\
\hline & Fevereiro/14 & $8,93 \mathrm{E}-05$ & \\
\hline & Outubro/14 & $2,67 \mathrm{E}-05$ & \\
\hline \multirow{4}{*}{ PMN-105A } & Junho/12 & - & \multirow{4}{*}{ Areia pouco argilosa } \\
\hline & Agosto/13 & $1,05 \mathrm{E}-04$ & \\
\hline & Fevereiro/14 & $5,41 \mathrm{E}-05$ & \\
\hline & Outubro/14 & $1,02 \mathrm{E}-04$ & \\
\hline \multirow{4}{*}{ PMN-105B } & Junho/12 & - & \multirow{4}{*}{ Areia siltosa } \\
\hline & Agosto/13 & $8,50 \mathrm{E}-05$ & \\
\hline & Fevereiro/14 & $1,08 \mathrm{E}-04$ & \\
\hline & Outubro/14 & $2,04 \mathrm{E}-05$ & \\
\hline \multirow{4}{*}{ PMN-106A } & Junho/12 & - & \multirow{4}{*}{ Argila arenosa } \\
\hline & Agosto/13 & $1,27 \mathrm{E}-03$ & \\
\hline & Fevereiro/14 & $1,25 \mathrm{E}-03$ & \\
\hline & Outubro/14 & $7,03 \mathrm{E}-04$ & \\
\hline \multirow{4}{*}{ PMN-106B } & Junho/12 & - & \multirow{4}{*}{ Silte argiloso } \\
\hline & Agosto/13 & $1,04 \mathrm{E}-04$ & \\
\hline & Fevereiro/14 & $1,02 \mathrm{E}-04$ & \\
\hline & Outubro/14 & $1,48 \mathrm{E}-04$ & \\
\hline
\end{tabular}

Deste modo, pode-se observar que a condutividade hidráulica calculada para área (Tabela 5), com dados de Slug Test, não diferem dos valores de condutividade hidráulica calculados com os dados da amostragem de baixa vazão (Tabela 6).

Pode-se observar que houve variações nas condutividades hidráulicas ao longo das campanhas de monitoramento que podem ter sido ocasionados pela variação do nível d'água, e assim, a água subterrânea fluir por solo com menor permeabilidade ou mesmo pelo menor volume de água subterrânea no aquífero.

Com base nos resultados de condutividade hidráulica obtidos pelas metodologias do Slug Test e amostragem de baixa vazão, a condutividade hidráulica da área de estudo varia entre $10^{-5}$ e $10^{-3}$ que, segundo Freeze \& Cherry (1979) - Figura 7, é compatível com o tipo de solo identificado durante a realização das sondagens ambientais, areia fina a argila. 


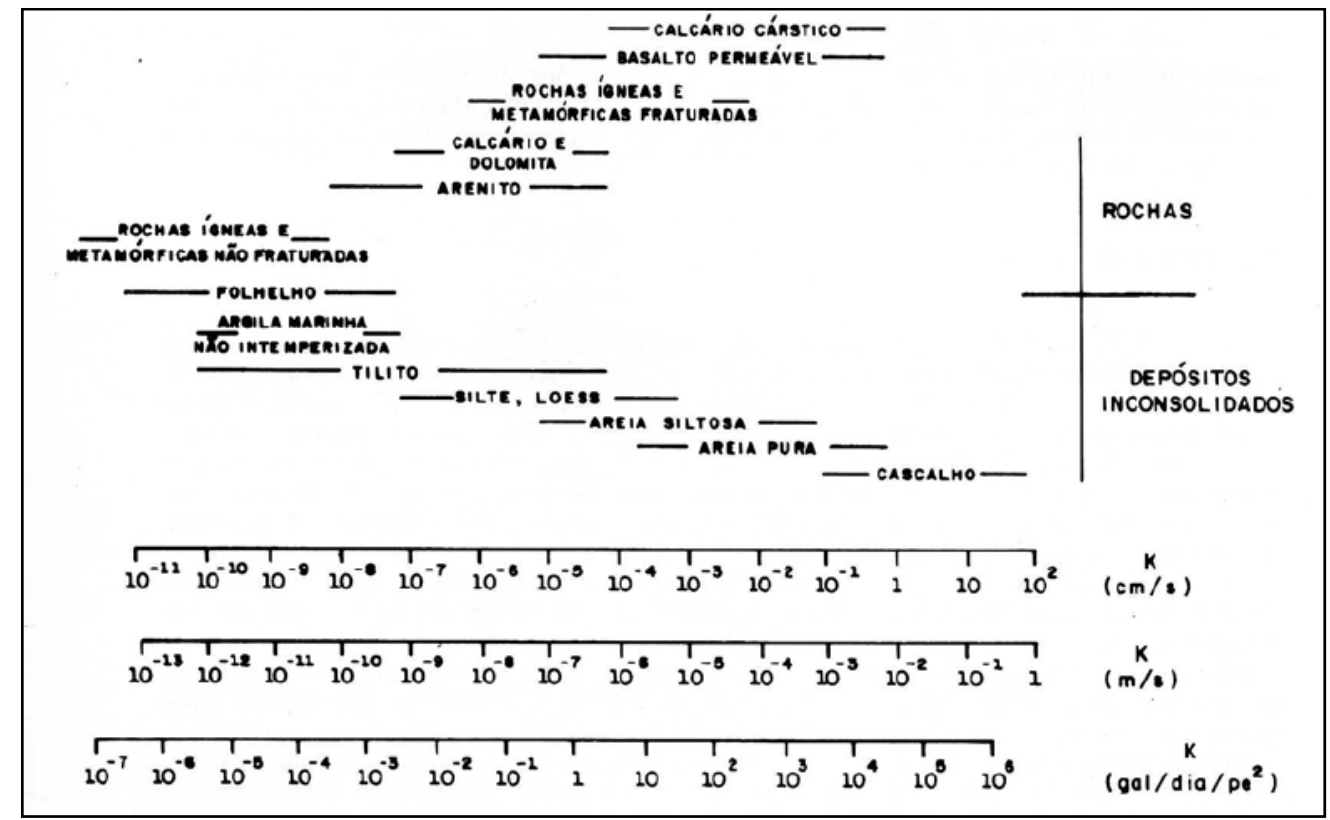

Figura 7 - Variações dos Valores de Condutividade Hidráulica e Permeabilidade (Freeze \& Cherry, 1979).

\subsubsection{4 \\ Fluxo da Água Subterrânea}

A avaliação do fluxo da água subterrânea foi realizado com base os dados do levantamento topográfico dos poços de monitoramento instalados na área de estudo, assim como, também foram utilizados dados de monitoramento do nível d'água para cálculo da carga hidráulica de cada poço e assim determinar o sentido do fluxo da água subterrânea.

Na Tabela 7 são apresentados os dados do levantamento topográfico, nível d'água e carga hidráulica das últimas duas campanhas de monitoramento realizadas nos poços de monitoramento da área de estudo.

Tabela 7 - Monitoramento dos Poços

\begin{tabular}{|c|c|c|c|c|c|c|c|}
\hline \multirow{2}{*}{ Poço } & \multirow{2}{*}{$\begin{array}{c}\text { Cota } \\
\text { Topográfica } \\
\text { Relativa }(\mathrm{m})\end{array}$} & \multicolumn{3}{|c|}{ Nível d’Água (m) } & \multicolumn{3}{|c|}{ Carga Hidráulica (m) } \\
\hline & & Ago/13 & Fev/14 & Out/14 & Ago/13 & Fev/14 & Out/14 \\
\hline PMN-75A & 99,60 & 4,41 & 3,61 & 4,25 & 95,19 & 95,99 & 95,35 \\
\hline PMN-75B & 100,00 & 4,73 & 3,98 & 4,34 & 95,27 & 96,02 & 95,66 \\
\hline PMN-100A & 99,63 & 4,41 & 3,44 & 4,16 & 95,22 & 96,19 & 95,47 \\
\hline PMN-100B & 99,66 & 3,51 & 3,76 & 4,16 & 96,15 & 95,90 & 95,50 \\
\hline PMN-101A & 99,26 & 5,02 & 3,87 & 4,46 & 94,24 & 95,39 & 94,80 \\
\hline PMN-101B & 99,87 & 6,02 & 4,61 & 5,15 & 93,85 & 95,26 & 94,72 \\
\hline PMN-102A & 99,58 & 4,54 & 3,84 & 4,38 & 95,04 & 95,74 & 95,20 \\
\hline PMN-102B & 99,12 & 4,02 & 3,03 & 3,71 & 95,10 & 96,09 & 95,41 \\
\hline PMN-103A & 99,47 & 5,02 & 4,71 & - & 94,45 & 94,76 & - \\
\hline
\end{tabular}


Tabela 7 - Monitoramento dos Poços

\begin{tabular}{|c|c|c|c|c|c|c|c|}
\hline \multirow{2}{*}{ Poço } & \multirow{2}{*}{$\begin{array}{c}\text { Cota } \\
\text { Topográfica } \\
\text { Relativa (m) }\end{array}$} & \multicolumn{3}{|c|}{ Nível d'Água (m) } & \multicolumn{3}{|c|}{ Carga Hidráulica (m) } \\
\hline & & Ago/13 & $\mathrm{Fev} / 14$ & Out/14 & Ago/13 & Fev/14 & Out/14 \\
\hline PMN-103B & 99,49 & 5,01 & 4,64 & 5,01 & 94,48 & 94,85 & 94,48 \\
\hline PMN-104A & 99,73 & 5,29 & 4,54 & 4,92 & 94,44 & 95,19 & 94,81 \\
\hline PMN-104B & 99,52 & 5,61 & 4,20 & 4,88 & 93,91 & 95,32 & 94,64 \\
\hline PMN-105A & 99,08 & 4,29 & 3,86 & 4,18 & 94,79 & 95,22 & 94,90 \\
\hline PMN-105B & 99,59 & 4,87 & 3,92 & 4,54 & 94,72 & 95,67 & 95,05 \\
\hline PMN-106A & 99,29 & 4,84 & 4,56 & 3,98 & 94,45 & 94,73 & 95,31 \\
\hline PMN-106B & 99,54 & 4,58 & 4,18 & 4,40 & 94,96 & 95,36 & 95,14 \\
\hline \multirow{2}{*}{ NA Médio } & PM Raso & 4,73 & 4,05 & 4,33 & & & \\
\hline & PM Profundo & 4,79 & 4,04 & 4,52 & & & \\
\hline
\end{tabular}

(-) Poço de monitoramento destruído.

Os mapas poteciométricos dos poços de monitoramento rasos e profundos elaborados com as cargas hidráulicas da tabela acima são apresentados nas Figuras 8 e 9. Com base nas linhas de fluxo, o sentido do fluxo da água subterrânea é para Noroeste. É possível observar que no mapa potenciométrico dos poços profundos de Agosto/13 há uma leve deflexão das linhas de fluxo para Oeste, que pode ter sido causado pela variação do nível d'água no aquífero profundo.

Com os dados das cargas hidráulicas dos pares de poços de monitoramento é possível calcular se o fluxo vertical da água subterrânea é ascendente ou descendente. Esta informação pode ser utilizada para determinar se a pluma de contaminação pode migrar para camadas litológicas mais profundas por meio do fluxo descendente da água subterrânea. Se a diferença da carga hidráulica do par multinível for negativa, o fluxo vertical da água subterrânea é ascendente, e se a diferença da carga hidráulica for positiva, o fluxo vertical da água subterrânea é descendente. O fluxo vertical da água subterrânea também atua nos processos de dispersão, advecção e difusão da pluma de contaminação.

Dessa forma, ao longo das últimas três campanhas de monitoramento, o fluxo vertical da água subterrânea foi ascendente nos pares PMN-75, PMN-102 e PMN-103. Apenas no par multinível PMN-101 o fluxo da água subterrânea manteve-se descendente ao longo dos monitoramentos. Já os demais pares, PMN-100, PMN-104, PMN-105 e PMN-106 tiveram variação no fluxo vertical 
de acordo com o mês da campanha de monitoramento, podendo ser influenciados pelos períodos de maior precipitação.

O fluxo vertical descendente de água subterrânea contribui para a migração da pluma de contaminação para níveis mais profundos do aquífero. Este fluxo identificado nos poços de monitoramento da área de estudo pode ser uma explicação para a detecção de concentrações de cromo hexavalente no aquífero profundo.

Além do sentido do fluxo horizontal e vertical da água subterrânea é possível calcular a velocidade real de deslocamento da água subterrânea, assim como, a velocidade de deslocamento da pluma de contaminação de cromo hexavalente. Para tanto, foram utilizados os dados físicos do solo adquiridos por meio dos ensaios geotécnicos realizados em laboratório, sendo: condutividade hidráulica de cada poço de monitoramento, gradiente hidráulico, porosidade efetiva $(6 \%)$, porosidade $(34 \%)$, densidade do solo $\left(1,16 \mathrm{~g} / \mathrm{cm}^{3}\right)$, e coeficiente de adsorção $(3,51 \mathrm{ml} / \mathrm{g})$.

Utilizando as equações de Fetter (1994), para o cálculo da velocidade real do aquífero (equação 1) e velocidade média da pluma de contaminação (equação 2), é possível obter os valores para a área de estudo apresentados na tabela abaixo.

Como pode ser observado na tabela acima cada poço de monitoramento possui valores específicos de condutividade hidráulica, deslocamento da água subterrânea e da pluma de contaminação, o que pode ser influência da heterogeneidade do meio hidrogeológico, a qual pode ser observada nas seções hidrogeológicas A-A' e B-B' que estão representadas nas Figuras 11 e 12. Avaliando os dados numa escala macro da área de estudo, pode-se observar que a velocidade média da água subterrânea no aquífero raso e profundo tem uma diferença de $48 \mathrm{~m} /$ ano e a velocidade média de deslocamento da pluma de contaminação uma diferença de $0,71 \mathrm{~m} / \mathrm{ano}$, sendo a migração da água subterrânea e da pluma no aquífero raso mais rápida. A velocidade da água subterrânea é em torno de 69 vezes maior que a velocidade de deslocamento da pluma de contaminação. 
Tabela 8 - Condutividade Hidráulica, Velocidade da Água Subterrânea e Velocidade da Pluma de Contaminação

\begin{tabular}{|c|c|c|c|}
\hline Poço de Monitoramento & $\begin{array}{l}\text { k médio } \\
\text { (m/ano) }\end{array}$ & $\begin{array}{l}\mathrm{V}_{\mathrm{X}} \text { média } \\
(\mathrm{m} / \text { ano })\end{array}$ & $\begin{array}{l}\mathrm{V}_{\mathrm{CX}} \text { média } \\
\text { (m/ano) }\end{array}$ \\
\hline PMN-75A & 64,44 & 43,54 & 0,63 \\
\hline PMN-75B & 66,24 & 35,74 & 0,52 \\
\hline PMN-100A & 46,36 & 33,15 & 0,48 \\
\hline PMN-100B & 116,58 & 68,13 & 0,99 \\
\hline PMN-101A & 47,71 & 11,93 & 0,17 \\
\hline PMN-101B & 483,34 & 44,49 & 0,65 \\
\hline PMN-102A & 67,70 & 39,79 & 0,58 \\
\hline PMN-102B & 25,08 & 15,32 & 0,22 \\
\hline PMN-103A & 194,73 & 185,91 & 2,70 \\
\hline PMN-103B & 46,95 & 31,09 & 0,45 \\
\hline PMN-104A & 34,57 & 6,64 & 0,10 \\
\hline PMN-104B & 20,97 & 1,94 & 0,03 \\
\hline PMN-105A & 27,45 & 19,11 & 0,28 \\
\hline PMN-105B & 22,43 & 21,74 & 0,32 \\
\hline PMN-106A & 338,80 & 287,43 & 4,17 \\
\hline PMN-106B & 37,21 & 20,03 & 0,29 \\
\hline Média PM Raso & 102,72 & 78,44 & 1,14 \\
\hline Média PM Profundo & 102,35 & 29,81 & 0,43 \\
\hline \multicolumn{4}{|c|}{$\begin{array}{l}\text { (k) Condutividade hidráulica; }\left(\mathrm{V}_{\mathrm{x}}\right) \text { Velocidade real da água subterrânea; }\left(\mathrm{V}_{\mathrm{cx}}\right) \\
\text { Velocidade da pluma de contaminante }\end{array}$} \\
\hline
\end{tabular}




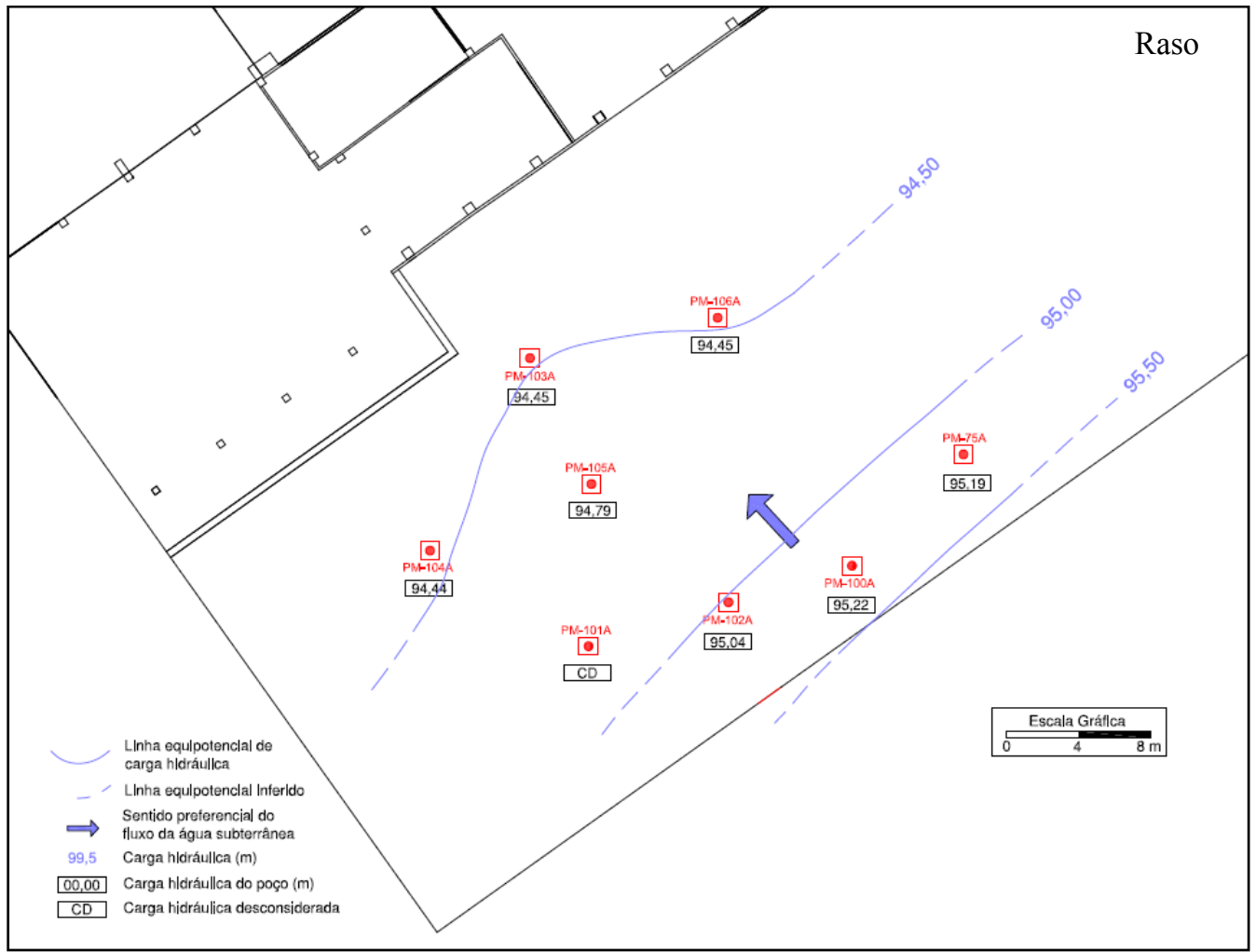

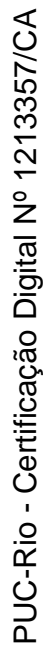

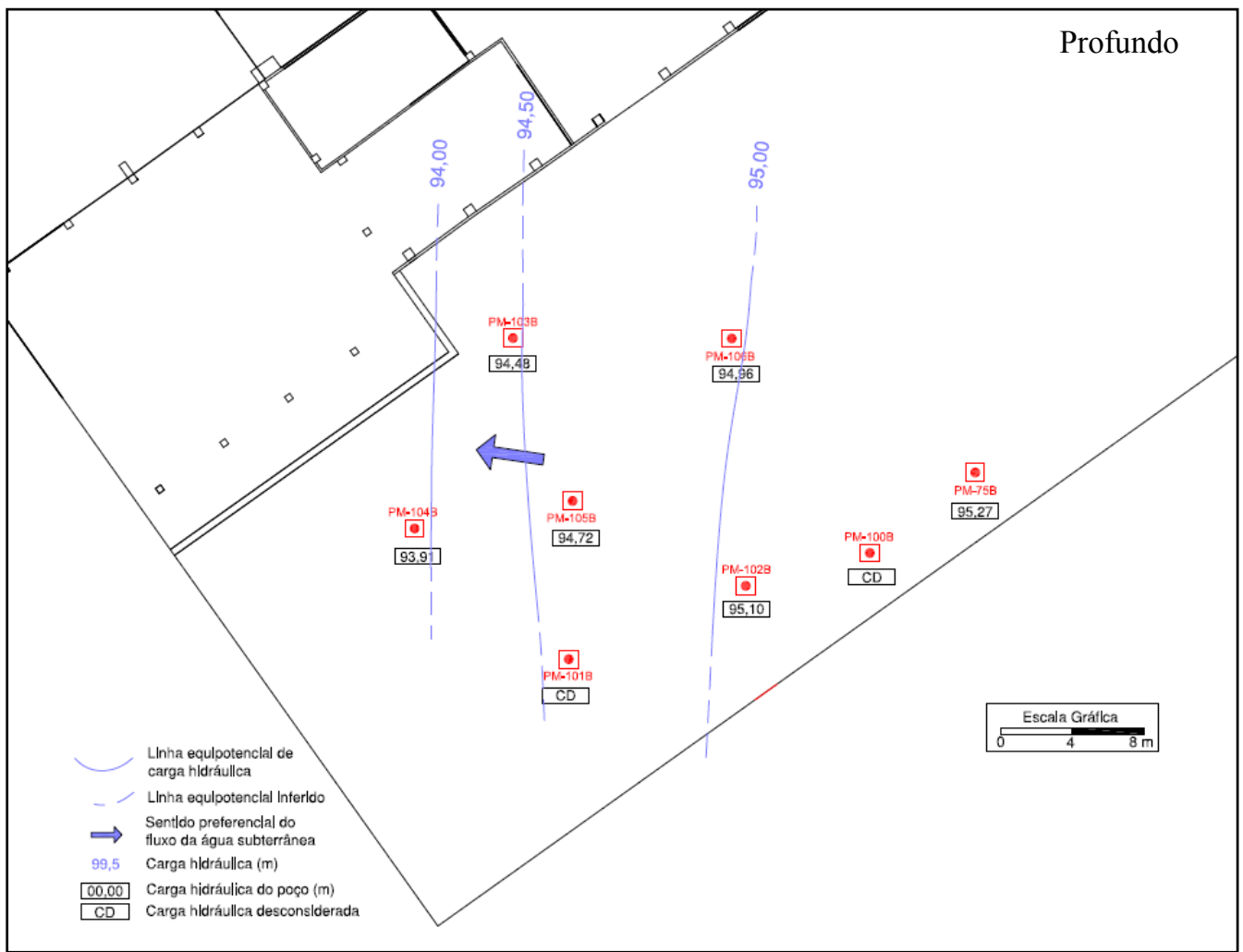

Figura 8 - Mapa Potenciométrico dos Poços de Monitoramento Rasos e Profundos- Agosto/13 


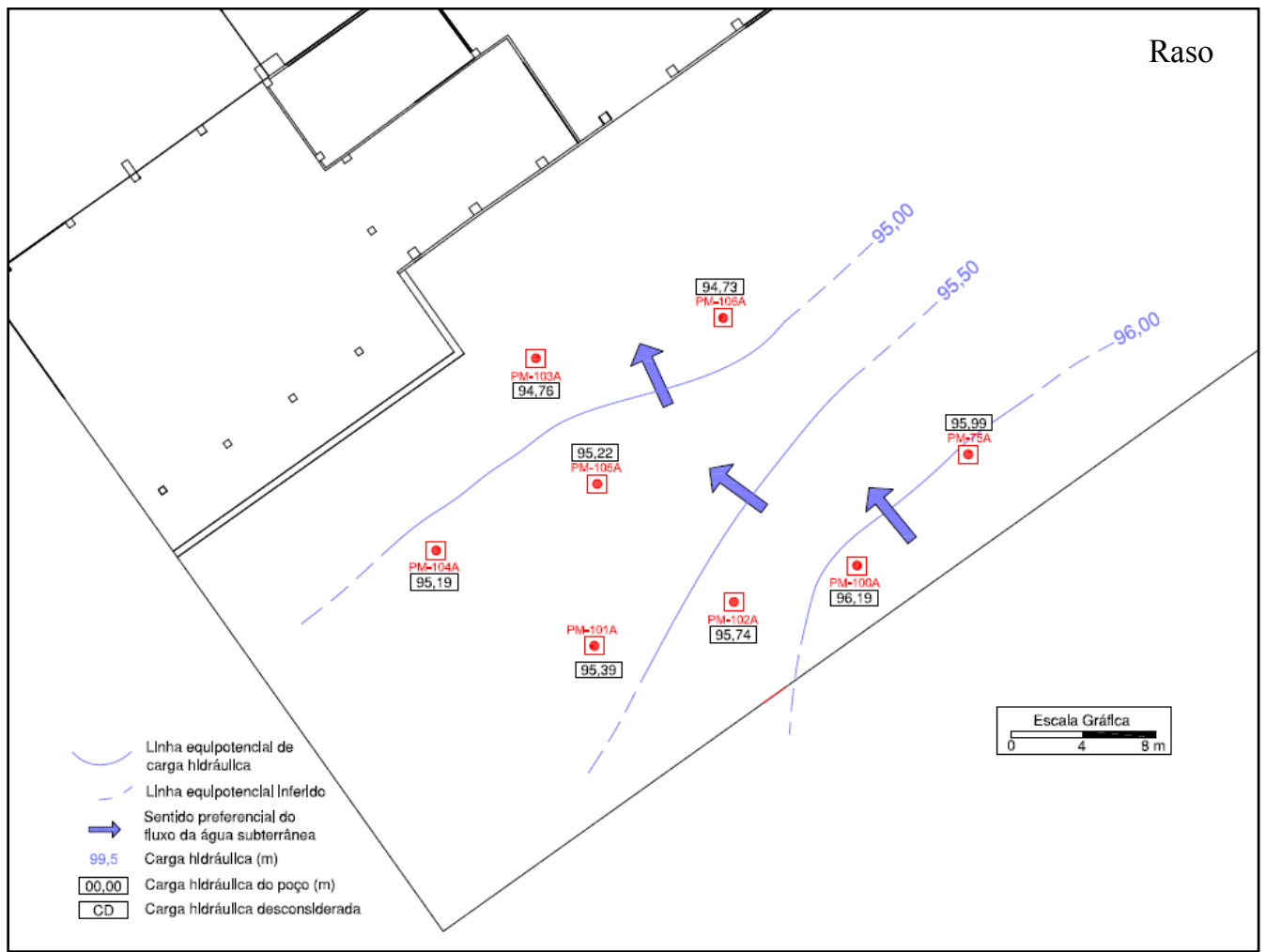

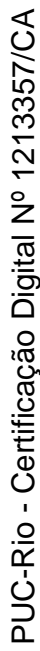

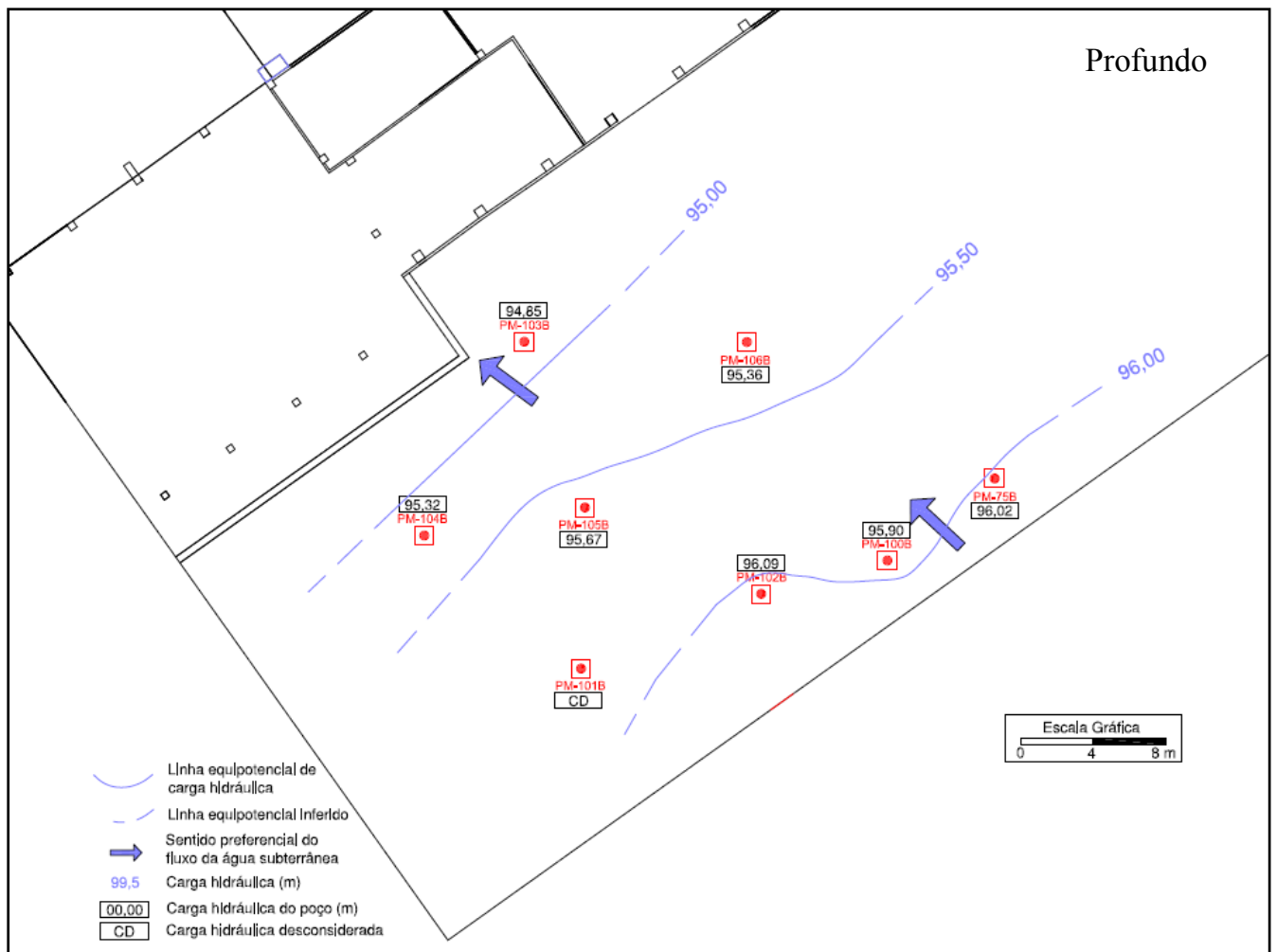

Figura 9 - Mapa Potenciométrico dos Poços de Monitoramento Rasos e Profundos Fevereiro/14 


\subsection{3}

\section{Plano de Intervenção da Área de Estudo}

Com base nos resultados das investigações ambientais realizadas na área de estudo, foram propostas medidas institucionais, de engenharia e de remediação, que tiveram o objetivo de mitigar os riscos identificados na avaliação de risco à saúde humana realizada para a área levando em consideração diversos cenários de exposição e potenciais receptores. Abaixo segue uma breve descrição das medidas adotadas.

\subsubsection{1}

\section{Medidas de Controle Institucional}

O projeto de construção foi alterado, uma vez que, estavam contemplados a construção de jardins e horta e, dessa forma, a implementação dos jardins e plantação de árvores na área de estudo só será realizada com o isolamento das plantas e árvores por meio de uma laje de concreto.

\subsubsection{2 Medidas de Engenharia}

O piso do empreendimento que seria permeável, para atender a legislação de arquitetura urbana, foi alterado para um piso de bloquete intertravado para evitar qualquer risco de contato com o solo da área ou mesmo que haja a infiltração da água da chuva. 


\section{4 Remediação da Área de Estudo}

Foram adotadas como medidas de remediação a escavação do solo contaminado por cromo hexavalente que atuava como fonte secundária de contaminação na área de estudo e a injeção de reagente químico para reduzir o cromo hexavalente dissolvido na água subterrânea para cromo trivalente.

\section{1 \\ Escavação do Solo Contaminado}

A escavação da área contaminada com cromo hexavalente foi realizada em duas etapas, sendo que na primeira foi escavada uma área de $538 \mathrm{~m}^{2}$ por 2 metros de profundidade para remoção do solo superficial, totalizando $1.076 \mathrm{~m}^{3}$ de solo escavado.

$\mathrm{Na}$ segunda etapa, que teve como objetivo remover o solo com cromo hexavalente adsorvido abaixo do nível d'água, a área foi escavada entre 2,0 e $5,5 \mathrm{~m}$ de profundidade. Nesta etapa foram escavados $1.880 \mathrm{~m}^{3}$ de solo e foram bombeados 25.000 litros de água que acumulou no fundo da cava.

\section{2}

\section{Redução Química In Situ}

Como os metais não podem ser destruídos ou ter seu processo de remediação aprimorado como os compostos orgânicos, a abordagem de redução química in situ é a mais indicada para a redução das concentrações de metais no solo e água subterrânea, as quais envolvem processos de precipitação, coprecipitação e adsorção, com o objetivo de imobilizar permanentemente os metais no solo do aquífero Suthersan, Horst, \& Ams (2009). 
Dessa forma, atingir as metas de remediação, em relação aos metais, estende-se além das metas numéricas de remedição no curto prazo. É necessário alguns cuidados e considerações de alguns fatores que podem comprometer a estabilidade dos metais precipitados no longo prazo.

Assim sendo, foi realizado um teste de bancada para avaliar o efeito do reagente químico na geoquímica da água subterrânea, assim como, para o cálculo da dose necessária para reduzir as concentrações.

\subsection{1}

\section{Teste de Bancada}

O teste de bancada realizado em Setembro/12 com três diferentes doses e uma amostra de controle compostas por $1 \mathrm{~kg}$ de solo e 1 litro de água subterrânea, sendo: controle (sem adição de $\mathrm{CaS}_{5}$ ), $4 \mathrm{~mL}$ de $\mathrm{CaS}_{5}, 10 \mathrm{~mL}$ de $\mathrm{CaS}_{5}$ e $20 \mathrm{~mL}$ de $\mathrm{CaS}_{5}$, conforme a Figura 10. A Foto 1 mostra os frascos com a mistura de solo e água subterrânea da área de estudo.

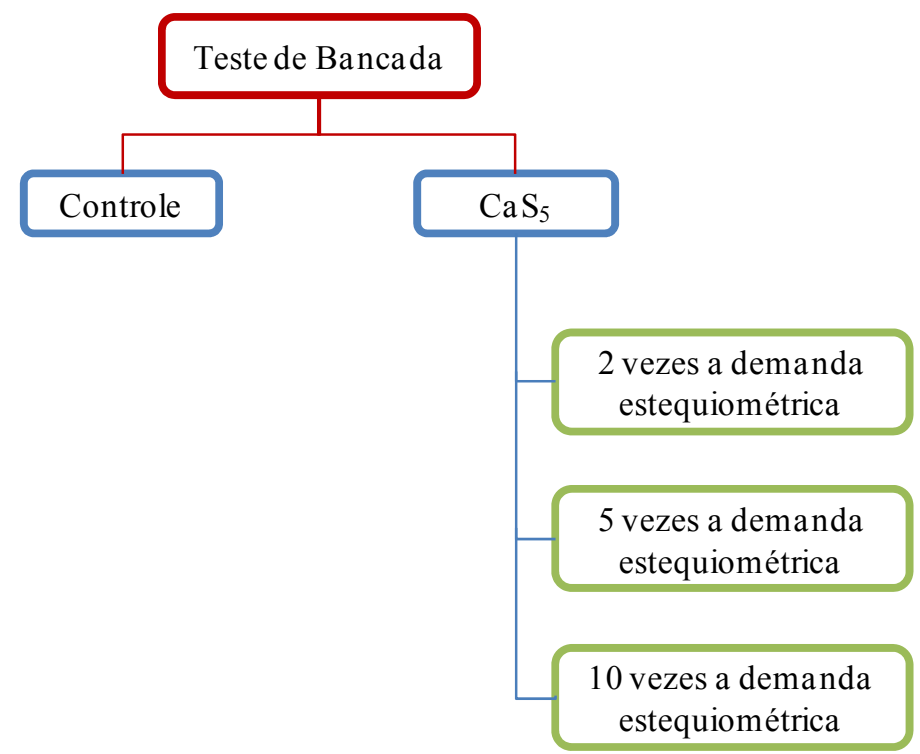

Figura 10 - Fluxograma do Teste de Bancada

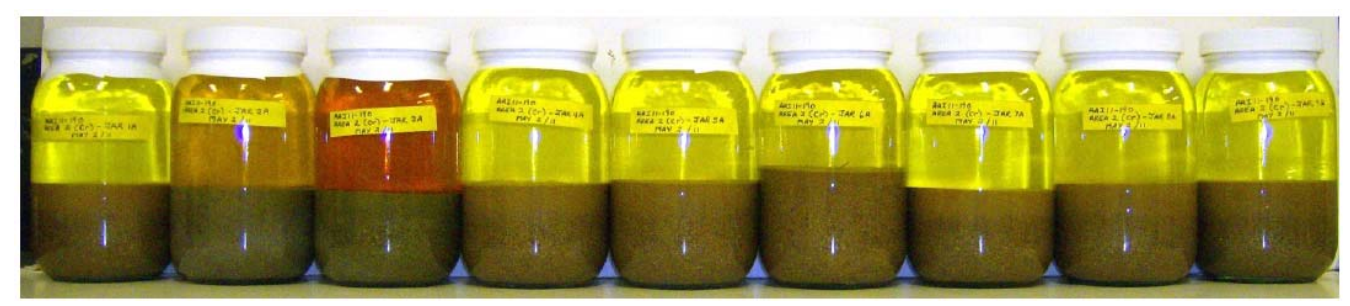

Foto 1 - Frascos do teste de bancada com solo, água subterrânea e reagente químico 
Os frascos foram amostrados no dia 0, após 7, 14 e 21 dias para avaliar a redução das concentrações de cromo hexavalente e as condições físicoquímicas.

A análise das amostras de solo e água subterrânea, antes do início do ensaio de tratabilidade, apresentaram concentrações de 58,7 e $5,55 \mathrm{mg} / \mathrm{kg}$ de cromo total e cromo hexavalente, respectivamente, e 6,52 e $5,44 \mathrm{mg} / \mathrm{L}$ de cromo total e cromo hexavalente, respectivamente.

Após 7 dias a análise da amostra de controle indicou redução das concentrações de cromo total $(2,06 \mathrm{mg} / \mathrm{L})$ e cromo hexavalente $(2,02 \mathrm{mg} / \mathrm{L})$ e a medição dos parâmetros físico-químicos indicou $\mathrm{pH}$ ácido $(5,5)$ e Eh com potencial oxidante. As amostras de água subterrânea dos tratamentos com $\mathrm{CaS}_{5}$ apresentaram concentrações abaixo do limite de quantificação, com exceção da amostra do tratamento com $4 \mathrm{ml}$ de $\mathrm{CaS}_{5}$ onde a concentração de cromo total reduziu para $0,025 \mathrm{mg} / \mathrm{L}$ e cromo hexavalente não apresentou concentração acima do limite de quantificação. As condições físico-químicas indicaram que o pH na faixa neutra $(6,84$ a 7,16) e faixa básica $(7,98$ e 8,71) e Eh redutor.

Após 14 dias as concentrações de cromo total e cromo hexavalente variaram em relação a amostra de controle. Em relação ao tratamento com 2 $\mathrm{ml} / \mathrm{kg}$ de $\mathrm{CaS}_{5}$ as concentrações de cromo total e cromo hexavalente aumentaram em relação ao sétimo dia, assim como o $\mathrm{pH}$ voltou para a faixa ácida. Os demais tratamentos não houveram variações na concentrações e nas condições físico-químicas.

Após 21 dias não foram detectadas concentrações de cromo hexavalente nos tratamentos e apenas o $\mathrm{pH}$ no tratamento com $4 \mathrm{~mL} / \mathrm{kg}$ de $\mathrm{CaS}_{5}$ ficou na faixa ácida.

Confirmando assim, a eficiência no uso deste reagente químico para a redução do cromo hexavalente tanto em solo, como em e água subterrânea da área de estudo. 


\subsection{2}

\section{Injeção de Reagente Químico}

\subsubsection{1}

\section{Monitoramento de Linha de Base}

Como parte da etapa de injeção de reagente químico foi realizado o monitoramento de linha de base na qual foram coletadas amostras de solo e água subterrânea para analisar as concentrações de cromo total e cromo hexavalente e assim ter as concentrações detectadas como a linha de base para comparar a redução das concentrações do cromo hexavalente após a injeção do reagente químico.

As amostras de solo e água subterrânea foram coletadas por meio de sondagens realizadas através da técnica de direct push utilizando liner de PVC com duas polegadas de diâmetro, conforme ABNT NBR 15.492 - Sondagem de Reconhecimento para Fins de Qualidade Ambiental - Procedimento.

\subsubsection{2 Método de Injeção}

Segundo Suthersan (1996) e Suthersan \& Payne (2004) para a escolha do método de injeção é necessário ter um modelo conceitual detalhado da área de injeção. Existem diversos métodos de injeção de reagentes químicos e a escolha do método mais apropriado para a área de trabalho depende do tipo de contaminante, meio geológico, interferências subterrâneas e superficiais, profundidade e espessura do aquífero impactado e tamanho da área. Se a área for muito grande dá para injetar o reagente químico em faixas reativas ao invés de injetar produto em toda a área.

Conforme descrito por Suthersan (1996), o principal objetivo da injeção na área de estudo tem de alcançar dois objetivos: (1) criação e manutenção de um ambiente redox ideal e outros parâmetros tais como $\mathrm{pH}$, presença ou ausência de oxigênio dissolvido, etc.; e (2) a entrega e distribuição dos reagentes necessários de uma maneira homogênea por toda a área de injeção, tanto horizontal e verticalmente.

Dessa forma, para a área de estudo foi escolhido injetar o reagente químico em toda sua extensão e até 8,5 metros de profundidade pelo método direct push. Este sistema de injeção utilizou o equipamento Geoprobe modelo 54LT, que foi montado sobre esteira metálica, para facilitar o deslocamento 
entre os pontos de injeção. A injeção foi realizada através da haste do equipamento que estava conectada ao tanque misturador com 100 litros de capacidade e uma bomba de cavidade progressiva.

A pressão de injeção foi monitorada por manômetros, contudo não foi possível garantir que a pressão de injeção constante, devido às características do solo, sendo que, o produto poderia saturar o meio de subsuperfície e aflorar ou a formação do solo pode não apresentar resistência suficiente para que fosse atingida a máxima pressão necessária.

Este método de injeção não altera as características geotécnicas do solo e a pressão de injeção não é suficiente para deslocar um grande volume de água subterrânea, evitando dessa forma, o deslocamento da pluma de cromo hexavalente.

Foi considerada a injeção de solução de polissulfeto de cálcio em uma área de aproximadamente $1.200 \mathrm{~m}^{2}$ na área remanescente de hot spot, visando reduzir o cromo hexavalente para cromo trivalente no aquífero local.

\subsubsection{3 Monitoramento Analítico Pós-Injeção}

Após a injeção de polissulfeto de cálcio foram executadas duas campanhas de monitoramento analítico de água subterrânea para avaliar as concentrações de cromo (total e dissolvido), cromo hexavalente (total e dissolvido) e os parâmetros para avaliação da geoquímica da água subterrânea e da reação de redução do cromo hexavalente (arsênio total e dissolvido, ferro total e dissolvido, manganês total e dissolvido, cálcio total e dissolvido, sulfato e sulfeto).

Também foram analisados os demais metais prioritários dissolvidos (Al, $\mathrm{Sb}, \mathrm{Ba}, \mathrm{Cd}, \mathrm{Pb}, \mathrm{Co}, \mathrm{Cu}, \mathrm{Hg}, \mathrm{Ni}, \mathrm{Ag}, \mathrm{Se}, \mathrm{Zn}$ ) para avaliar se a injeção de polissulfeto de cálcio mobilizou estes metais para a água subterrânea.

O procedimento das amostras de água subterrânea adotado para esta etapa foi o mesmo para a amostragem de água subterrânea das investigações ambientais explicadas anteriormente.

As campanhas de monitoramento analítico de água subterrânea foram realizadas nas seguintes datas: 
- $1^{\text {a }}$ Campanha - Agosto/2013 - campanha executada 6 meses após a injeção do reagente químico;

- $2^{\mathrm{a}}$ Campanha - Fevereiro/2014 - campanha executada 12 meses após a injeção do reagente químico;

- $3^{\mathrm{a}}$ Campanha - Outubro/2014 - campanha executada 19 meses após a injeção do reagente químico.

Os resultados analíticos das campanhas de monitoramento analítico de água subterrânea serão discutidos no próximo item. 


\section{5 \\ Resultados Obtidos}

\section{1 Modelo Conceitual da Área de Estudo}

A área de estudo está situada numa área onde, historicamente, a sua jusante foi ocupada por indústrias e a montante sempre foi ocupada por residências, sendo que a área teve um adensamento de conjuntos residenciais nos última anos e, consequentemente, as áreas impermeáveis foram reduzidas, diminuindo a influência das chuvas na recarga do aquífero. Desse mesmo ponto de vista, a própria área de estudo teve sua área permeável reduzida com o início das obras de construção dos prédios.

O clima da área de estudo é tropical atlântico, apresentando verões quentes e úmidos e invernos amenos e com regime de chuvas mais restrito. A temperatura média anual gira em torno dos $23^{\circ} \mathrm{C}$, sendo o mês de Julho o mais frio (média de $21^{\circ} \mathrm{C}$ ) e Janeiro o mais quente (média de $32^{\circ} \mathrm{C}$ ). A precipitação média anual varia entre 700 e $1300 \mathrm{~mm}$.

Para avaliar localmente a precipitação foram utilizados dados de três estações de medições do Sistema de Alerta Rio da Prefeitura do Rio de Janeiro (Alerta Rio, 2014). Conforme a Figura 16 (página 77), a época de maior índice pluviométrico varia entre os meses de Outubro e Abril e de maior estiagem varia entre os meses de Junho e Setembro.

A geomorfologia da área é relativamente plana, sendo que, a 1.000 metros a Sul-Sudeste (montante) existem morros com cota de elevação entre 150 e 200 metros. E a cerca de 500 metros a jusante da área há um córrego canalizado que possui fluxo da água para Nordeste, que pode ser o ponto de descarga do aquífero local.

A geologia da área de estudo foi classificada por meio das sondagens realizadas ao longo dos estudos ambientais. Até a profundidade investigada de 9,0 metros, o solo é composto do topo para a base por: aterro (areia, silte, 
argila), areia argilosa, silte argiloso, argila siltosa, silte compacto e alteração de rocha (saprólito).

Durante a realizada das sondagens foi interceptado um aquífero raso, que pode ser classificado como livre, com profundidade média de 3,43 m. Já os poços de monitoramento instalados no aquífero profundo, possuem nível d'água médio de 4,00 $\mathrm{m}$ de profundidade. Com o cálculo das cargas hidráulicas foi possível avaliar o fluxo horizontal e vertical da água subterrânea, sendo o fluxo horizontal dos aquíferos raso e profundo para Noroeste (Figuras 8 e 9). O fluxo vertical da água subterrânea em geral é ascendente, sendo que, há uma variação em alguns pares de poços ao longo das campanhas de monitoramento.

Devido a heterogeneidade da geologia local, que pode ser observada nas Figuras 11 e 12 (seções hidrogeológicas), os cálculos da condutividade hidráulica na área de estudo mostram valores diferentes para cada poço de monitoramento, que podem ser observados nas Figuras 13 e 14. Essa diferença nos valores de condutividade hidráulica interferem no deslocamento da pluma de contaminação, onde pode haver deflexão do vetor do fluxo da pluma em relação a direção do fluxo das linhas potenciométricas. Essa deflexão pode ser observada nas Figuras 13 e 14, onde estão plotados as linhas potenciométricas e as concentrações de cromo hexavalente.

Com base nos dados adquiridos ao longo das investigação ambientais realizadas, a área impactada por cromo hexavalente era de $1.300,0 \mathrm{~m}^{2}$, sendo que as concentrações no solo foram detectadas a partir do solo superficial até 5,0 metros de profundidade e na água subterrânea a pluma está distribuída verticalmente entre 4,0 e 9,0 metros de profundidade. As concentrações de cromo hexavalente variaram entre 0,29 e $17,66 \mathrm{mg} / \mathrm{kg}$ e 0,14 e $35,7 \mathrm{mg} / \mathrm{L}$ respectivamente no solo e na água subterrânea. Nas Tabelas 9 e 10 são apresentados as maiores e menores concentrações identificadas nos estudos ambientais, assim como as médias, dos compostos: arsênio, cromo total, cromo hexavalente, ferro e manganês. 
Tabela 9 - Concentrações dos compostos químicos de interesse no solo da área de estudo $(\mathrm{mg} / \mathrm{kg})$

\begin{tabular}{|c|c|c|c|c|c|c|c|c|c|c|}
\hline \multirow{2}{*}{ Composto } & \multicolumn{9}{|c|}{ Campanhas de Monitoramento } \\
\cline { 2 - 11 } & \multicolumn{3}{|c|}{ Nov/10 } & \multicolumn{3}{c|}{ Set 11} & \multicolumn{3}{c|}{ Jun/12 } \\
\cline { 2 - 11 } & Maior & Menor & Média & Maior & Menor & Média & Maior & Menor & Média \\
\hline Arsênio & 5,000 & 2,000 & 2,857 & 1,780 & 1,780 & 1,780 & na & na & na \\
\hline Cr Total & 2983,5 & 31,900 & 566,3 & 57,800 & 34,700 & 46,250 & 313,5 & 7,680 & 75,127 \\
\hline Cr(VI) & na & na & na & na & na & na & 100,8 & 0,290 & 17,660 \\
\hline Ferro & 51137,0 & 12291,0 & 21739,9 & na & na & na & na & na & na \\
\hline Manganês & 76,100 & 34,800 & 50,143 & na & na & na & na & na & na \\
\hline
\end{tabular}

(na) - não analisado

Tabela 10 - Concentrações dos compostos químicos de interesse na água subterrânea da área de estudo (mg/L)

\section{Campanhas de Monitoramento}

\begin{tabular}{|c|c|c|c|c|c|c|c|c|c|}
\hline \multirow{3}{*}{ Composto } & \multicolumn{9}{|c|}{ Campanhas de Monitoramento } \\
\hline & \multicolumn{3}{|c|}{ Nov/10 } & \multicolumn{3}{|c|}{ Set/11 } & \multicolumn{3}{|c|}{ Jun/12 } \\
\hline & Maior & Menor & Média & Maior & Menor & Média & Maior & Menor & Média \\
\hline Arsênio & 0,340 & 0,050 & 0,292 & 0,010 & 0,010 & 0,010 & 0,001 & 0,0001 & 0,0002 \\
\hline Cr Total & 34,340 & 0,399 & 12,463 & 35,800 & 0,511 & 15,367 & 20,748 & 0,155 & 9,784 \\
\hline $\mathrm{Cr}(\mathrm{VI})$ & 21,855 & 0,769 & 9,594 & 33,700 & 0,638 & 18,091 & 20,000 & 0,140 & 9,435 \\
\hline Ferro & 20,700 & 0,500 & 3,263 & 7,860 & 0,050 & 2,606 & na & na & na \\
\hline Manganês & 0,420 & 0,020 & 0,210 & 0,331 & 0,018 & 0,109 & na & na & na \\
\hline
\end{tabular}

(na) - não analisado 


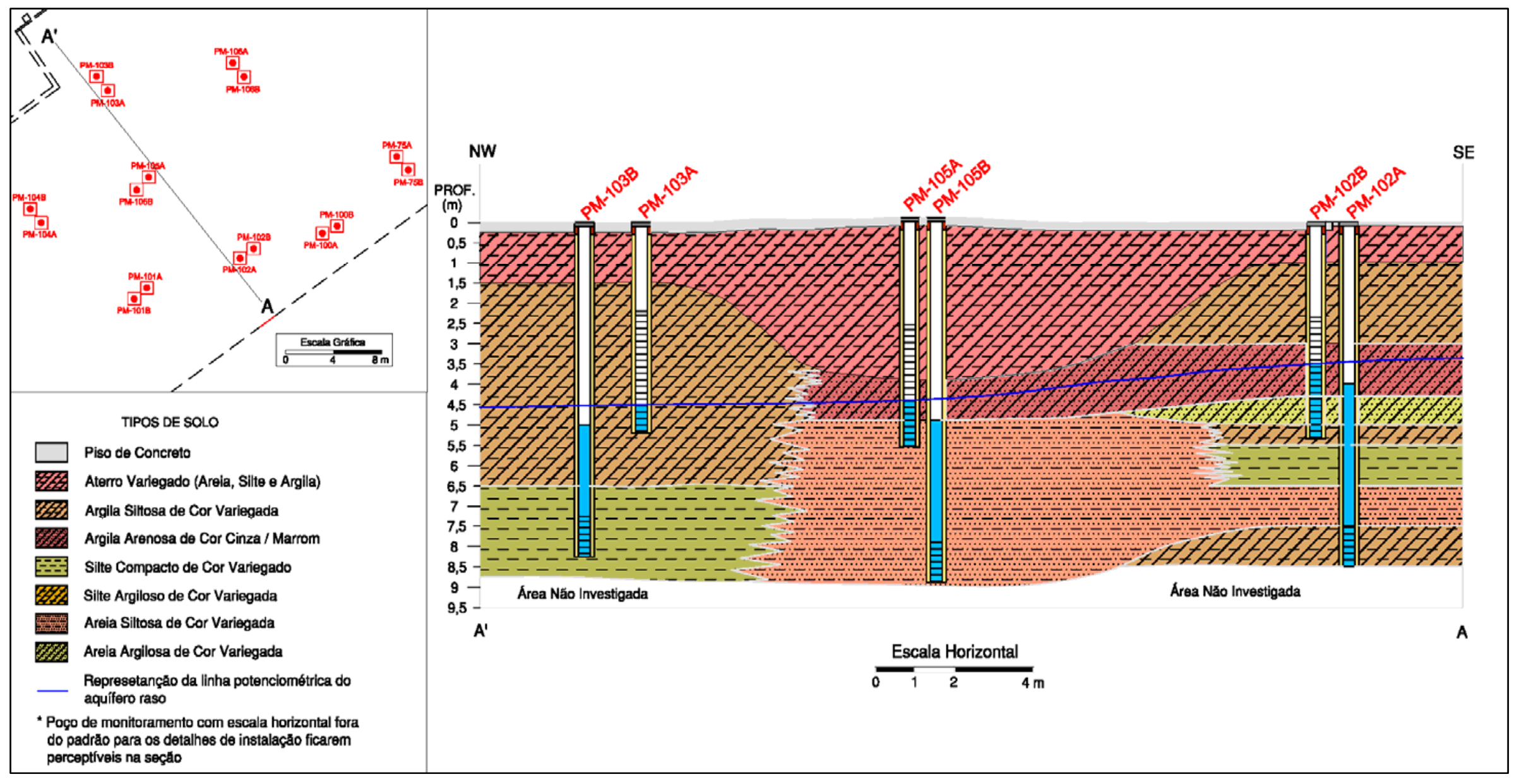

Figura 11 - Seção Hidrogeológica A-A' 


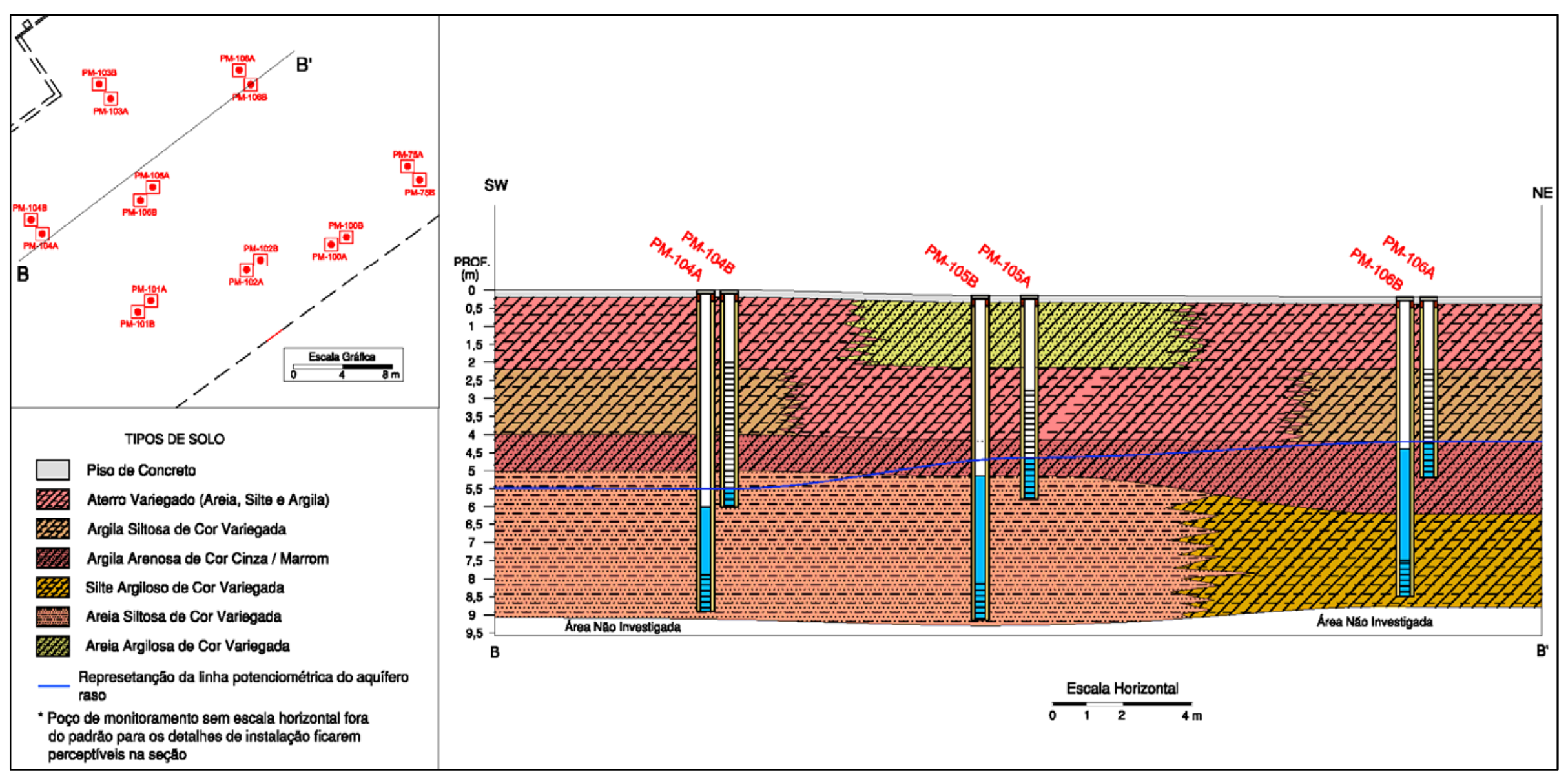

Figura 12 - Seção Hidrogeológica B-B' 

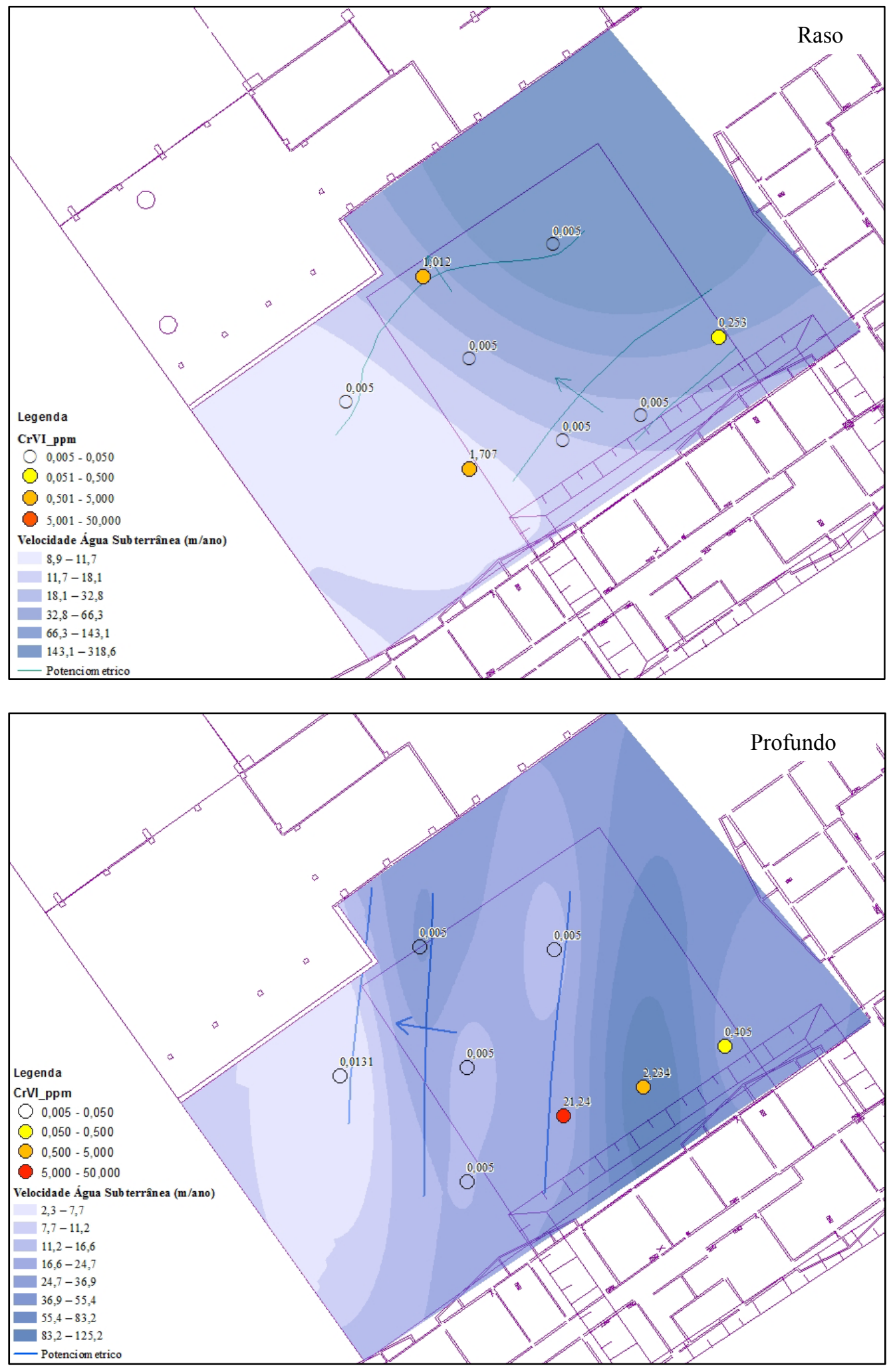

Figura 13 - Concentrações de cromo hexavalente, velocidade da água subterrânea e linhas potenciométricas nos poços de monitoramento rasos e profundos - 2013 


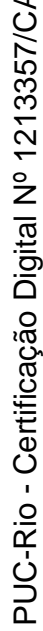
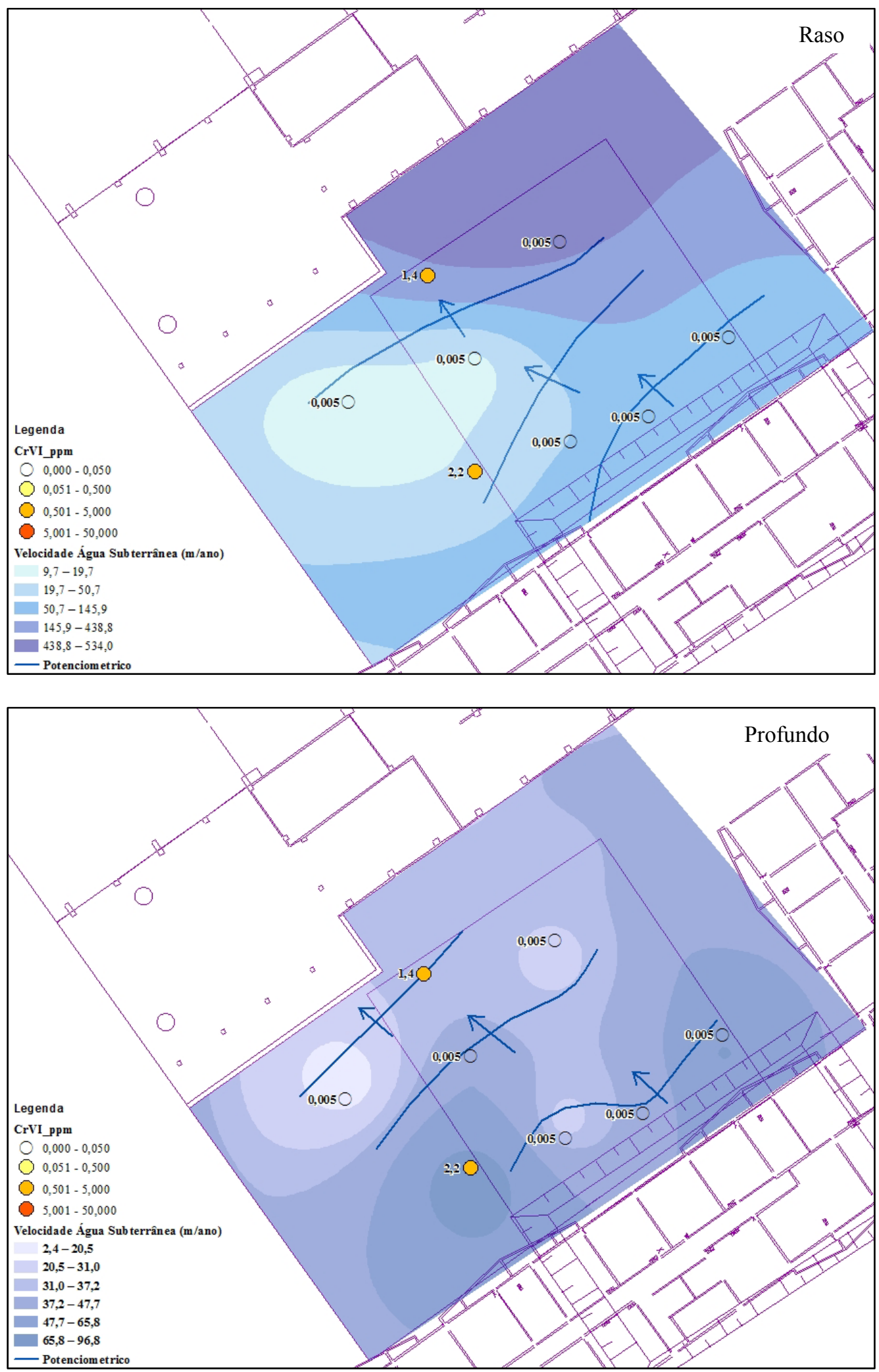

Figura 14- Concentrações de cromo hexavalente, velocidade da água subterrânea e linhas potenciométricas nos poços de monitoramento rasos e profundos - Fevereiro/2014 


\section{2}

\section{Cálculo da Dose do Reagente}

A demanda estequiométrica e a cinética química da redução de $\mathrm{Cr}(\mathrm{VI})$ pelo polissulfeto de cálcio em solução aquosa foram estudadas por Graham, et al., (2006) em resíduos proveniente do processamento de minério de cromita (COPR). Com este estudo foi relatado que é necessário uma proporção molar de 1,66 (próximo ao valor teórico de 1,5) e uma cinética de primeira ordem com uma concentração inicial de $26,8 \mathrm{mg} / \mathrm{L}$ e pH da solução de CPS em torno de 11,5, com presença de oxigênio.

Em áreas contaminadas, se o solo possuir altas concentrações de oxigênio, isto pode prejudicar a reação cinética da redução química, uma vez que o oxigênio tem a capacidade de oxidar os sulfetos (Chrysochoou \& Ting, 2011).

Dessa forma, o cálculo da dose de injeção foi realizado com base na demanda estequiométrica entre o polissulfeto de cálcio e cromo hexavalente presente na área de estudo, assim como nos dados obtidos durante os testes de bancada.

A reação teórica de oxidação-redução entre o cromo hexavalente e o polissulfeto de cálcio sobre condições anaeróbicas é:

$$
\mathrm{CrO}_{4}^{2-}+3 \mathrm{CaS}_{5}+10 \mathrm{H}^{+} \leftrightarrow 2 \mathrm{Cr}(\mathrm{OH})_{3(\mathrm{~s})}+15 \mathrm{~S}_{(\mathrm{s})}+3 \mathrm{Ca}^{2+}+2 \mathrm{H}_{2} \mathrm{O}
$$

Desta forma, o cromo hexavalente é reduzido a hidróxido de cromo, um composto pouco solúvel em água que é precipitado para o meio sólido. O cromo trivalente tem baixa solubilidade, toxicidade, mobilidade, reatividade e é considerado estável.

Além disso, para o cálculo da dose de polissulfeto de cálcio foram consideradas as propriedades do aquífero e as dimensões da área alvo de remediação. A Tabela 11 apresenta o resumo dos cálculos. 
Tabela 11 - Dados da área de injeção e cálculo da dose

\begin{tabular}{|c|c|c|}
\hline 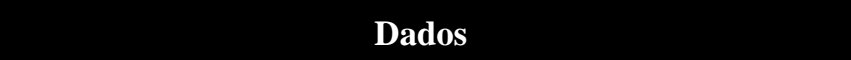 & Valor & Unidade \\
\hline \multicolumn{3}{|l|}{ Dados da área de tratamento } \\
\hline Profundidade do topo da área de tratamento & 2,5 & $\mathrm{~m}$ \\
\hline Profundidade do fundo da área de tratamento & 8,5 & $\mathrm{~m}$ \\
\hline Espessura da zona de tratamento & 7,0 & $\mathrm{~m}$ \\
\hline Área de tratamento & 556,6 & $\mathrm{~m}^{2}$ \\
\hline Volume da zona de tratamento & $4.453,0$ & $\mathrm{~m}^{3}$ \\
\hline Porosidade total estimada & 34,0 & $\%$ \\
\hline Volume dos poros & $2.939,0$ & $\mathrm{~m}^{3}$ \\
\hline Densidade do solo (estimada) & $1.700,0$ & $\mathrm{~kg} / \mathrm{m}^{3}$ \\
\hline Massa de solo da zona de tratamento & $4.996 .300,0$ & $\mathrm{~kg}$ \\
\hline Volume de poros & $1.514,0$ & $\mathrm{~m}^{3}$ \\
\hline \multicolumn{3}{|l|}{ Cromo hexavalente } \\
\hline Concentração média em água subterrânea & 10 & $\mathrm{mg} / \mathrm{L}$ \\
\hline Concentração média no solo & 150 & $\mathrm{mg} / \mathrm{kg}$ \\
\hline Massa de cromo hexavalente na água subterrânea & 15 & $\mathrm{~kg}$ \\
\hline Massa de cromo hexavalente no solo & 749 & $\mathrm{~kg}$ \\
\hline Peso molecular & 51,996 & $\mathrm{~g} / \mathrm{mol}$ \\
\hline \multicolumn{3}{|l|}{ Características do polissulfeto de cálcio } \\
\hline Concentração do produto & 29 & $\%$ \\
\hline Densidade específica & 1,270 & $\mathrm{~kg} / \mathrm{m}^{3}$ \\
\hline Peso molecular & 200,403 & $\mathrm{~g} / \mathrm{mol}$ \\
\hline $\mathrm{pH}$ & $11.5-11.8$ & - \\
\hline \multicolumn{3}{|l|}{ Cálculo da massa de polissulfeto de cálcio } \\
\hline Demanda do solo - teste de tratabilidade & 4 & $\mathrm{ml} \mathrm{CPS} / \mathrm{kg}$ \\
\hline Mols de $\mathrm{Cr}(\mathrm{VI})$ no solo & 14.412 & mol \\
\hline Mols de CPS necessário para tratar Cr(VI) no solo & 21.617 & mol \\
\hline Mols de CPS em 1 litro de solução a 29\% & 1,84 & mol \\
\hline $\begin{array}{llllll}\text { CPS }(29 \%) \text { necessário para tratar } & \mathrm{Cr}(\mathrm{VI}) & \text { no } & \text { solo } \\
(2,5 \mathrm{x} \text { demanda estequiométrica }) & & & & \\
\end{array}$ & 29.436 & Litros \\
\hline Mols de $\mathrm{Cr}(\mathrm{VI})$ na água subterrânea & 291 & mol \\
\hline Mols de CPS necessário para tratar Cr(VI) na água & 437 & mol \\
\hline $\begin{array}{l}\text { CPS }(29 \%) \text { necessário para tratar } \mathrm{Cr}(\mathrm{VI}) \text { na água } \\
(2,5 \mathrm{x} \text { demanda estequiométrica })\end{array}$ & 595 & Litros \\
\hline $\begin{array}{l}\text { Volume de CPS (29\%) baseado na demanda } \\
\text { estequiométrica }\end{array}$ & 30.030 & Litros \\
\hline \multicolumn{3}{|l|}{ Especificações da Injeção } \\
\hline Razão de diluição de água/CPS (29\%) & 7,4 & - \\
\hline Volume de água para diluição & 222.000 & Litros \\
\hline Espaçamento das injeções & 3,0 & $\mathrm{~m}$ \\
\hline Número de pontos de injeção & 72 & - \\
\hline Volume de solução por ponto & 3.500 & Litros \\
\hline
\end{tabular}




\section{3}

\section{Injeção do Reagente Químico}

Para a injeção do produto foram realizadas 72 sondagens com 8,5 metros de profundidade, sendo que, a faixa de injeção do produto foi entre 2,5 e 8,5 metros. O nível d'água médio da área de injeção é de 3,87 e 4,08 m, nos poços rasos e profundos, respectivamente. Dessa forma, a injeção a partir de $2,5 \mathrm{~m}$ abrangeu qualquer variação do nível d'água devido a variação sazonal. A Figura 15 apresenta a pluma de fase dissolvida de cromo hexavalente (monitoramento de linha de base) e os pontos de injeção.

De acordo com os cálculos realizados com os dados adquiridos nos ensaios de tratabilidade, foram utilizados 30.000 litros de solução contendo $29 \%$ de polissulfeto de cálcio e cerca de 222.000 litros de para realizar a sua mistura, totalizando 252.030 litros de solução.

Em cada sondagem foi injetado a solução de reagente químico composto por 417 litros de polissulfeto de cálcio diluídos em 3.083 litros de água, totalizando um volume de aproximadamente 3.500 litros de solução injetado por ponto. 


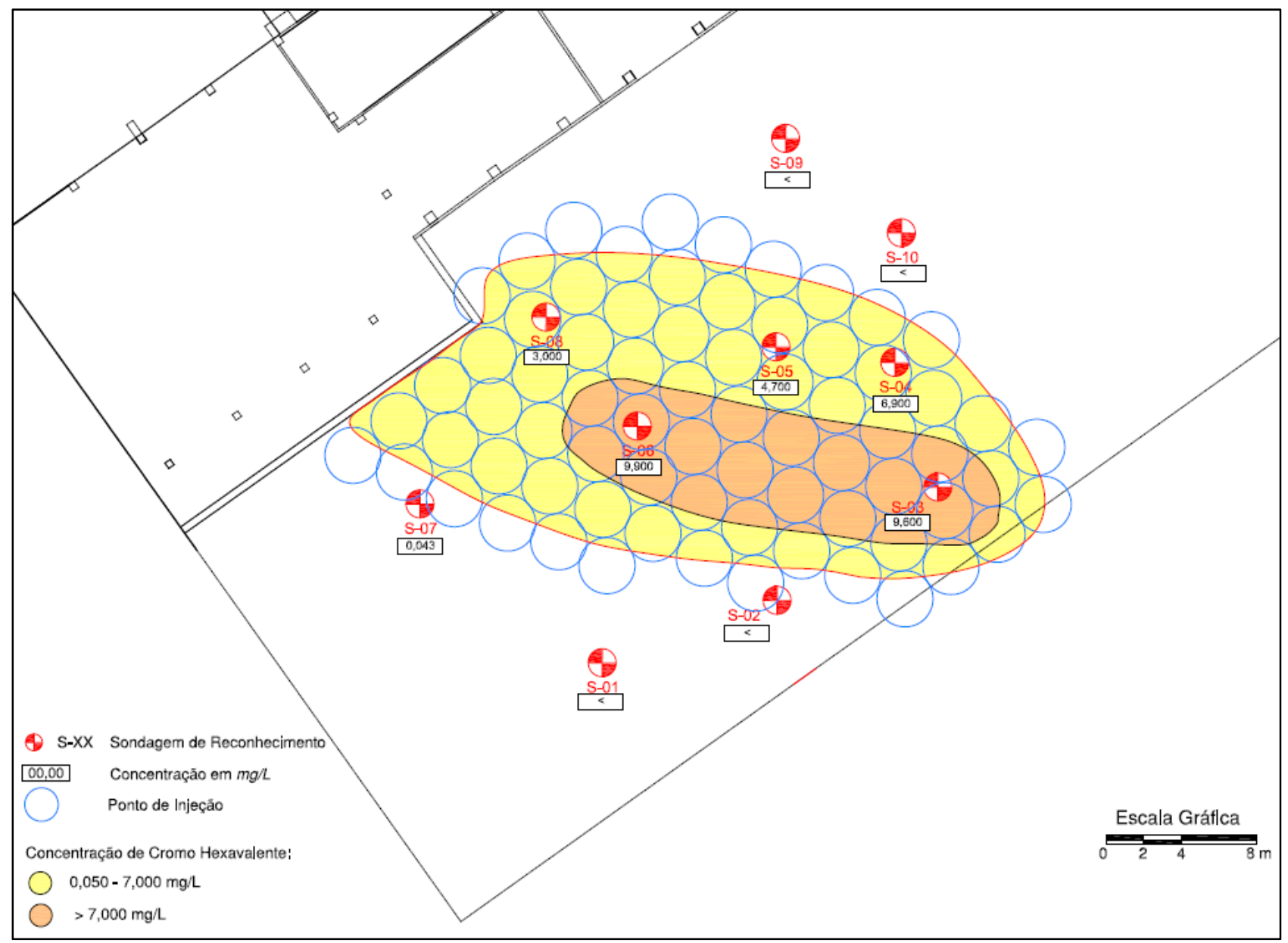

Figura 15 - Pluma de concentrações de cromo hexavalente no monitoramento de linha de base e pontos de injeção de reagente químico 


\section{1}

\section{Monitoramento de Linha de Base}

\section{1 .1}

Solo

A área de estudo sofreu duas intervenções para a remoção de solo que estava com $\mathrm{Cr}(\mathrm{VI})$ adsorvido. A área foi escavada até 5,5 metros de profundidade para remover o solo contaminado, totalizando a destinação de 3.000 toneladas.

As amostras de solo coletadas na área de interesse apresentaram concentrações de cromo total entre 7,68 e $313,5 \mathrm{mg} / \mathrm{kg}$, e cromo hexavalente entre 0,29 e $100,8 \mathrm{mg} / \mathrm{kg}$. Dentre as dez amostras coletadas em apenas uma foi detectada concentração de cromo total acima do valor orientador estabelecido pela CONAMA 420/2009 para áreas residenciais. Esta amostra foi coletada na sondagem realizada próximo ao limite da área escavada.

Os resultados analíticos das amostras e solo estão apresentados na Tabela 12.

Tabela 12 - Concentrações de cromo nas amostras de solo $(\mathrm{mg} / \mathrm{kg})$

\begin{tabular}{|c|c|c|c|c|c|c|c|c|c|c|}
\hline \multirow{3}{*}{ Composto } & \multicolumn{10}{|c|}{ Sondagem / Profundidade da amostra (m) } \\
\cline { 2 - 12 } & S-01 & S-02 & S-03 & S-04 & S-05 & S-06 & S-07 & S-08 & S-09 & S-10 \\
\cline { 2 - 12 } & 5,7 & 5,0 & 5,0 & 4,9 & 4,8 & 4,6 & 4,8 & 4,8 & 5,0 & 5,0 \\
\hline Cr Total & 24,0 & 65,1 & 313,5 & 85,3 & 112,1 & 56,5 & 7,7 & 16,5 & 61,3 & 9,3 \\
\hline Cr(VI) & $<$ & 4,6 & 17,8 & 11,4 & 100,8 & 13,4 & 0,8 & 0,7 & 9,2 & 0,3 \\
\hline
\end{tabular}

$(<)$ concentração menor que o limite de quantificação

\section{1 .2}

\section{Água Subterrânea}

Os resultados analíticos das amostras de água subterrânea são apresentados na Tabela 13 .

Após a escavação e destinação do solo contaminado, a concentração de cromo hexavalente reduziu para abaixo do limite de quantificação na área escavada e a sua jusante a concentração de cromo hexavalente reduziu de 30,6 para 20,0 mg/L, conforme pode ser observado na Tabela 10 (pág. 56) com o histórico das concentrações em água subterrânea.

No monitoramento de linha de base de água subterrânea, os resultados analíticos demonstraram que houveram reduções pontuais nas concentrações de 
cromo total e cromo hexavalente, indicando que a remoção do solo contaminado removeu a fonte secundária de contaminação.

Tabela 13 - Concentrações de cromo nas amostras de água subterrânea (mg/L)

\begin{tabular}{|c|c|c|c|c|c|c|c|c|c|c|}
\hline \multirow{3}{*}{ Composto } & \multicolumn{8}{|c|}{ Sondagem / Amostra de água subterrânea } \\
\cline { 2 - 12 } & S-01 & S-02 & S-03 & S-04 & S-05 & S-06 & S-07 & S-08 & S-09 & S-10 \\
\cline { 2 - 11 } & AS-01 & AS-02 & AS-03 & AS-04 & AS-05 & AS-06 & AS-07 & AS-08 & AS-09 & AS-10 \\
\hline Cr Total & 0,086 & 0,214 & 10,900 & 7,160 & 7,100 & 10,800 & 0,142 & 3,900 & 0,058 & 0,017 \\
\hline Cr(VI) & $<$ & $<$ & 9,600 & 6,900 & 4,700 & 9,900 & 0,043 & 3,000 & $<$ & $<$ \\
\hline
\end{tabular}

$(<)$ concentração menor que o limite de quantificação

\section{2}

\section{Monitoramento Pós-Injeção}

\section{2 .1}

$1^{\text {a }}$ Campanha

\subsubsection{1}

Solo

Os resultados analíticos apresentaram concentrações de cromo total em todas as amostras, e na amostra da sondagem S-102 a concentração de cromo total $(330 \mathrm{mg} / \mathrm{kg})$ ultrapassou o valor orientador $(300 \mathrm{mg} / \mathrm{kg})$ para solo em áreas residenciais da CONAMA 420/2009. Os resultados analíticos são apresentados na Tabela 14.

Nas amostras de solo não foram detectadas concentrações de cromo hexavalente, mostrando que a injeção de polissulfeto de cálcio dessorveu o cromo hexavalente que estava adsorvido ao solo e que foram detectadas nas amostras de solo coletadas na campanha de linha de base.

O processo de adsorção/dessorção é a interação físico-química do contaminante com a superfície do meio sólido como por exemplo, a troca catiônica, o contaminante pode ficar adsorvido ao solo até que as condições físico-químicas do meio sejam alteradas (pH, Eh, OD), e o contaminante liberado novamente para a água subterrânea. De acordo com o processo de remediação, após a injeção do polissulfeto de cálcio as condições físicoquímicas são alteradas e, dessa forma, possibilita a dessorção do cromo hexavalente $\left(\mathrm{CrO}_{4}^{2-}\right)$ que estava adsorvido na superfície do solo. Após ser 
disponibilizado o cromo hexavalente na água subterrânea, o mesmo foi precipitado como sólido $\left[\mathrm{Cr}(\mathrm{OH})_{3(\mathrm{~s})}\right]$.

Tabela 14 - Concentrações de cromo nas amostras de solo (mg/kg)

\begin{tabular}{|c|c|c|c|c|c|c|c|}
\hline \multirow{2}{*}{ Composto } & \multicolumn{7}{|c|}{ Sondagem / Profundidade da amostra (m) } \\
\cline { 2 - 8 } & S-100 & S-101 & S-102 & S-103 & S-104 & S-105 & S-106 \\
\cline { 2 - 8 } & 3,0 & 3,5 & 3,0 & 4,0 & 4,0 & 4,0 & 3,5 \\
\hline Cr Total & 146,0 & 51,0 & 330,0 & 14,0 & 1,8 & 222,0 & 6,2 \\
\hline Cr(VI) & $<$ & $<$ & $<$ & $<$ & $<$ & $<$ & $<$ \\
\hline
\end{tabular}

$(<)$ concentração abaixo do limite de quantificação

\subsubsection{2}

\section{Água Subterrânea}

Antes da injeção de polissulfeto de cálcio na área, haviam concentrações de cromo hexavalente entre 0,04 e $20,00 \mathrm{mg} / \mathrm{L}$, nos aquíferos raso e profundo.

A maior e menor concentração detectada, assim como, a média nesta campanha para cromo total foi $24,80 / 0,001 / 3,68 \mathrm{mg} / \mathrm{L}$, respectivamente. Para cromo hexavalente foi de 21,24 / 0,01 / 1,68 mg/L. As maiores concentrações de cromo total e cromo hexavalente ainda estão altas mas pela média é possível avaliar que na maioria dos poços de monitoramento da área de estudo as concentrações estão baixas, mas ainda acima do valor orientador para cromo total estabelecido pela CONAMA 420/2009. A Tabela 15 (pág. 72) apresenta as concentrações dos compostos químicos de interesse e parâmetros físico-químicos.

Não foram detectadas concentrações de cromo hexavalente (total e dissolvido) nas amostras dos poços de monitoramento PMN-100A, PMN101B, PMN-102A, PMN-103B, PMN-104A, PMN-105A, PMN-105B, PMN106A e PMN-106B, resultado da reação do polissulfeto de cálcio nesses pontos. Foram observadas reduções nas concentrações de cromo hexavalente total nas amostras dos poços PMN-75B, PMN-100B e PMN-103A, quando comparados com os resultados analíticos das campanhas anteriores. Em relação ao PMN104B foi detectada concentração de cromo hexavalente próximo ao valor do limite de quantificação.

Em contrapartida, foi observado aumento da concentração de $\mathrm{Cr}$ (VI) total na amostra do poço PMN-101A, quando comparado com os resultados 
analíticos da campanha de linha de base, sendo que este poço está localizado próximo da borda da área de injeção e as reações químicas podem estar um pouco mais lentas.

O par multinível PMN-75 não foi amostrado na campanha de linha de base porque eles não foram encontrados. No local do poço PMN-102B não foi realizada nenhuma sondagem profunda na campanha de linha de base. Dessa forma, não foi possível comparar a evolução das concentrações de cromo hexavalente nestes poços de monitoramento.

A análise dos parâmetros geoquímicos indicou que na água subterrânea ainda estão disponíveis concentrações de ferro e sulfato para a reação química de redução de cromo hexavalente e também há concentrações de cálcio que regulam o pH na faixa básica (acima de 7,5). As condições físico-químicas da água subterrânea ainda permaneciam com condições ideais, com $\mathrm{pH}$ na faixa neutra a básica e ambiente moderadamente redutor a redutor.

\section{2 .2 \\ $2^{\mathrm{a}}$ Campanha}

A avaliação geral dos resultados analíticos mostra que a maior e menor concentração, assim como a média, para o cromo total foi de 17,10 / 0,001/ $1,50 \mathrm{mg} / \mathrm{L}$, respectivamente. Para o cromo hexavalente foi de 17,10/0,01/ 1,40 mg/L. A Tabela 16 (pág. 73) apresenta as concentrações dos compostos químicos de interesse e parâmetros físico-químicos.

Os resultados analíticos indicaram que, em relação a primeira campanha de monitoramento pós-injeção, as concentrações de cromo hexavalente em nove dos 16 poços de monitoramento permaneceram abaixo do limite de quantificação utilizado pelo método analítico do laboratório; em quatro dos 16 poços de monitoramento as concentrações reduziram; e em três poços de monitoramento foram detectados aumento das concentrações de cromo hexavalente.

$\mathrm{O}$ aumento das concentrações de cromo hexavalente foram observadas nos poços PMN-75B (localizado na borda Oeste da área de injeção), PMN-101A (localizado na borda Norte da área de injeção), PMN-103A (localizado na borda Noroeste da área de injeção). Já a redução das 
concentrações foram identificadas nos poços PMN-75A, PMN-100B, PMN102B, localizados na borda Sul-Leste da área de injeção, e PMN-104B, localizado na boda Oeste da área de injeção.

As concentrações de cromo total também reduziram na maioria dos poços de monitoramento, quando comparadas com os resultados da primeira campanha de monitoramento pós-injeção.

A avaliação dos parâmetros geoquímicos mostra que ainda há concentrações dos compostos que atuam na redução do cromo hexavalente para cromo trivalente, tais como: cálcio, ferro, manganês e sulfato. E a mudança do $\mathrm{pH}$ básico para $\mathrm{pH}$ ácido não interfere no processo de redução do cromo hexavalente.

\section{2 .2 \\ $3^{\mathrm{a}}$ Campanha}

A Tabela 17 (pág. 74) apresenta os resultados analíticos e parâmetros físico-químicos da $3^{\mathrm{a}}$ Campanha. A avaliação geral dos resultados analíticos mostra que a maior e menor concentração, assim como a média, para o cromo total foi de $26,70 / 0,001 / 1,95 \mathrm{mg} / \mathrm{L}$, respectivamente. Para o cromo hexavalente foi de 13,00/0,01/0,928 mg/L.

Nesta campanha foram detectadas concentrações de cromo hexavalente apenas em 3 dos 15 poços de monitoramento existentes, cabe ressaltar que o poço PMN-103A foi destruído e não foi possível coleta água deste ponto. Em comparação com a última campanha, houve a redução de um poço de monitoramento com a ocorrência de cromo hexavalente, e as concentrações nos demais poços reduziram entre 24 e $72 \%$.

Não foi detectado aumento das concentrações de cromo hexavalente nesta campanha quando comparada com as anteriores, indicando tendência de redução deste composto na água subterrânea. 
Tabela 15 - Concentrações dos compostos químicos de interesse e parâmetros físico-químicos nas amostras de água subterrânea (Agosto/13)

\begin{tabular}{|c|c|c|c|c|c|c|c|c|c|c|c|c|c|c|c|c|c|}
\hline \multirow{2}{*}{ Parâmetro } & \multirow{2}{*}{ Unid. } & \multicolumn{16}{|c|}{ Poço de Monitoramento } \\
\hline & & $75 \mathrm{~A}$ & $75 \mathrm{~B}$ & $100 \mathrm{~A}$ & 100B & $101 \mathrm{~A}$ & 101B & $102 \mathrm{~A}$ & $102 B$ & $103 \mathrm{~A}$ & 103B & $104 \mathrm{~A}$ & 104B & $105 \mathrm{~A}$ & $105 B$ & $106 \mathrm{~A}$ & 106B \\
\hline Cr Total & $\mathrm{mg} / \mathrm{L}$ & 0,52 & 0,67 & 0,0766 & 3,8 & 2,1 & $<$ & 0,0268 & 24,8 & 1,8 & $<$ & 0,0028 & 24,8 & 0,0306 & $<$ & 0,176 & 0,019 \\
\hline $\mathrm{Cr}(\mathrm{VI})$ & $\mathrm{mg} / \mathrm{L}$ & 0,253 & 0,405 & $<$ & 2,234 & 1,707 & $<$ & $<$ & 21,24 & 1,012 & $<$ & 0,005 & 0,0131 & $<$ & $<$ & $<$ & $<$ \\
\hline Arsênio & $\mathrm{mg} / \mathrm{L}$ & na & na & $<$ & $<$ & $<$ & 0,0129 & na & na & $<$ & $<$ & na & na & $<$ & $<$ & na & na \\
\hline Sulfato & $\mathrm{mg} / \mathrm{L}$ & na & na & 169 & 154 & 167 & 28,3 & na & na & 68 & 47,2 & na & na & 893 & 203 & na & na \\
\hline Sulfeto & $\mathrm{mg} / \mathrm{L}$ & na & na & $<$ & $<$ & $<$ & $<$ & na & na & $<$ & $<$ & na & na & 2,9 & $<$ & na & na \\
\hline Cálcio & $\mathrm{mg} / \mathrm{L}$ & na & na & 76,6 & 9,306 & 4,303 & 2,345 & na & na & 11,828 & 7,97 & na & na & 196,56 & 13,458 & na & na \\
\hline Ferro & $\mathrm{mg} / \mathrm{L}$ & na & na & 8,615 & 3,202 & 0,835 & 6,146 & na & na & 1,191 & 3,64 & na & na & 119,28 & 3,635 & na & na \\
\hline Manganês & $\mathrm{mg} / \mathrm{L}$ & na & na & 0,585 & 0,336 & 0,17 & 0,385 & na & na & 0,176 & 0,0953 & na & na & 1,596 & 0,934 & na & na \\
\hline $\mathrm{pH}$ & - & 6,46 & 7,26 & 6,76 & 6,8 & 10,69 & 10,04 & 11,6 & 6,77 & 9,6 & 9,85 & 10,42 & 10,22 & 9,81 & 9,59 & 4,89 & 5,62 \\
\hline OD & $\mathrm{mg} / \mathrm{L}$ & 1,18 & 0,06 & 0,23 & 0,6 & 0,44 & 0,57 & 0,1 & 1,65 & 0,38 & 0,57 & 0 & 0,62 & 0,57 & 0 & 1,13 & 0,42 \\
\hline ORP & $\mathrm{mV}$ & 93,1 & 137,3 & 123,6 & 142,7 & 118,8 & 124,8 & 144,7 & 115,9 & 134,8 & 152 & 143,9 & 132 & 100,3 & 185,1 & 86,1 & 121,4 \\
\hline
\end{tabular}

(-) adimensional; $(<)$ concentração abaixo do limite de quantificação; (na) não analisado 
Tabela 16 - Concentrações dos compostos químicos de interesse e parâmetros físico-químicos nas amostras de água subterrânea (Fevereiro/14)

\begin{tabular}{|c|c|c|c|c|c|c|c|c|c|c|c|c|c|c|c|c|c|}
\hline \multirow{2}{*}{ Parâmetro } & \multirow{2}{*}{ Unid. } & \multicolumn{16}{|c|}{ Poço de Monitoramento } \\
\hline & & $75 \mathrm{~A}$ & $75 \mathrm{~B}$ & $100 \mathrm{~A}$ & 100B & $101 \mathrm{~A}$ & 101B & $102 \mathrm{~A}$ & 102B & $103 \mathrm{~A}$ & $103 \mathrm{~B}$ & $104 \mathrm{~A}$ & 104B & $105 \mathrm{~A}$ & 105B & $106 \mathrm{~A}$ & $106 \mathrm{~B}$ \\
\hline Cr Total & $\mathrm{mg} / \mathrm{L}$ & $<$ & 1,1 & 0,0062 & 1,5 & 2,42 & 0,0116 & 0,0201 & 17,1 & 1,5 & $<$ & 0,0041 & $<$ & 0,025 & $<$ & 0,3333 & $<$ \\
\hline $\mathrm{Cr}(\mathrm{VI})$ & $\mathrm{mg} / \mathrm{L}$ & $<$ & 0,67 & $<$ & 0,9083 & 2,2 & $<$ & $<$ & 17,1 & 1,4 & $<$ & $<$ & $<$ & $<$ & $<$ & $<$ & $<$ \\
\hline As & $\mathrm{mg} / \mathrm{L}$ & na & na & 0,0054 & $<$ & $<$ & $<$ & na & na & $<$ & $<$ & na & na & 0,0078 & $<$ & na & na \\
\hline Sulfato & $\mathrm{mg} / \mathrm{L}$ & na & na & 261 & 109 & 80 & 31 & na & na & 10 & 8,3 & na & na & 520 & 83 & na & na \\
\hline Sulfeto & $\mathrm{mg} / \mathrm{L}$ & na & na & na & $<$ & $<$ & $<$ & na & na & $<$ & $<$ & na & na & $<$ & $<$ & na & na \\
\hline $\mathrm{Ca}$ & $\mathrm{mg} / \mathrm{L}$ & na & na & 150,4 & 14 & 8,71 & 2,61 & na & na & 8,84 & 5,86 & na & na & 315,1 & 22,2 & na & na \\
\hline $\mathrm{Fe}$ & $\mathrm{mg} / \mathrm{L}$ & na & na & 48 & 0,3879 & 0,295 & 0,7933 & na & na & 0,3955 & 0,1909 & na & na & 176,8 & 4,01 & na & na \\
\hline $\mathrm{Mn}$ & $\mathrm{mg} / \mathrm{L}$ & na & na & 0,513 & 0,4164 & 0,0997 & 0,0995 & na & na & 0,1142 & 0,0695 & na & na & 0,7586 & 0,5048 & na & na \\
\hline $\mathrm{pH}$ & - & 6,5 & 5,62 & 4,21 & 5,66 & 4,17 & 5,25 & 4,81 & 5,39 & 3,63 & 4,82 & 5,85 & 6,37 & 7,19 & 6,38 & 4,45 & 5,53 \\
\hline OD & $\mathrm{mg} / \mathrm{L}$ & 3,91 & 3,62 & $\mathrm{nc}$ & $\mathrm{nc}$ & 1,11 & 3,63 & nc & 7,1 & 1,19 & 1,79 & 1,08 & 1,12 & 0,76 & 0,82 & 1,87 & 1,39 \\
\hline ORP & $\mathrm{mV}$ & 292,7 & 411,8 & 415,5 & 358,2 & 559 & 438,6 & 188,5 & 429,6 & 347,2 & 269 & 238 & 334,2 & 278,4 & 105,2 & 404,1 & 253,4 \\
\hline
\end{tabular}

(-) adimensional; (<) concentração abaixo do limite de quantificação; (na) não analisado; (nc) dado não considerado 
Tabela 17 - Concentrações dos compostos químicos de interesse e parâmetros físico-químicos nas amostras de água subterrânea (Outubro/14)

\begin{tabular}{|c|c|c|c|c|c|c|c|c|c|c|c|c|c|c|c|c|c|}
\hline \multirow{2}{*}{ Parâmetro } & \multirow{2}{*}{ Unid. } & \multicolumn{16}{|c|}{ Poço de Monitoramento } \\
\hline & & $75 \mathrm{~A}$ & $75 \mathrm{~B}$ & $100 \mathrm{~A}$ & 100B & $101 \mathrm{~A}$ & 101B & $102 \mathrm{~A}$ & $102 \mathrm{~B}$ & $103 \mathrm{~A}$ & $103 \mathrm{~B}$ & $104 \mathrm{~A}$ & $104 \mathrm{~B}$ & $105 \mathrm{~A}$ & $105 \mathrm{~B}$ & $106 \mathrm{~A}$ & $106 \mathrm{~B}$ \\
\hline Cr Total & $\mathrm{mg} / \mathrm{L}$ & 0,0317 & 0,619 & 0,0063 & 0,313 & 1,36 & 0,0273 & 0,0338 & 26,7 & na & 0,0048 & $<$ & 0,0033 & 0,0357 & 0,0005 & 0,0757 & 0,0064 \\
\hline $\mathrm{Cr}(\mathrm{VI})$ & $\mathrm{g} / \mathrm{L}$ & $<$ & 0,32 & $<$ & $<$ & 0,54 & $<$ & $<$ & 13 & na & $<$ & $<$ & $<$ & $<$ & $<$ & $<$ & $<$ \\
\hline As & $\mathrm{mg} / \mathrm{L}$ & $<$ & $<$ & 0,0011 & $<$ & $<$ & 0,0035 & 0,0017 & $<$ & na & $<$ & 0,0029 & $<$ & 0,0113 & $<$ & $<$ & $<$ \\
\hline Sulfato & $g / L$ & 185 & 61,6 & 431 & 1050 & 302 & 0,25 & 1290 & 69,8 & na & 27,9 & 1320 & 24,3 & 2660 & 440 & 276 & 39 \\
\hline Sulfeto & $\mathrm{mg} / \mathrm{L}$ & $<$ & $<$ & $<$ & $<$ & $<$ & $<$ & $<$ & $<$ & na & $<$ & $<$ & $<$ & 4 & $<$ & $<$ & $<$ \\
\hline $\mathrm{Ca}$ & $\mathrm{g} / \mathrm{L}$ & 29,3 & 5,96 & 68,7 & 51,5 & 8,49 & 3,16 & 232 & 3,31 & na & 5,41 & 32,7 & 10,5 & 404 & 14,3 & 81,4 & 5,41 \\
\hline $\mathrm{Fe}$ & $\mathrm{mg} / \mathrm{L}$ & 1,410 & 0,241 & 18,700 & 4,230 & 0,774 & 12,900 & 45,400 & 0,230 & na & 0,600 & 7,120 & 3,760 & 252 & 5,600 & 7,470 & 1,540 \\
\hline $\mathrm{Mn}$ & $\mathrm{mg} / \mathrm{L}$ & 0,1760 & 0,0350 & 0,2550 & 1,4300 & 0,0798 & 0,3550 & 0,8820 & 0,0440 & na & 0,0736 & 0,1940 & 0,2670 & 0,4800 & 0,8430 & 0,1720 & 0,0429 \\
\hline $\mathrm{pH}$ & - & 5,95 & 5,86 & 5,65 & 5,29 & 4,27 & 5,31 & 4,10 & 5,92 & na & 5,81 & 6,08 & 6,62 & 4,86 & 6,28 & 5,37 & 6,30 \\
\hline OD & $\mathrm{mg} / \mathrm{L}$ & 0,56 & 2,51 & 0,25 & 0,47 & 0,72 & 0,51 & 0,35 & 0,70 & na & 3,71 & 0,91 & 3,07 & 0,31 & 1,28 & 2,48 & 1,11 \\
\hline ORP & $\mathrm{mV}$ & 457,7 & 462,6 & 308,6 & 417,5 & 650,7 & 668,5 & 346,1 & 498,2 & na & 450,1 & 378,1 & 414 & 308,6 & 247,8 & 382,7 & 387,7 \\
\hline
\end{tabular}

(-) adimensional; (<) concentração abaixo do limite de quantificação; (na) não analisado; (nc) dado não considerado 


\section{6 \\ Discussão dos Resultados}

A área impactada por cromo hexavalente teve como histórico a atividade de preparo dos moldes das fôrmas de vidro que utilizava $\mathrm{Cr}(\mathrm{VI})$ e, ao longo das investigações ambientais realizadas, foi constatado que a fonte de contaminação foi pontual com a migração/dispersão da contaminação por meio do solo e do fluxo da água subterrânea, com influência da anisotropia do meio geológico.

Devido ao uso futuro da área e otimizando o processo de remediação, foi realizada a escavação e destinação do solo impactado por cromo hexavalente, para remoção desse contaminante que estava adsorvido ao solo superficial e subsuperficial e atuava como uma fonte secundária de contaminação.

Após a remoção do solo contaminado foi observada a redução das concentrações de cromo hexavalente na área escavada e imediatamente a sua jusante, confirmando a hipótese de que o solo com produto adsorvido atuava como fonte secundária de contaminação. Tal diminuição da concentração pode ser observado na Tabela 14 (pág. 69) que apresenta os resultados das campanhas de monitoramento.

Nas amostras de solo, coletadas durante a realização das sondagens para instalação de poços de monitoramento, não foram detectadas concentrações de cromo hexavalente, indicando que o polissulfeto de cálcio dessorveu o cromo hexavalente que estava adsorvido ao solo, disponilizando-o na água subterrânea para ser precipitado como sólido.

O nível d'água médio da subterrânea no local impactado por cromo hexavalente é de 4,05 e 4,04 m nos poços rasos e poços profundos, respectivamente. A Tabela 18 apresenta a cronologia da variação da carga hidráulica ao longo das campanhas de monitoramento e a Figura 16 apresenta a variação do nível médio da água subterrânea nos poços de monitoramento rasos e profundo e a precipitação mensal monitorada em três estações (Alerta Rio, 2014) que estão localizadas nas proximidades da área de estudo. 
Tabela 18 - Cronologia da Variação da Carga Hidráulica nos Poços de Monitoramento

\begin{tabular}{|c|c|c|c|}
\hline Poço & $\mathbf{1 6 / 0 8 / 1 3}$ & $\mathbf{2 1 / 0 2 / 1 4}$ & $\mathbf{1 7 / 1 0 / 1 4}$ \\
\hline PMN-75A & 95,95 & 95,87 & 95,35 \\
\hline PMN-75B & 95,67 & 95,10 & 95,47 \\
\hline PMN-100A & 95,94 & 96,01 & 95,45 \\
\hline PMN-100B & 95,91 & 95,66 & 95,46 \\
\hline PMN-101A & 95,38 & 95,95 & 94,71 \\
\hline PMN-101B & 94,41 & 94,60 & 94,65 \\
\hline PMN-102A & 95,86 & 95,66 & 95,20 \\
\hline PMN-102B & 95,51 & 96,93 & 95,39 \\
\hline PMN-103A & 95,42 & 94,90 & - \\
\hline PMN-103B & 95,39 & 94,95 & 94,48 \\
\hline PMN-104A & 94,96 & 94,81 & 94,70 \\
\hline PMN-104B & 95,05 & 95,36 & 94,56 \\
\hline PMN-105A & 96,11 & 96,14 & 94,90 \\
\hline PMN-105B & 95,52 & 95,57 & 95,04 \\
\hline PMN-106A & 95,86 & 95,23 & 95,25 \\
\hline PMN-106B & 95,63 & 95,36 & 95,15 \\
\hline Média PM Rasos & 94,73 & 95,40 & 95,08 \\
\hline Média PM Profundos & 94,80 & 95,56 & 95,02 \\
\hline
\end{tabular}

A análise das cargas hidráulicas dos poços de monitoramento permitiu avaliar que entre a primeira (Agosto/2014) e segunda (Fevereiro/2014) campanha de monitoramento pós-injeção, o nível d'água médio ficou mais profundo, cerca de 0,67 e $0,76 \mathrm{~m}$ nos poços rasos e profundos, respectivamente. Em contrapartida ocorreu maior precipitação nos meses anteriores ao monitoramento realizado na segunda campanha de monitoramento pós-injeção, como poder ser observado na Figura 16. Mesmo com maior precipitação nos meses anteriores a $2^{\mathrm{a}}$ campanha de monitoramento, não houve infiltração da água de chuva a montante da área de injeção porque a área está impermeabilizada, devido as obras realizadas no local. Já na $3^{\text {a }}$ Campanha, as cargas hidráulicas médias ficaram mais profundas, cerca de 0,28 e $0,49 \mathrm{~m}$ nos poços rasos e profundos, respectivamente. Esta diminuição nas cargas hidráulicas estão relacionadas a baixa precipitação registrada nos meses anteriores (entre maio e outubro/2014). 
A comparação dos resultados analíticos da segunda campanha de monitoramento pós-injeção (Fevereiro/2014) com a campanha de linha de base (Setembro/2012) indicaram redução das concentrações de cromo hexavalente entre 64,10 e 99,95\%, com exceção do PMN-101A, onde foi observado aumento da concentração de cromo hexavalente.

Em relação a segunda campanha de monitoramento pós-injeção (Agosto/2014), as concentrações de cromo hexavalente reduziram entre 19,49 e 98,02\% em quatro de 16 poços de monitoramento, em contrapartida, foram detectados aumento das concentrações em três poços de monitoramento. Em nove dos 16 poços as concentrações de cromo hexavalente permaneceram abaixo do limite de quantificação utilizado pelo método analítico do laboratório.

A comparação dos resultados analíticos da $3^{\mathrm{a}}$ campanha de monitoramento com a campanha de baseline (Setembro/2012) indicaram redução das concentrações de cromo hexavalente entre 46,67 e 99,95\%. A Figura 19 apresenta a variação das concentrações de cromo hexavalente ao longo dos estudos ambientais realizados na área de estudo.

Em relação a segunda campanha de monitoramento, realizada em Fevereiro/2014, as concentrações de cromo hexavalente reduziram entre 23,98 e $99,79 \%$ em cinco dos 15 poços de monitoramento que foram amostrados. Em três dos 15 poços de monitoramento as concentrações de cromo hexavalente permaneceram abaixo do limite de quantificação utilizado pelo método analítico do laboratório. Não foi observado aumento da concentração de cromo hexavalente, quando comparados os resultados da atual e primeira campanha de monitoramento. 


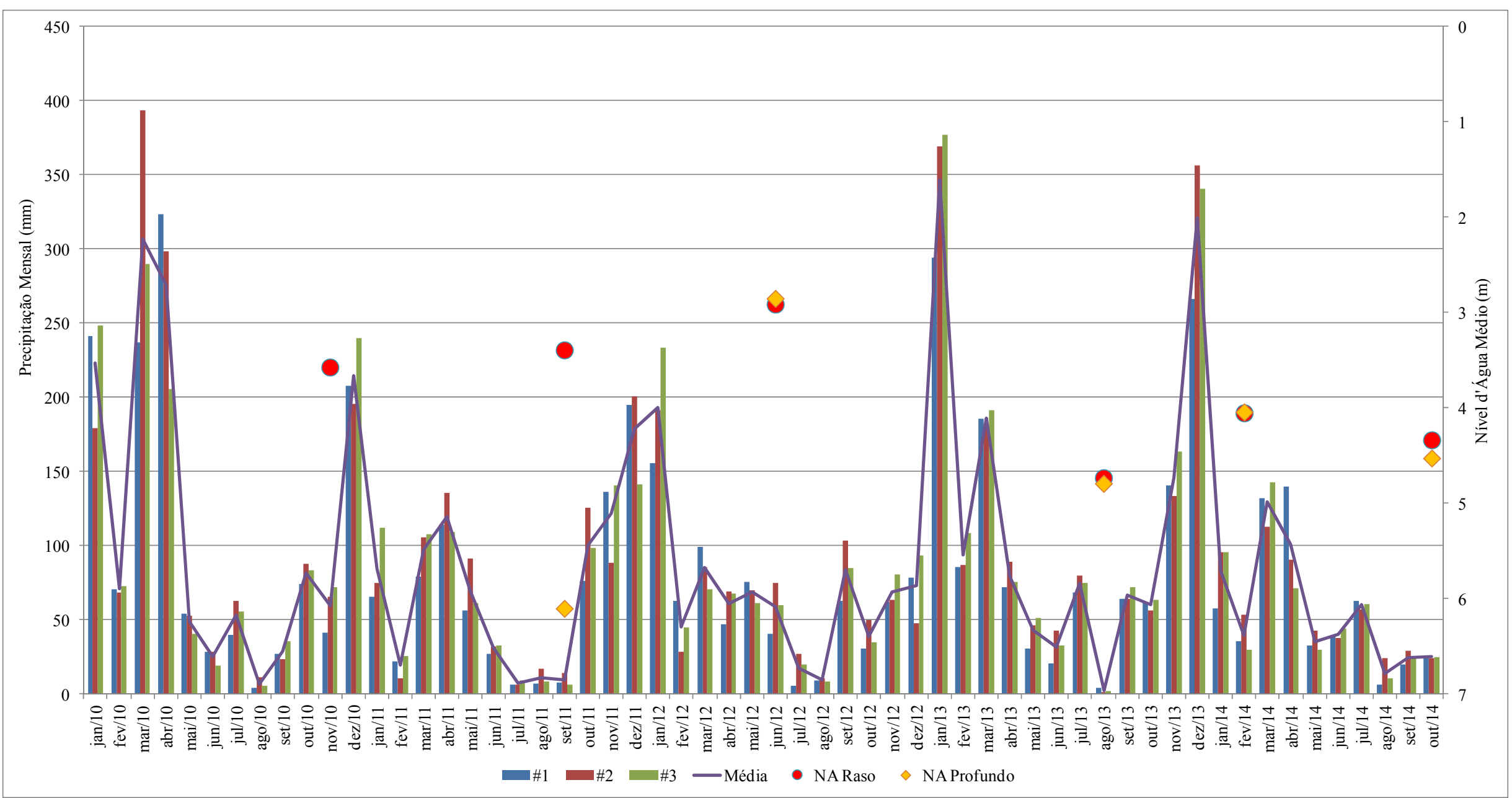

Figura 16 - Dados da pluviometria e nível d'água da área de estudo. 


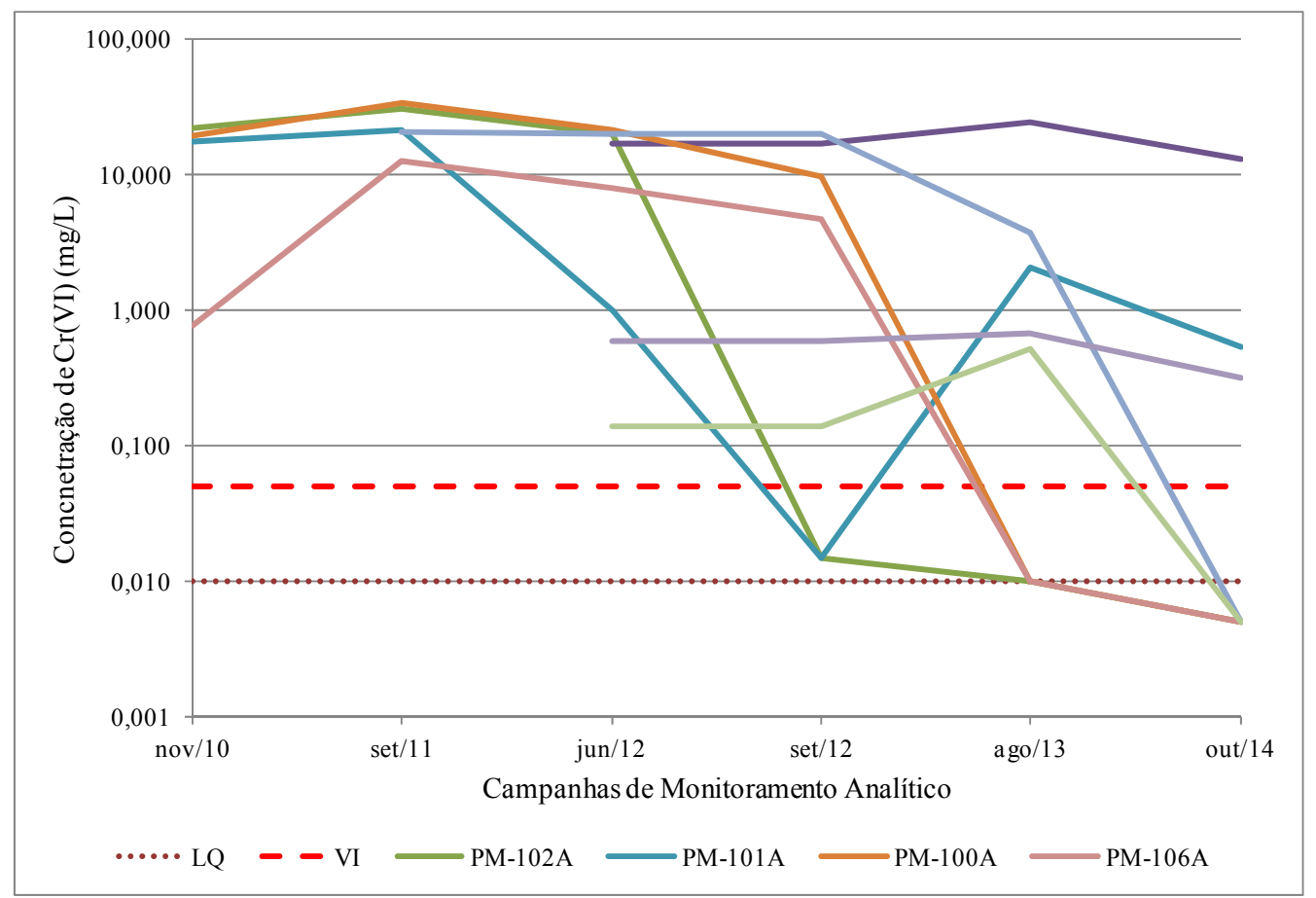

Figura 17 - Evolução das concentrações de $\mathrm{Cr}(\mathrm{VI})$ na área de estudo

As Figuras 20 e 21 apresentam a tendência dos dados físico-químicos, geoquímicos e do cromo.

As concentrações de oxigênio dissolvido estavam na faixa anóxica $(0,00 \mathrm{mg} / \mathrm{L})$ na primeira campanha pós-injeção (Agosto/2013) e na $2^{\mathrm{a}}$ e $3^{\mathrm{a}}$ campanhas houve aumento das concentrações de OD na água subterrânea, sendo as concentrações médias de 1,86 (Fev/14) e 1,26 mg/L (Out/14). Esta variação das concentrações de oxigênio dissolvido podem estar relacionada a flutuação do nível d'água subterrânea que estava mais raso na segunda campanha (Fevereiro/2014) e entrou em contato com uma camada de solo que possuía mais oxigênio.

$\mathrm{O}$ aumento das concentrações de oxigênio dissolvido na segunda campanha de monitoramento (Fevereiro/14) e o consumo do polissulfeto de cálcio pelas reações de redução do cromo hexavalente, podem reduzir ainda mais o tempo para que o processo de redução seja realizado.

A avaliação dos valores de $\mathrm{pH}$ e Eh mensurados em campo nas campanhas de monitoramento realizadas (Nov/2010, Set/2011, Jun/2012, $\mathrm{Ag} / 2013$, Fev/2014 e Out/2014) mostram que o valor de $\mathrm{pH}$ estava na faixa ácida (em torno de 4) e após a remoção do solo contaminado por cromo hexavalente o pH elevou-se para entre 5 e 6 , e após a injeção do reagente 
químico elevou-se para a faixa básica (acima de 7,5). Nas duas últimas campanhas o $\mathrm{pH}$ reduziu para a faixa ácida (abaixo de 6,5), que pode ser considerado como valor de $\mathrm{pH}$ de background da área. $\mathrm{O}$ comportamento do Eh foi inversamente proporcional, aumentando entre Agosto/2013 e Outubro/2014, sendo que, na última campanha os valores medidos estão nas faixas consideradas como moderadamente redutor $(100 \mathrm{a} 400 \mathrm{mV})$ e oxidante (>400 mV). A interpretação das variações do pH e Eh estão representadas nas Figuras 22 e 23, respectivamente.

A variação de $\mathrm{pH}$ também mostrou relação entre o aumento das concentrações de cálcio, ferro, manganês e sulfato (em alguns poços de monitoramento). Também houveram reduções nas concentrações de cromo hexavalente nos poços de monitoramento.

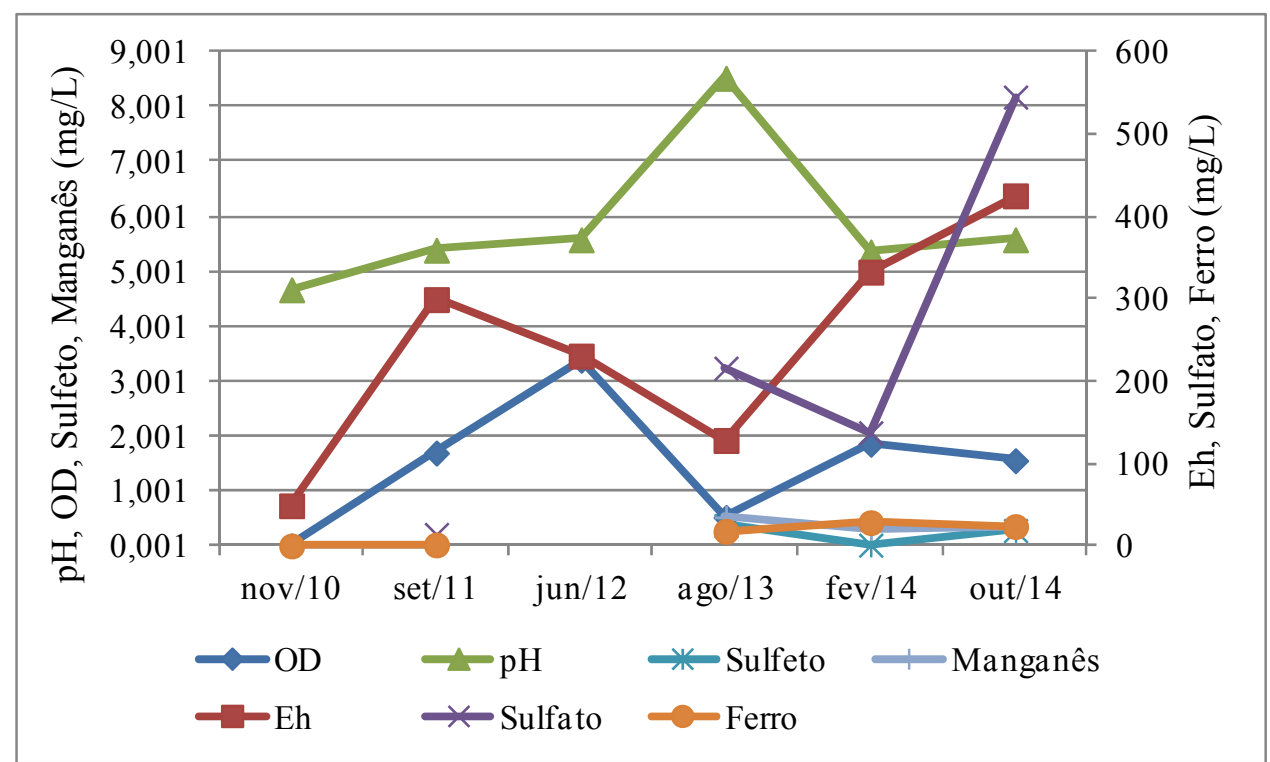

Figura 18 - Tendência dos dados físico-químicos e geoquímica 


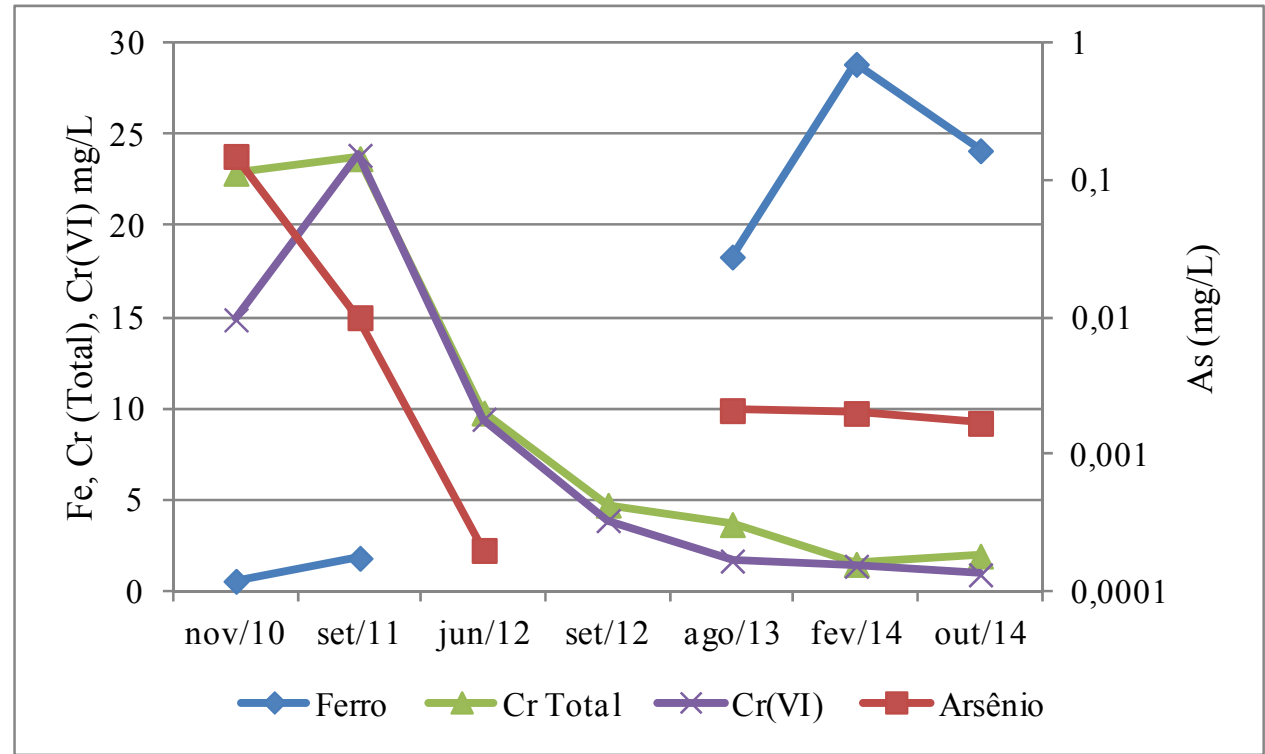

Figura 19 - Tendência das concentrações do cromo (total e hexavalente), ferro e arsênio

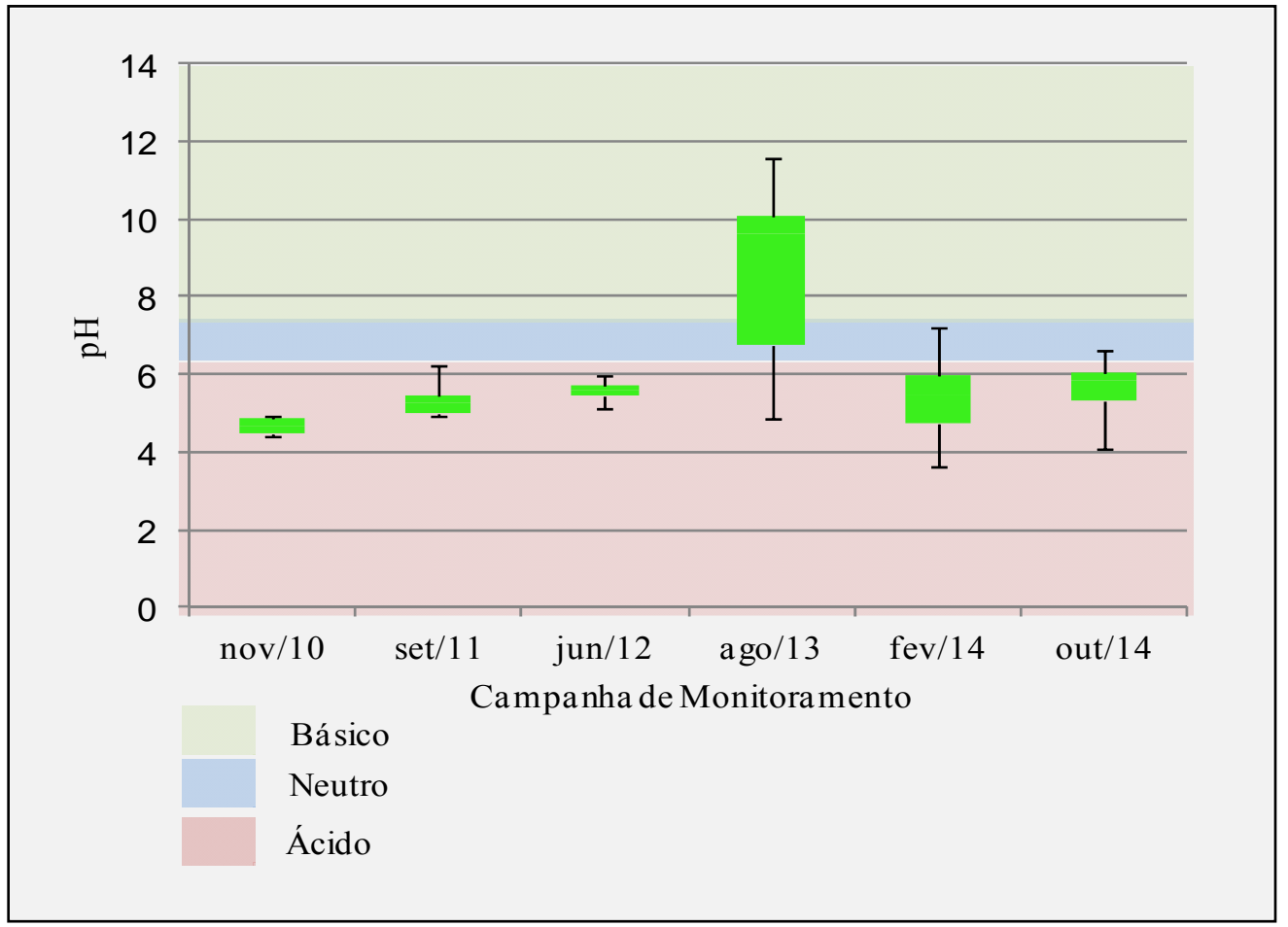

Figura 20 - Variação do pH ao longo das campanhas de monitoramento 


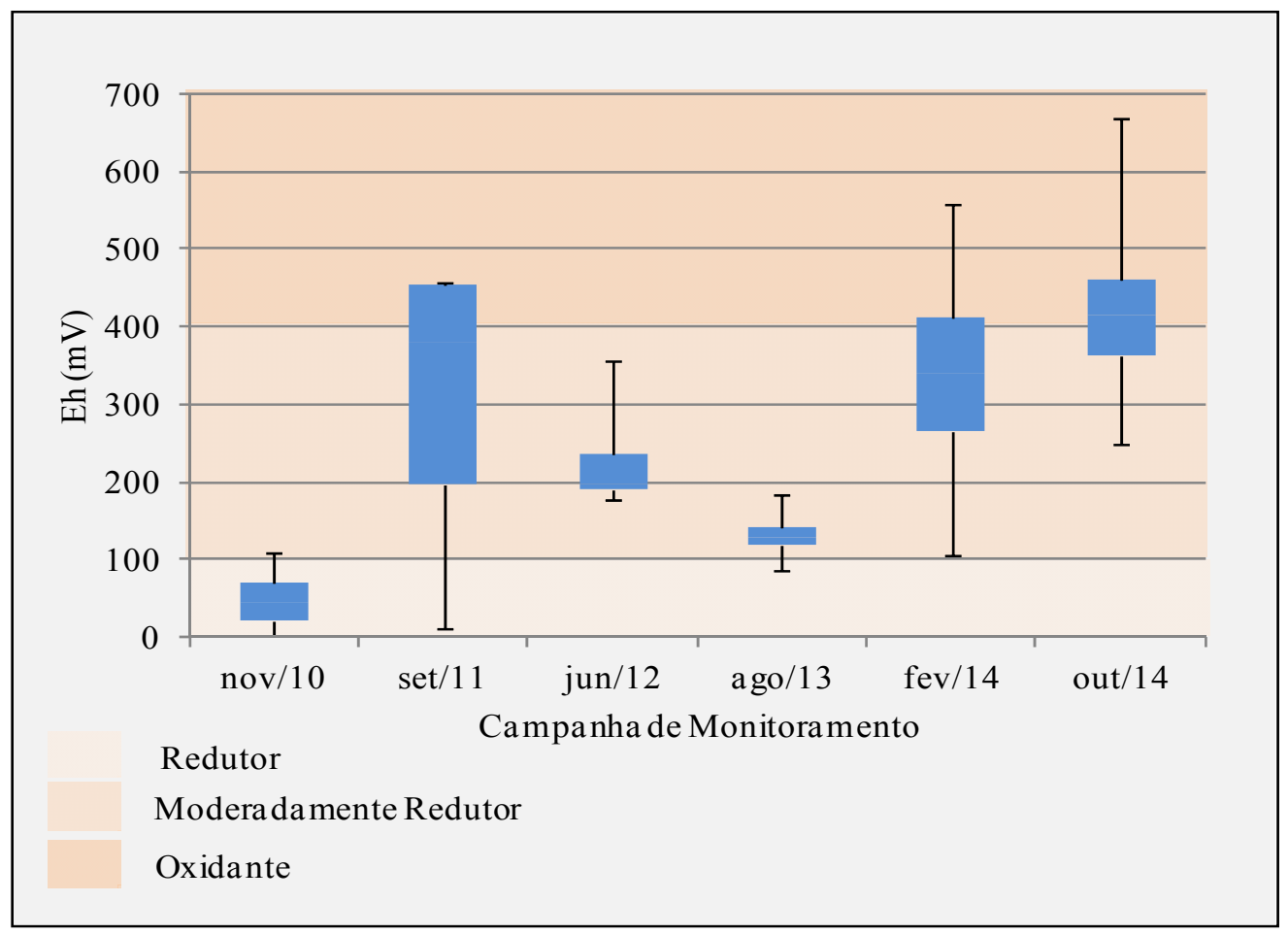

Figura 21 - Variação do Eh ao longo das campanhas de monitoramento

Conforme poder ser observado no diagrama de Eh-pH do cromo (Figura 24), as condições identificadas na água subterrânea da área de estudo está ideal para manter o cromo na sua valência trivalente. Neste diagrama foram plotados os dados dos poços de monitoramento, e indicam que o cromo hexavalente foi reduzido para cromo trivalente em seu estado mais estável no meio subterrâneo. 


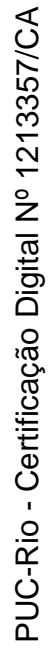

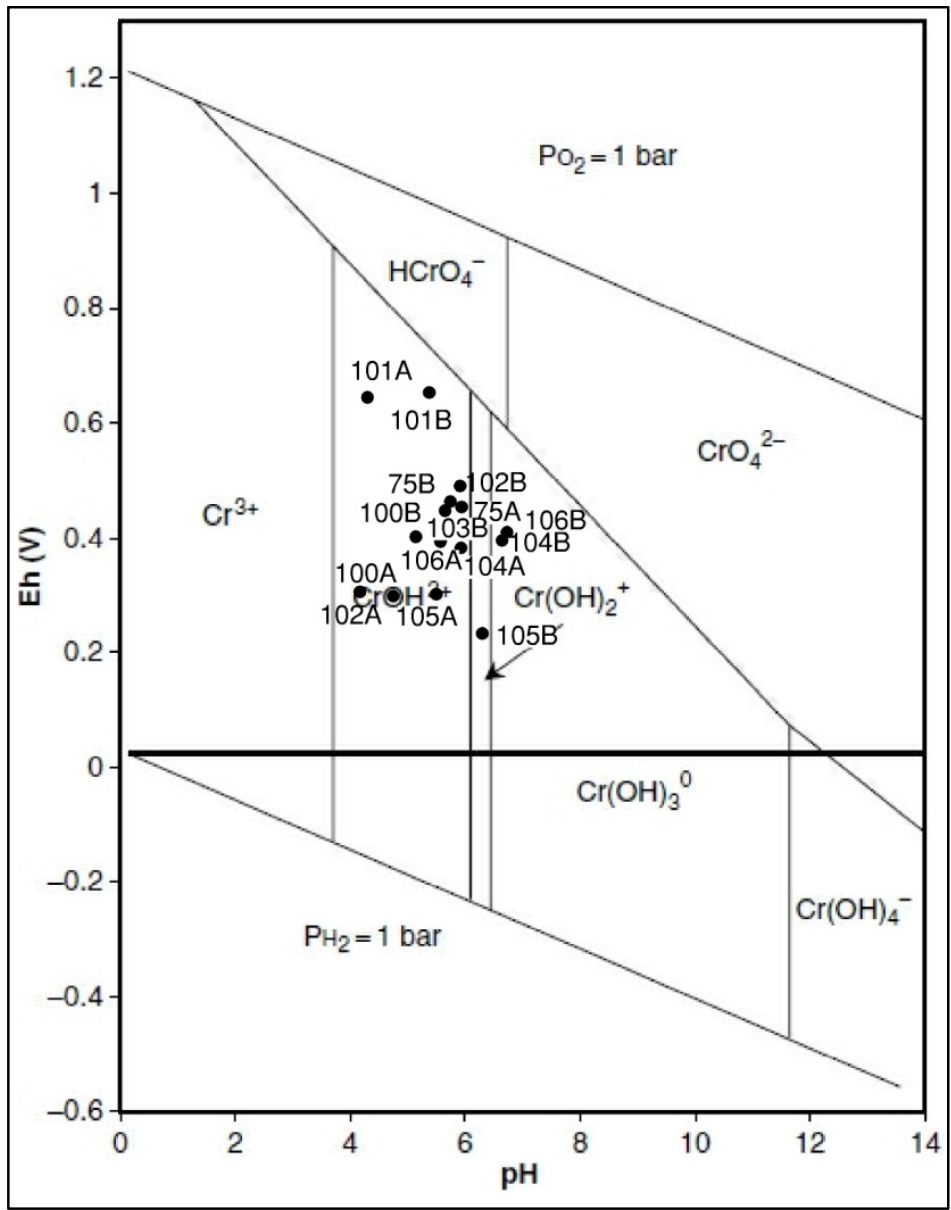

Figura 22 - Diagrama de Eh-pH para cromo (Palmer and Wittbrodt, 1991)

Godoy, R. F. 


\section{7 \\ Conclusões e Recomendações}

O presente trabalho teve o objetivo de apresentar e discutir a aplicação da tecnologia de redução química in situ (ISCR) para remediação de cromo hexavalente em solo e água subterrânea, visando reduzir os riscos à saúde humana associados a toxicidade deste composto.

Para melhor compreensão desta tese, inicialmente foi abordado na revisão bibliográfica o processo de gerenciamento de áreas contaminadas, a revitalização de áreas contaminadas, valores orientadores, comportamento de metais em subsuperfície, informações sobre o cromo e propriedade químicas do polissulfeto de cálcio.

Em relação ao processo de áreas contaminadas, é necessário que sejam cumpridas as etapas de investigação ambiental estabelecidas pela Resolução CONAMA 420/2009, assim como, envolver o órgão ambiental em todas as etapas, em especial no estágio da seleção da técnica de remediação que é um ponto crítico e oneroso ao proprietário da área em estudo.

Foi possível verificar que no Brasil não há valor de intervenção para cromo hexavalente em água subterrânea. Isto é um ponto crítico devido a toxicidade do cromo hexavalente se a água subterrânea for ingerida e se houver contato dérmico. Em contrapartida, o órgão ambiental dos Estados Unidos está avaliando reduzir o valor orientador $(0,043 \mathrm{mg} / \mathrm{L})$ para água subterrânea, devido aos riscos associados a este composto.

O cromo hexavalente é amplamente utilizado em diversos processos industriais e, historicamente, a área de uso e seu manuseio são negligenciados causando a contaminação do solo e da água subterrânea, uma vez que, a preocupação é com o tratamento do efluente industrial. O cromo hexavalente é classificado como cancerígeno para o ser humano pela IARC e, como citado anteriormente, as principais vias de exposição a este composto é o contato dérmico e ingestão de solo e água subterrânea contaminados. 
A revisão bibliográfica também abordou o uso de polissulfeto de cálcio como agente redutor em áreas contaminadas por cromo hexavalente em alguns estudos de caso nos Estados Unidos e Reino Unido. Este redutor químico mostrou-se promissor por ser um fertilizante amplamente comercializado e mais barato do que outros reagentes químicos produzidos apenas para projetos de remediação.

Dessa forma, após todo embasamento teórico, foi apresentado a caracterização da área de estudo, a qual está localizada no Rio de Janeiro e funcionou por cerca de 60 anos como fábrica de vidros. Em uma parte do processo industrial o cromo hexavalente era utilizado para preparação das fôrmas de vidro. Após a realização dos estudos ambientais para delimitação e detalhamento da contaminação, foi elaborado o plano de intervenção que contemplou a escavação e remoção do solo contaminado por cromo hexavalente e a aplicação da técnica de redução química in situ para reduzir as concentrações de cromo hexavalente na água subterrânea.

O teste de tratabilidade com polissulfeto de cálcio comprovou a viabilidade do uso deste reagente químico por meio da Redução Química In Situ (ISCR) para reduzir as concentrações do cromo hexavalente em solo e na água subterrânea. O teste resultou em uma demanda estequiométrica de $4 \mathrm{mlCPS} / \mathrm{kg}$ de solo para o tratamento da área de estudo.

As amostras de solo coletadas seis meses após a injeção mostrou que o polissulfeto de cálcio conseguiu dessorver o cromo hexavalente do solo, uma vez que, não foram detectadas concentrações do contaminante nas amostras.

Após 19 meses da injeção do reagente químico as concentrações de cromo hexavalente foram reduzidas entre 46,67 e 99,95\% na água subterrânea, em relação a campanha de linha de base. Sendo que, dos 15 poços de monitoramento, em apenas três poços foram detectadas concentrações de cromo hexavalente.

Isto demonstra a eficiência do uso de polissulfeto de cálcio para remediação de cromo hexavalente no solo e na água subterrânea, confirmando os estudos realizados por (Storch, et al., 2002; Graham, et al., 2006; Charboneau, et al., 2006; Wazne, et al., 2007a; Wazne, et al., 2007b; Chrysochoou, et al., 2010; Chrysochoou \& Ting, 2011; Pakzadeh \& Batista, 
2011; Chrysochoou, et al., 2012) em diversas áreas nos Estados Unidos e Europa.

Com base nos resultados obtidos ao longo do processo de gerenciamento de passivo ambiental da área de estudo, é possível fazer as seguintes recomendações:

- Implementar procedimento para o descomissionamento de indústrias pelos órgãos ambientais. O procedimento é de extrema importância para que seja minimizado o risco de contaminação do solo e da água subterrânea durante o processo de desmobilização de unidades industriais;

- Detalhar ao máximo possível o modelo conceitual de áreas contaminadas por cromo hexavalente;

- Avaliar a geoquímica da água subterrânea;

- Analisar no solo e na água subterrânea cromo (total e dissolvido) e cromo hexavalente (total e dissolvido). Não utilizar preservante nas amostras de água subterrânea para que não haja interferências nas análises, caso isso seja possível logisticamente;

- Realizar teste de bancada detalhado para avaliar a eficiência do polissulfeto de cálcio no solo e água subterrânea, assim como, para verificar o potencial de mobilização de outros metais para a água subterrânea;

- Analisar no solo, pelo método de lixiviação, a quantidade de cromo total e cromo hexavalente que pode mobilizar do solo para a água subterrânea, para incluir esta demanda no cálculo da dose;

- Avaliar os métodos de injeção mais adequados para a área de tratamento;

- Definir a área de injeção, quantidade de pontos de injeção, extensão vertical e horizontal de injeção, necessidade de solução para adequar o pH da água subterrânea. 


\section{8 Referências Bibliográficas}

ABNT, 1987. NBR 9813 - Solo - Determinação da massa específica aparente in situ com emprego de cilindro de cravação. s.I.:s.n.

ABNT, 2007. NBR 15.492 - Sondagem de reconhecimento para fins de qualidade ambiental. s.I.:s.n.

ABNT, 2007. NBR 15.495 - Poços de monitoramento de águas subterrâneas em aqüíferos granulados. s.I.:s.n.

ABNT, 2010. NBR 15.847 - Amostragem de Água Subterrânea em Poços de Monitoramento - Métodos de Purga. s.I.:S.n.

ABNT, 2011. NBR 15515-1 - Passivo Ambiental em Solo e Água Subterrânea - Parte 1: Avaliação Preliminar. s.l.:s.n.

Alerta Rio, 2014. Sistema Alerta Rio da Prefeitura do Rio de Janeiro. [Online]

Available

at:

http://www0.rio.ri.gov.br/alertario/

[Acesso em 24 Fevereiro 2014].

ASTM, 2002. Standard Practice for Low-Flow Purging and Sampling for Wells and Devices Used for Groundwater Investigation (d6771-02). s.l.:s.n.

ASTM, 2005. Standard Practice for Environmental Site Assessments: Phase I Environmental Sites Assessment Process (E1527). s.I.:s.n.

ATSDR, 2012. Toxicological Profile for Chromium - TP7, Atlanta: U.S. Department of Health and Human Services.

Bartlett, R., 1991. Chromium cycling in soils and water: Links, gaps, and methods. Environmental Health Perspectives (92), p. 17-24.

Bear, J., 1972. Dynamics of fluids in porous media. New York: America Elsevier Publishing Company, Inc..

Bertolo, R. et al., 2011. Geochemistry of natural chromium occurrence in a sandstone aquifer in Bauru Basin, São Paulo State, Brazil. Applied geochemistry, Volume 26, pp. 1353-1363.

Cetesb, 2012. Crômio e seus compostos, São Paulo: s.n.

Charboneau, B. et al., 2006. Hanford groundwater remediation. Tucson, AZ, Waste Management 2006 Conference.

Chrysochoou, M., Ferreira, D. \& Johnston, C., 2010. Calcium polysulfide treatment of $\mathrm{Cr}(\mathrm{VI})$-contaminated soil. Journal of Hazardous Materials, Volume 179, pp. 650-657. 
Chrysochoou, M., Johnston, C. \& Dahal, G., 2012. A comparative evaluation of hexavalent chromium treatment in soil by calcium polysulfide and green-tea nanoscale zero-valent iron. Journal of Hazardous Materials, Volume 201-202, pp. 33-42.

Chrysochoou, M. \& Ting, A., 2011. A kinetic study of $\mathrm{Cr}(\mathrm{VI})$ reduction by calcium polysulfide. Science of the Total Environment, Volume 209, pp. 4072-4077.

Cleary, R. W., 1989. Águas Subterrâneas. s.l.:Princeton Groundwater, Inc..

Deutsch, W. J., 1997. Groundwater Geochemistry: Fundamentals and applications to contamination. Boca Raton / Florida: CRC Press.

DNPM, 2011. Balanço Mineral Brasileiro, s.l.: s.n.

DNPM, 2013. Sumário Mineral - Cromo, Salvador/BA: s.n.

EPA, 1996. Low flow (Minimal Drawdown) Groundwater Sampling Procedures, s.I.: s.n.

EPA, 1999. Volume II: Review of Geochemistry and Available Kd Values for Cadmium, Cesium, Chromium, Lead, Plutonium, Radon, Strontium, Thorium, Tritium (3H), and Uranium. 402-R-90-004B, s.I.: S.n.

EPA, 2000. In Situ Treatment of Soil and Groundwater Contaminated with Chromium - EPA/625/R-00/005, s.I.: s.n.

EPA, 2007. Method 6200 - Field Portable X-Ray Fluorescence Spectrometry for the Determination of Elemental Concentrations in Soil and Sediment, s.I.: s.n.

EPA, 2014. Screening Level Tables. [Online] Available at: http://www.epa.gov/reg3hwmd/risk/human/rbconcentration table/Generic Tables/index.htm [Acesso em 27 Maio 2014].

Fetter, C., 1994. Applied Hydrogeology. Upper Saddle River/New Jersey: Merril Publishing Co..

Freeze, A. \& Cherry, J., 1979. Groundwater. Englewood Cliffs(New Jersey): Prentice-Hall.

Fruchter, J., 2002. In Situ Treatment of Chromium Contaminated Groundwate. Environmental Science \& Technology, 1 December, pp. 464A-472A.

Graham, M. et al., 2006. Calcium polysulfide remediation of hexavalent chromium contamination from chromite ore processing residue. Science of the Total Environment, Issue 364, pp. 32-44.

Hellerich, L. \& Nokolaidis, N., 2005. Studies of hexavalent chromium attenuation in redox variable soil obtained from a sandy to sub-wetland groundwater environment. Water Research, Volume 39, pp. 2851-2868.

Hellerich, L., Nokolaidis, N. \& Dobbs, G., 2007. Evaluation of the potential for the natural attenuation of hexavalent chromium within a 
sub-wetland ground water. Journal of Environmental Management, Volume 88, pp. 1513-1524.

Hering, J. \& Harmon, T., 2004. Geochemical Controls on Chromium Occurrence, Speciation and Treatability - Report 91043F, Denver: American Water Works Association Research Foundation.

Hvorslev, M., 1951. Time Lag and Soil Permeability in Ground-Water Observations. Vicksburg(Mississippi): Waterways Experiment Station Corps of Engineers, U.S. Army.

IETEG, 2005. Chromium(VI) Handbook. Boca Raton, FL: CRC Press.

Marcolan, L., Bourotte, C. \& Bertolo, R., 2008. Estratificação das Concentrações de Cromo Hexavalente nas Águas Subterrâneas do Aquífero Adamantina, Município de Urânia, SP, Brasil. XV Congresso Brasileiro de Águas Subterrâneas, p. 20.

McLean, J. E. \& Bledsoe, B. E., 1992. Behavior of Metals in Soils Ground Water Issue, s.I.: EPA/540/S-92/018.

Negrão, P., 2012. Planilha - Determination of $K$ from Low Flow Sampling Data. Created by Paulo Negrão after Robbins et al (2009). s.l.:s.n.

Oliveira, E., 1992. Contaminação de Aqüíferos por Hidrocarbonetos Provenientes de Vazamentos de Tanques de Armazenamento Subterrâneo, São Paulo: s.n.

Pakzadeh, B. \& Batista, J., 2011. Chromium removal from íonexchange waste brines with calcium polysulfide. Water Research, Volume 45, pp. 3055-3064.

Palmer, C. \& Puls, R., 1994. Natural Attenuation of Hexavalent Chromium in Groundwater and Soils, s.I.: s.n.

Puls, R. \& Barcelona, M., 1996. Ground water issue: Low-flow (minimal drawdown) ground-water sampling procedures - EPA/540/S-95/504, Ada, Oklahoma: s.n.

Rai, D., Eary, L. \& Zachara, J., 1989. Environmental Chemistry of Chromium. The Science of the Total Environment, Issue 86, pp. 15-23.

Rai, D. et al., 1988. Geochemical Behavior of Chromium Species. EPRI-EA-4544, Palo Alto, California: Electric Power Research Institute.

Robbins, G. A., Aragon-Jose, A. T. \& Romero, A., 2009. Determining Hydraulic Conductivity Using Pumping Data from Low-Flow Sampling. Ground Water, March-April, 47(2), pp. 271-276.

Sánchez, L. H., 2001. Desengenharia: O Passivo Ambiental na Desativação de Empreendimentos Industriais. São Paulo: Editora da Universidade de São Paulo.

Silva, C. S. \& Pedrozo, M. F. M., 2001. Ecotoxicologia do cromo e seus compostos, Salvador, BA: s.n. 
Storch, P., Messer, A., Palmer, R. \& Pyrih, R., 2002. Pilot test for in situ geochemical fixation of chromium (VI) using calcium polysulfide. Monterey, s.n.

Sueker, J. K., 2006. Chromium. In:: Environmental Forensics. s.l.:Elsevier Inc., pp. 81-95.

Suthersan, S., 1996. Remediation Engineering: Design and Concepts (Geraghty \& Miller Environmental Science \& Engineering). s.l.:CRC Press.

Suthersan, S., Horst, J. \& Ams, D., 2009. In Situ Metals Precipitation: Meeting the Standards. Ground Water Monitoring \& Remediation, pp. 44-50.

Suthersan, S. \& Payne, F., 2004. In Situ Remediation Engineering. s.I.:CRC Press.

Wazne, M. et al., 2007a. Assessment of calcium polysulfide for the remediation of hexavalent chromium in chromite ore processing residue. Journal of Hazardous Materials, Volume 143, pp. 620-628.

Wazne, M. et al., 2007b. Remediation of chromite ore processing residue using ferrous sulfate and calcium polysulfide. Geosciences Journal, 11(2), pp. 105-110.

Zachara, J., Ainsworth, C., Cowan, C. \& Resch, C., 1989. Adsorption of Chromate by Subsurface Soil Horizons. Soil Science Society American Journal, March-April, pp. 418-428. 